NASA Contractor Report 145317

\title{
AEROTHERMODYNAMIC ASSESSMENT OF CORRUGATED PANEL THERMAL PROTECTION SYSTEMS
}

\author{
Final Report
}

\author{
H.J. Brandon, A.H. Britt, H.W. Kipp, and R.V. Masek
}

McDonnell Douglas Astronautics Company - St. Louis

St. Louis, Missouri 63166

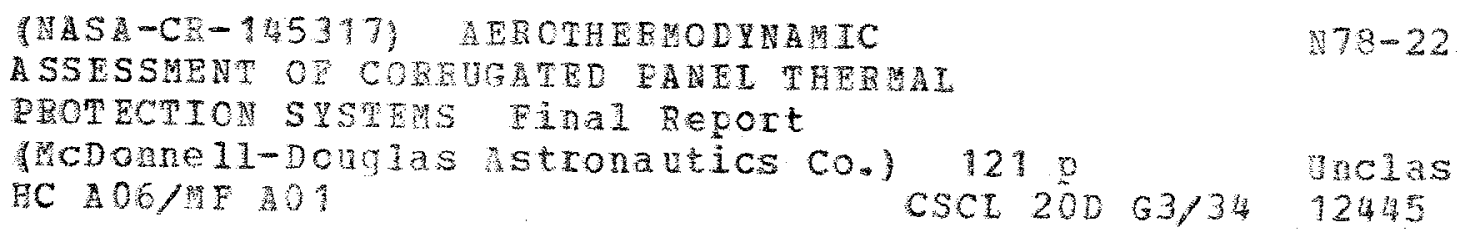

January 31, 1978

Prepared Under Contract No. NAS1-12436

National Aeronautics and Space Administration 
FOREWORD

This report summarizes the work conducted by McDonnel1 Douglas Astronautics Company-St. Louis (MDAC-St. Louis) for the NASA Langley Research Center under Contract NAS1-12436. Mr. James C. Dunavant was the technical monitor for the study. Mr. H. J. Fivel (MDAC-St. Louis) made a significant contribution in developing the computer coding used in the assimilation and analysis of the wind tunnel data presented in this report. Dr. R. T. Krieger, Mr. J. K. Lehman, and Dr. R. M. Laurenson contributed to the aerodynamic, material, and structural dynamic aspects of the study. Mr. Darrell Weber assisted in formulating and coding the heating models used in the thermal flight assessment. 
Page

1. SUMMARY $\ldots \ldots \ldots \ldots \ldots \ldots \ldots \ldots \ldots \ldots \ldots \ldots \ldots \ldots \ldots \ldots \ldots \ldots \ldots \ldots \ldots \ldots \ldots$

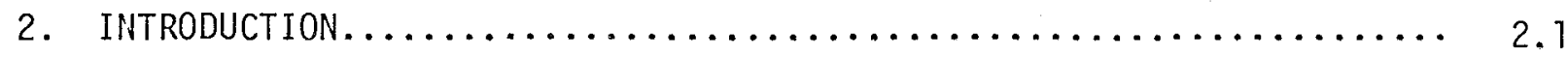

3. MODEL AND INSTRUMENTATION.......................... 3.1

4. TEST PROGRAM............................. 4

5. EXPERIMENTAL HEATING AND PRESSURE DISTRIBUTIONS $\ldots \ldots \ldots \ldots \ldots \ldots \ldots \ldots .7$

6. CORRELATION OF WIND TUNNEL DATA $\ldots \ldots \ldots \ldots \ldots \ldots \ldots \ldots \ldots \ldots \ldots \ldots \ldots \ldots \ldots \ldots$

7. THERMAL FLIGHT ASSESSMENT $\ldots \ldots \ldots \ldots \ldots \ldots \ldots \ldots \ldots \ldots \ldots \ldots \ldots \ldots \ldots \ldots \ldots \ldots$

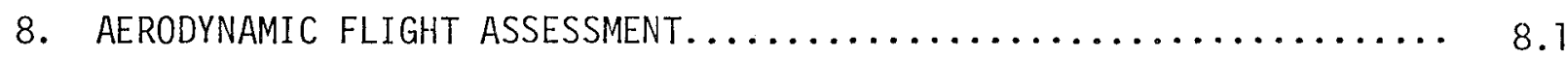

9. STRENGTH AND FLUTTER FLIGHT ASSESSMENT $\ldots \ldots \ldots \ldots \ldots \ldots \ldots \ldots \ldots \ldots \ldots . . . \ldots \ldots$

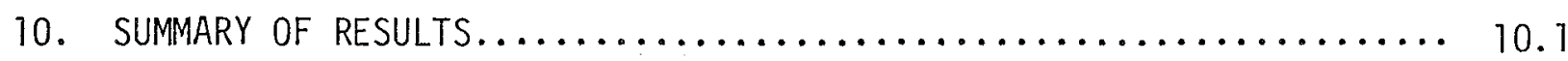

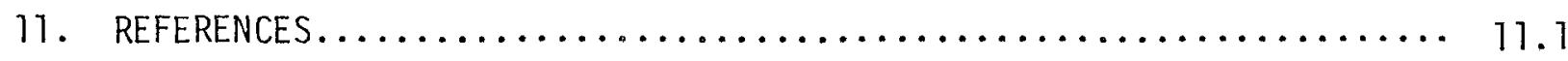

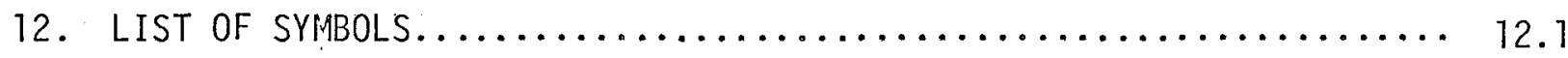

Appendix A: Wave Shape Fold Out A-1

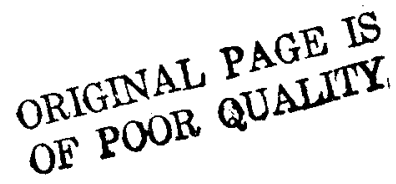




\subsection{SUMMARY}

A study has been conducted to investigate the feasibility of using corrugated panels as a thermal protection system (TPS) for an advanced space transportation vehicle. The study consisted of two major tasks: (1) development of improved correlations for wind tunnel heat transfer and pressure data to yield design techniques, and (2) application of the design techniques to determine if corrugated panels have application on future aerospace vehicles. A single-stage-to-orbit (SSTO) vehicle was used in this study to assess advantages and aerothermodynamic penalties associated with use of such panels.

In the correlation task, experimental turbulent heat transfer and pressure data obtained on corrugation roughened surfaces during wind tunnel testing were analyzed and compared with flat plate data. The correlations and data comparisons include the effects of a large range of geometric, inviscid flow, internal boundary layer, and bulk boundary layer parameters in supersonic and hypersonic flow.

The formulated wind tunnel correlations were used in the second task to evaluate the increased surface temperatures and added insulation requirements associated with the use of corrugated panels on an advanced space transportation system. The thermal evaluation considered the effects of panel location, material selection, and lateral heat conduction due to the large structural temperature gradients normal to the corrugation axes. The second task also included an analysis of the impact of corrugated panels on reentry vehicle aerodynamics and an evaluation of the flutter characteristics associated with corrugated panels on a SSTO in the supersonic and hypersonic range. 


\subsection{INTRODUCTION}

The thermal protection system (TPS) is an important factor in the design of advanced space transportation systems. The space systems of current interest range from reusable, ballistic-entry systems to single-stage-to-orbit (SSTO), lifting-entry vehicles. Interest in the present study is focused on the SSTO which will be a winged reentry vehicle anticipated to be operational in the 1990's and beyond. The TPS for the SSTO must be reusable, rugged, and forgiving of abnormal operating conditions. The Reusable Surface Insulation (RSI) being used for the Space Shuttle TPS is fragile and may not be applicable for the SSTO due to stringent service life requirements.

A reusable, non-fragile TPS which is being studied for advanced space transportaion systems is composed of radiation-cooled, metallic panels (Ref. 1). The panels are stiffened by corrugations or waves which protrude above the equivalent smooth surface of the vehicle and distort the boundary layer flow during flight. The overall effect of this flow distortion on the vehicle performance characteristics is a significant technical consideration which must be considered during the development of corrugated panel TPS. The emphasis of this study is focused on the effect of surface corrugations on the thermal characteristics of an advanced reentry vehicle. The effect of the corrugations on the flight performance is also considered, but in less detail.

A meaningful investigation of the boundary layer distortion due to surface corrugations must address the situation for which the surface corrugations are deeply submerged in the thick turbulent boundary layers which will develop on large vehicles such as the SSTO. Several investigators have studied the influence of surface waves on turbulent boundary layers (Refs. 2-7). However, these studies did not include data for which the boundary layer was orders of magnitude thicker than the corrugation height. The first detailed investigation which considered heat transfer to corrugations deeply submerged in a thick turbulent boundary layer was reported by Brandon, Masek, and Dunavant (Refs. 8 and 9). During that study, questions arose regarding the influence of several geometric parameters on the boundary layer distortion. As a result, NASA/LRC conducted additional wind tunnel experiments to study the effect of the wave shape on the boundary layer.

In this report the additional data for the effect of wave shape are analyzed, correlated, and compared with the previous data obtained in thick and thin turbulent boundary layers. The correlations developed in Refs. 8 and 9 are improved by including data for additional wave configurations and flow conditions and by 
updating the boundary layer parameters to conform with recent wind tunnel experiments. The results of the wind tunnel data analysis are then used to assess the feasibility of using corrugated panels on a SST0 vehicle. In the flight assessment, available engineering design procedures are used to compute the inviscid and boundary layer flow for a given flight trajectory. The flight vehicle flow field calculations are then used in conjunction with the wind tunnel correlations to examine the heating penalties associated with corrugated panels at several locations on the vehicle. The wind tunnel data and flight flow field calculations are also used to deduce the reduction in aerodynamic performance and structural integrity due to the corrugations. It should be noted that an engineering solution was chosen for the flight flow field calculations because it was felt that a more exact solution was not warranted. It was thought that if the results of an engineering solution showed that corrugated panels appear feasible, a more exact analysis could then be justified in a benchmark assessment before conducting a flight test program. 


\subsection{MODEL AND INSTRUMENTATION}

Three corrugation roughened flat panels were tested in this program. The panels were similar to those fabricated and tested in Ref. 8 . A11 three panels were $50.8 \mathrm{~cm} \times 50.8 \mathrm{~cm} \times 2.54 \mathrm{~cm}$ and were fabricated from nominally $0.051 \mathrm{~cm}$ thick 347 stainless steel. As shown in Figure $3-1$, the panels were designated $-1,-2$, and -3 and had peak amplitudes of $1.06, .525$, and $.405 \mathrm{~cm}$, respectively. The wavelength was $7.32 \mathrm{~cm}$ for panels -1 and -2 , and 3.66 for panel -3 . Cross-section shapes for panels $-1,-2$, and -3 are compared with the shapes previously tested (designated -4 and -5 ) in Ref. 8 and with the configuration tested by Sawyer in Ref.10 (designated pane $1-6$ ).* A11 the shapes shown in this figure are for sections normal to the corrugation axes. Further details of the overall pane 1 shape for $-1,-2$, and -3 are presented in Figures $3-2$ and 3-3. For a11 three panels the amplitude was constant over a $25.4 \mathrm{~cm}$ section in the center, and tapered to zero near the panel edge. Panels -1 and -2 contained 6 corrugations (wave cycles) and panel -3 contained 12 corrugations which ran the entire length of the model. The corrugation sections were constructed of circular arcs connected by straight line segments, as shown in Figure 3-4. Also shown in this figure is the nomenclature associated with the wave construction.

The effective wave shapes for panels $-1,-2,-3$, and -6 were computed as a function of the flow angle relative to the corrugations, $\emptyset$, using elliptical integrals. It was apparent that the wave shapes were greatly influenced by the flow angle. For example, the maximum surface deflection angle varied from $15.1^{\circ}$ for $\emptyset=15^{\circ}$ to $43.9^{\circ}$ for $\emptyset=90^{0 * *}$ for panel -1 , from $4.6^{\circ}$ for $\emptyset=15^{\circ}$ to $17.2^{\circ}$ for $\emptyset=90^{\circ}$ for panel -2 , and from $7.4^{\circ}$ for $\emptyset=15^{\circ}$ to $26.6^{\circ}$ for $\emptyset=90^{\circ}$ for pane1 -3. The maximum surface deflection angle for Panel -6 (Sawyer pane1) varied from $6.9^{\circ}$ for $\emptyset=15^{\circ}$ to $30.1^{\circ}$ for $\emptyset=90^{\circ}$.

Panels $-1,-2$, and -3 were instrumented with thermocouples and pressure orifices. These panels were instrumented in much more detail than those tested in Ref. 8 so that a much better definition of the heating and pressure distributions was obtained. With the waves normal to the flow direction (configuration termed $\emptyset=90^{\circ}$ ), corrugations in the center of the panel were instrumented in the flow

*To facilitate reference to the corrugation shapes as they are discussed in the text, Figure 3-1 is reproduced as a foldout page in Appendix A.

$\star *$ Note $\emptyset=90^{\circ}$ indicates the flow is normal to the corrugation axis. 


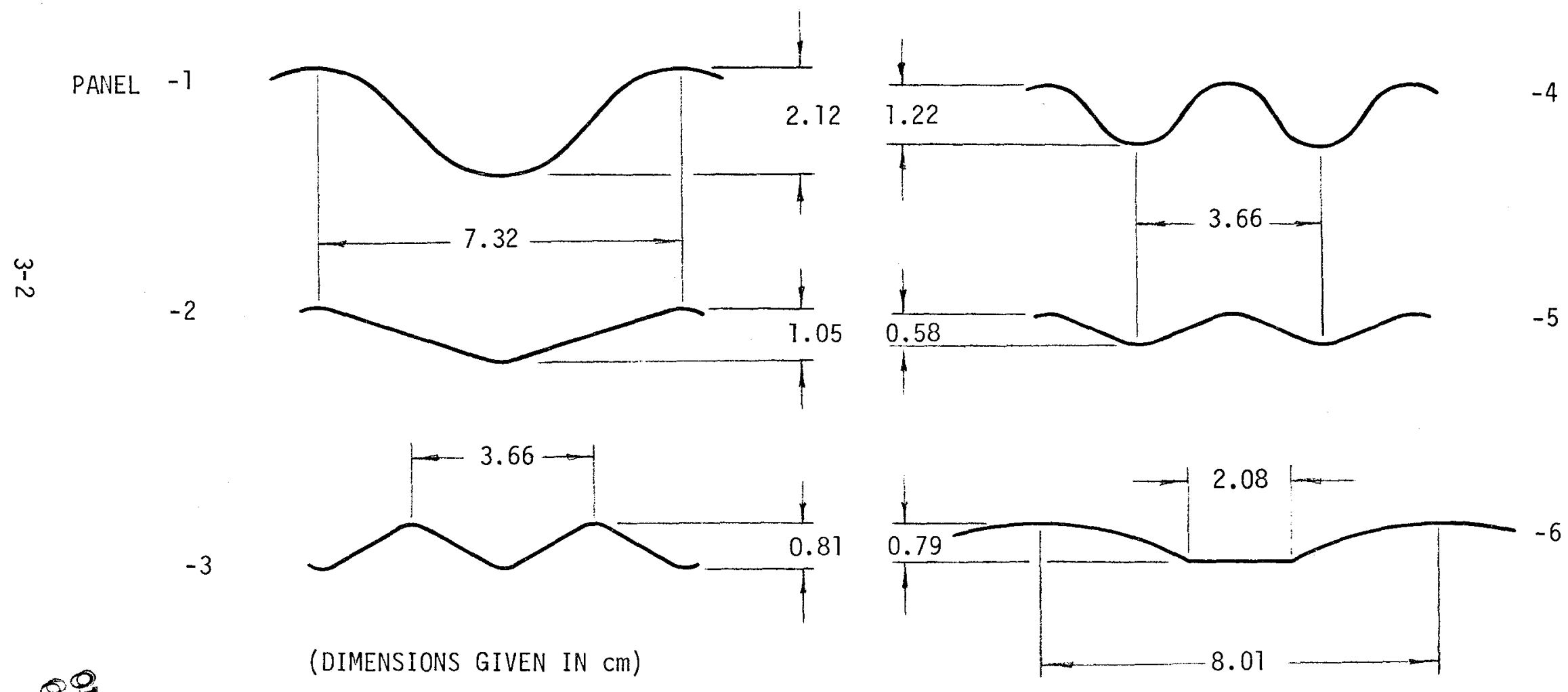

证

晨

䞌

स

FIGURE 3- 7 CORRUGATION SHAPES INVESTIGATED 
NOIIINAL VALUES GIVEN ARE NONDIMENSIONALIZED BY $2.54 \mathrm{~cm}$

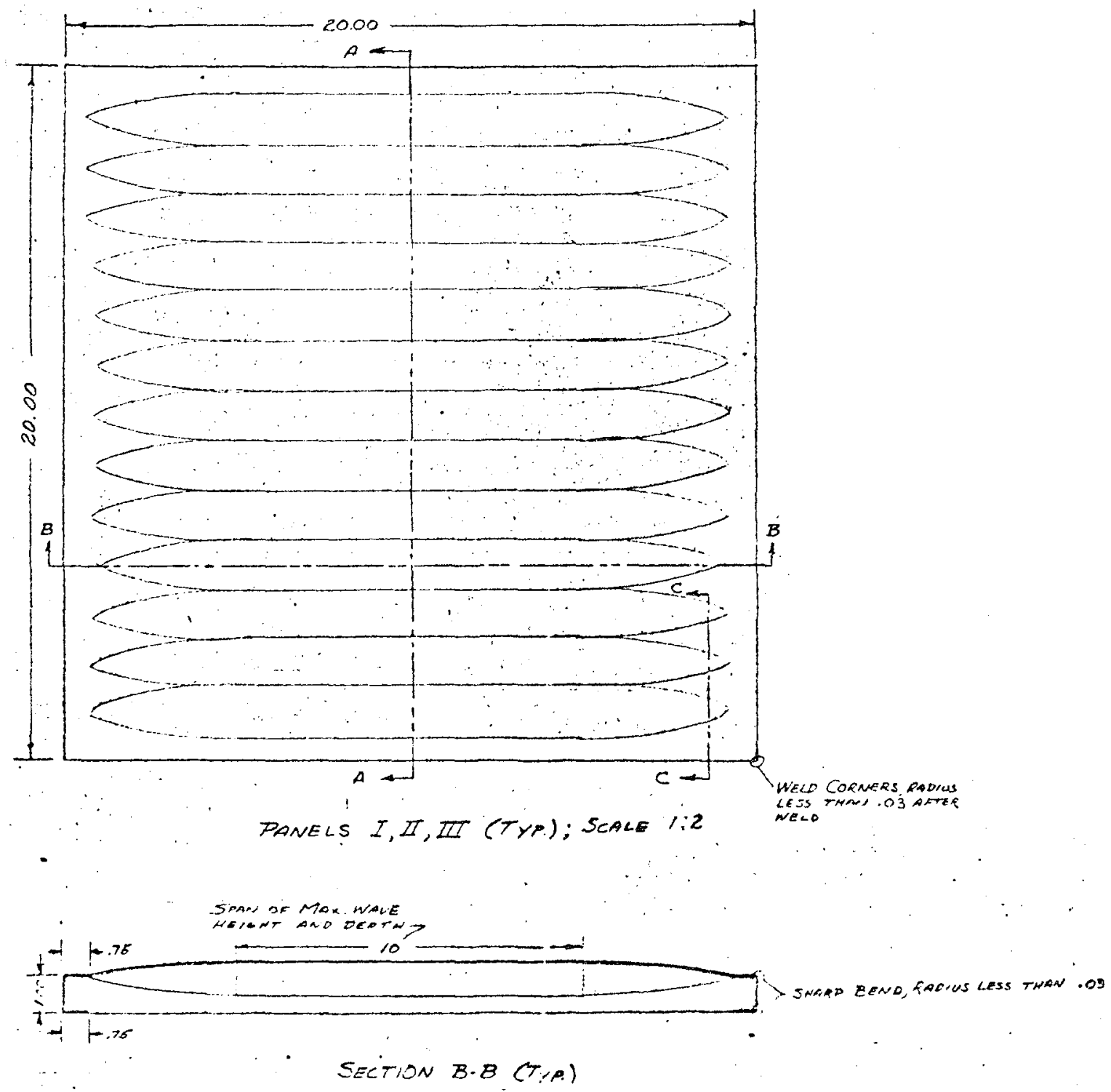

FIGURE 3-2 PANEL CONFIGURATION - TOP AND SIDE VIEWS 
NOMINAL VALUES GIVEN ARE NONDIMENSIONALIZED BY $2.54 \mathrm{~cm}$

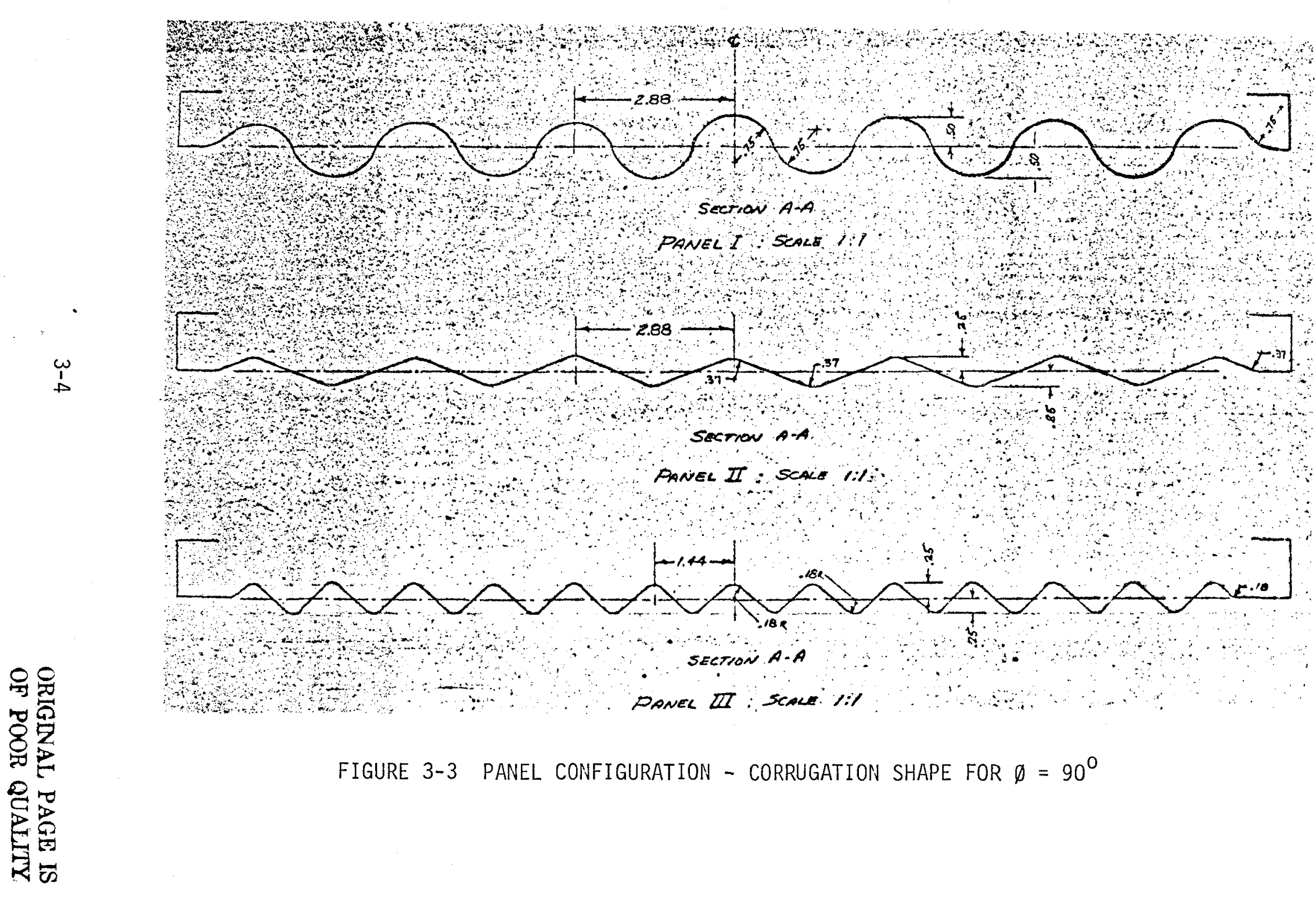




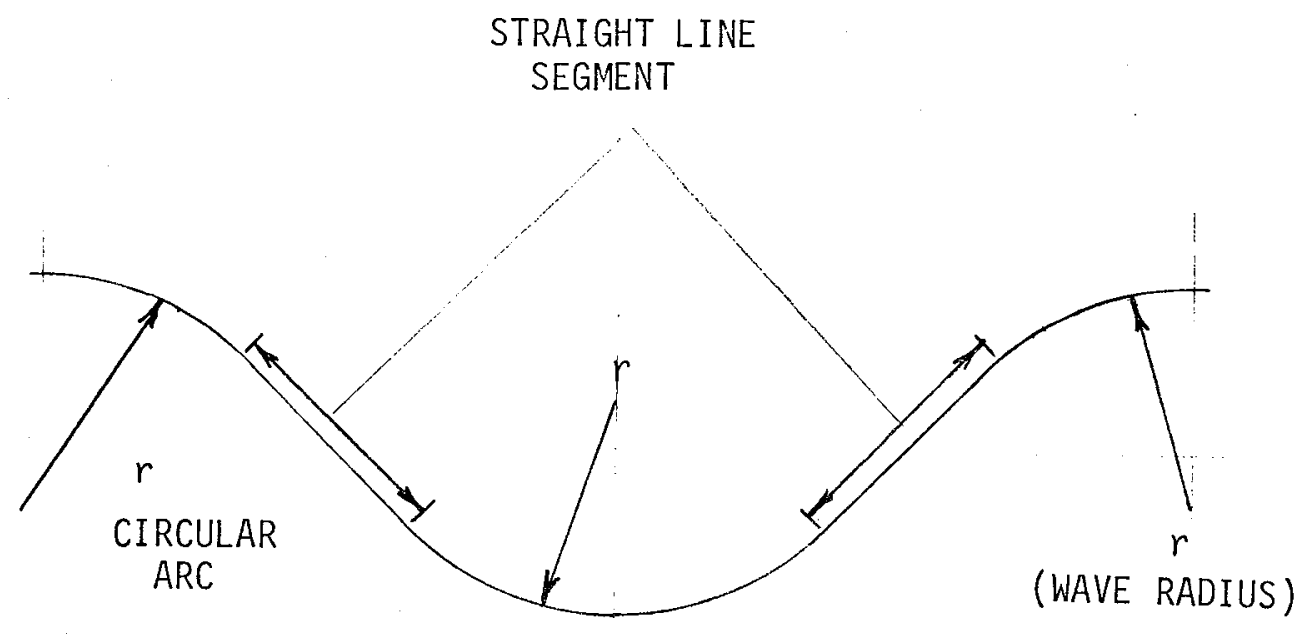

A) BASIC WAVE CONSTRUCTION

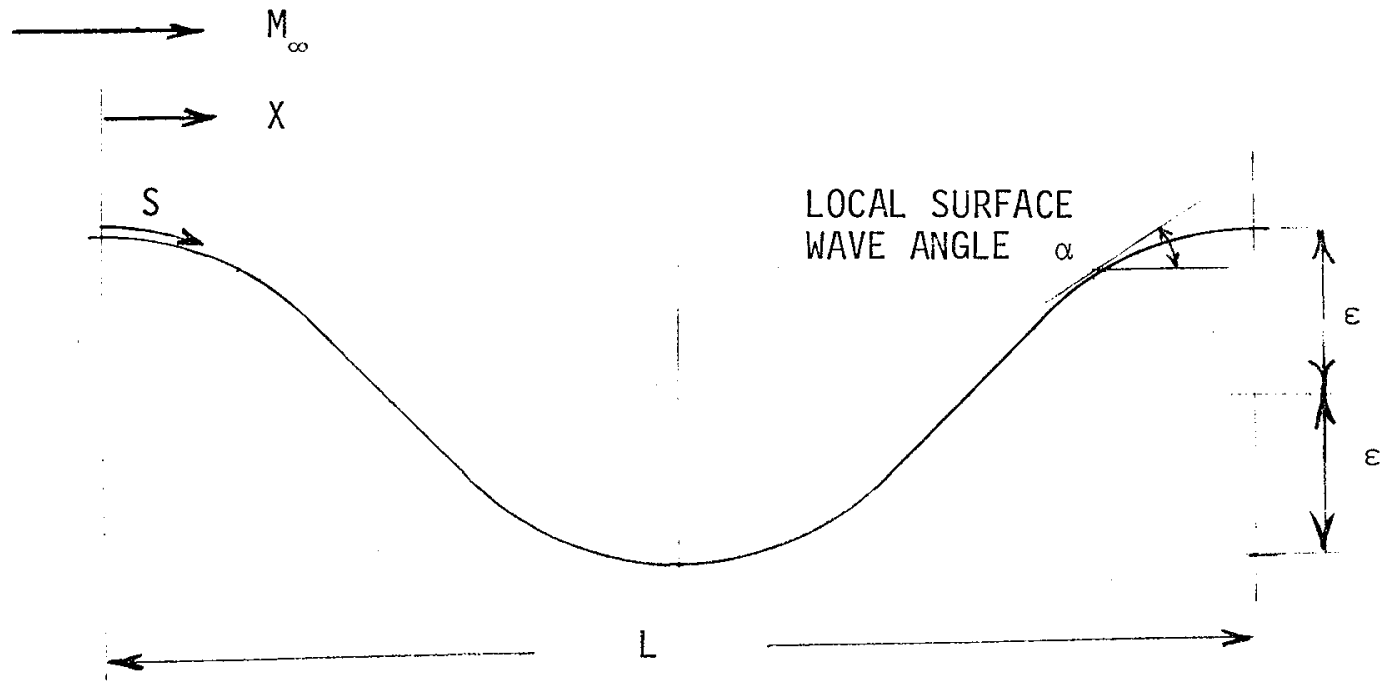

B) NOMENCLATURE

FIGURE 3-4 BASIC WAVE CONSTRUCTION AND NOMENCLATURE 
direction. The first complete cycle and the last complete wave cycle were also instrumented. However, only the data in the center of the panel are of interest to the present study since they have previously been shown to be representative of all the waves in very thick turbulent boundary layers (neglecting edge effects). Details of the geometry and instrumentation for panels -4 and -5 , and -6 are discussed in Ref. 8 and 10, respectively. 


\subsection{TEST PROGRAM}

Panels $-1,-2$, and -3 were tested in the turbulent wall boundary layer of the Langley Continuous Flow Hypersonic Wind Tunnel (CFHT) which has a freestream Mach number of 10.3. The wall boundary layer provided simulation of the thick boundary layers occurring on a flight vehicle. The procedure used in the test program was the same as that described in Ref. 8. The panels were attached to an adapter plate which was mounted flush with the wind tunnel wal1, as shown schematically in Figure 4-1. A schematic of the corrugation angle, $\phi$, is also shown in this figure. For the CFHT tests, the corrugation orientation angle relative to the freestream direction could be varied from $0^{\circ}$ to $15^{\circ}$ and from $75^{\circ}$ to $90^{\circ}$. Angles between $15^{\circ}$ and $75^{\circ}$ could not be obtained due to the arrangement of the tunnel injection mechanism. Panels -1 , -2 , and -3 were not tested in the Unitary Plan Wind Tunnel (UPWT) during the present test program.

Heating and pressure data obtained on panels -4 and -5 and previously reported in Refs. 8 and 9 are also considered in this study. These two panels were not further tested for the present study. In this study these previously obtained data are used in conjunction with improved boundary layer calculations. The data obtained by Sawyer (Ref.10) are also used in this study. The Sawyer data were obtained on a corrugated panel configuration which was tested in the UPWT at freestream Mach numbers of 2.5 and 4.5 .

The flow and panel geometric conditions for the data considered in the present study are listed in Table 4-I. Flat plate data were also obtained for a11 the Mach number and Reynolds number combinations. The boundary layer parameters for the turbulent wall boundary layers are listed in Table 4-II. These values differ from those published in Ref. 8 . which were computed assuming that the freestream static pressure was constant through the boundary layer. Subsequent wall pressure measurements in the CFHT showed that this was not the case. Hence, all the CFHT calculations were repeated using measured pitot and total temperature profiles and an assumed linear static pressure distribution from the freestream static pressure to the measured wall pressure. The computed boundary layer profiles for the CFHT are shown in Figures 4-2 to 4-4 as a function of the freestream Reynolds number. The boundary layer data measured in Refs. 11 and 12 were used to obtain the UPWT boundary layer parameters. For both the CFHT and UPWT, the laminar sublayer thickness was computed from Beckwith's correlation (Ref, 13). 

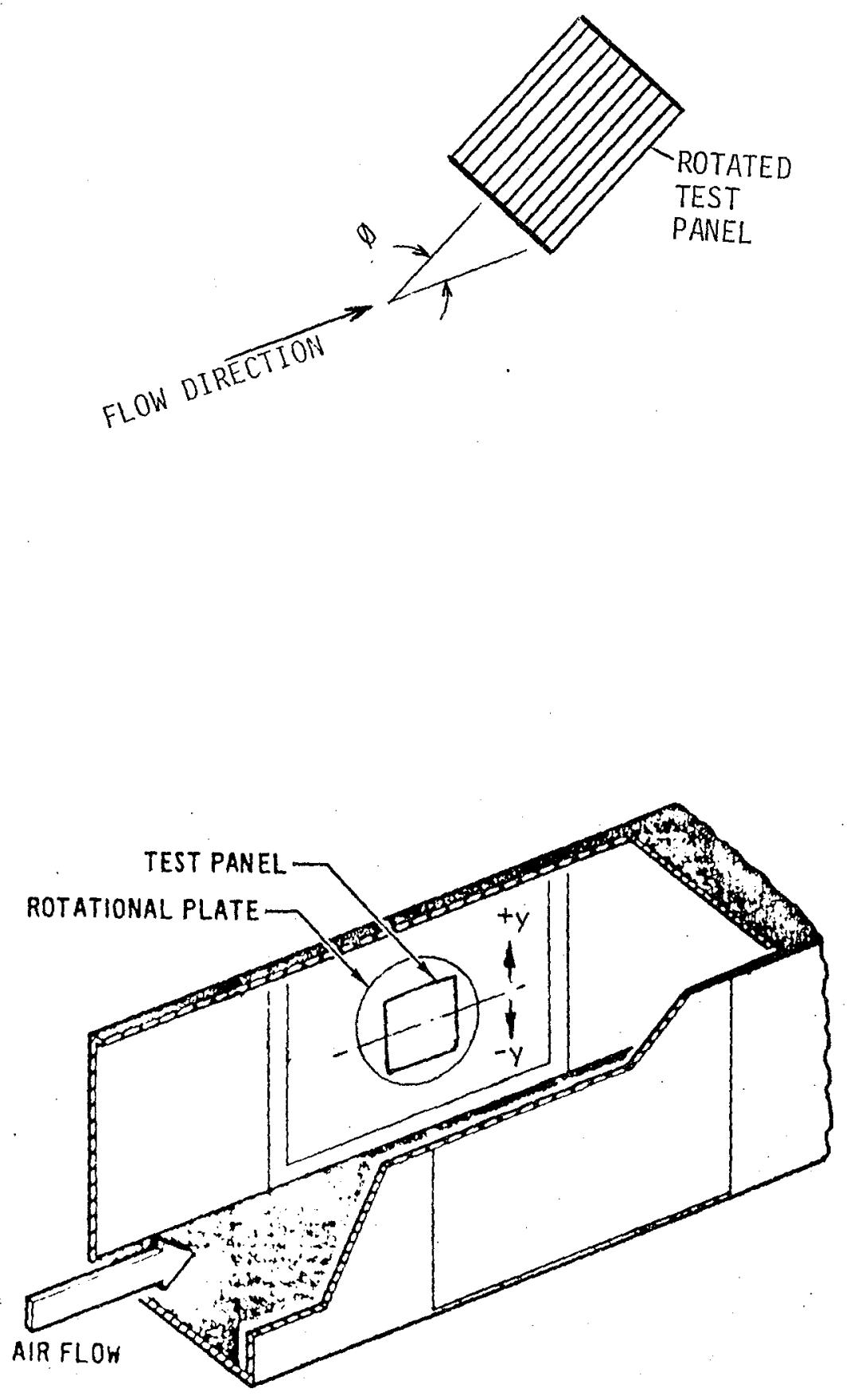

ORIGINAL PAGE IS OF POOR QUAINTY

FIGURE 4-1 - MODEL INSTALLATION 


\begin{tabular}{|c|c|c|c|c|c|c|c|}
\hline PANEL & $\begin{array}{l}\text { WAVE HE IGHT } \\
\text { (cm) }\end{array}$ & $\begin{array}{l}\text { WAVE LENGHT } \\
\begin{array}{l}(\mathrm{cm}) \\
\end{array}\end{array}$ & $\begin{array}{l}\text { WAVE RADIUS } \\
(\mathrm{cm})\end{array}$ & TYPE OF DATA & $\underline{\emptyset(\mathrm{deg})}$ & $\underline{M_{\infty}}$ & $\mathrm{Re}_{\infty} / M \times 10^{-6}$ \\
\hline-1 & 1.06 & 7.32 & 1.905 & $\begin{array}{l}\text { HEAT TRANSFER } \\
\text { AND } \\
\text { PRESSURE }\end{array}$ & $0,15,75,90^{\circ}$ & 10.3 & $1.3,3.3,6.6,8.2$ \\
\hline-2 & .525 & 7.32 & .864 & & & & \\
\hline-3 & . 405 & 3.66 & .457 & $\gamma$ & $\psi$ & $\psi$ & $\psi$ \\
\hline
\end{tabular}

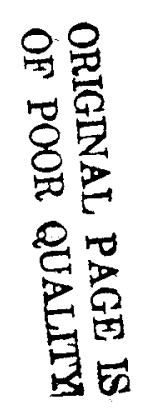




$\begin{array}{cccccccc}M_{\infty} & R_{e_{\infty} / M \times 10^{-6}} & \delta^{*}(\mathrm{~cm}) & \theta(\mathrm{cm}) & \frac{\delta_{s}(\mathrm{~cm})}{} & \frac{T_{W}}{T_{t_{\infty}}} \text { (NOMINAL) } & \frac{P_{f p}}{P_{\infty}} \\ 2.4 & 3.3 & 2.62 & .734 & .028 & & .80 & 1 \\ 2.4 & 10 & 2.32 & .658 & .013 & .80 & 1 \\ 4.5 & 10 & 5.46 & .521 & .062 & & .80 & 1 \\ 10.3 & 1.3 & 10.69 & 1.36 & .737 & .30 & 2.024 \\ & 3.3 & 10.83 & 1.19 & .381 & & .30 & 1.714 \\ & 6.6 & 10.94 & 1.05 & .279 & & .30 & 1.489 \\ & 8.2 & 10.89 & .945 & .229 & & .30 & 1.355\end{array}$




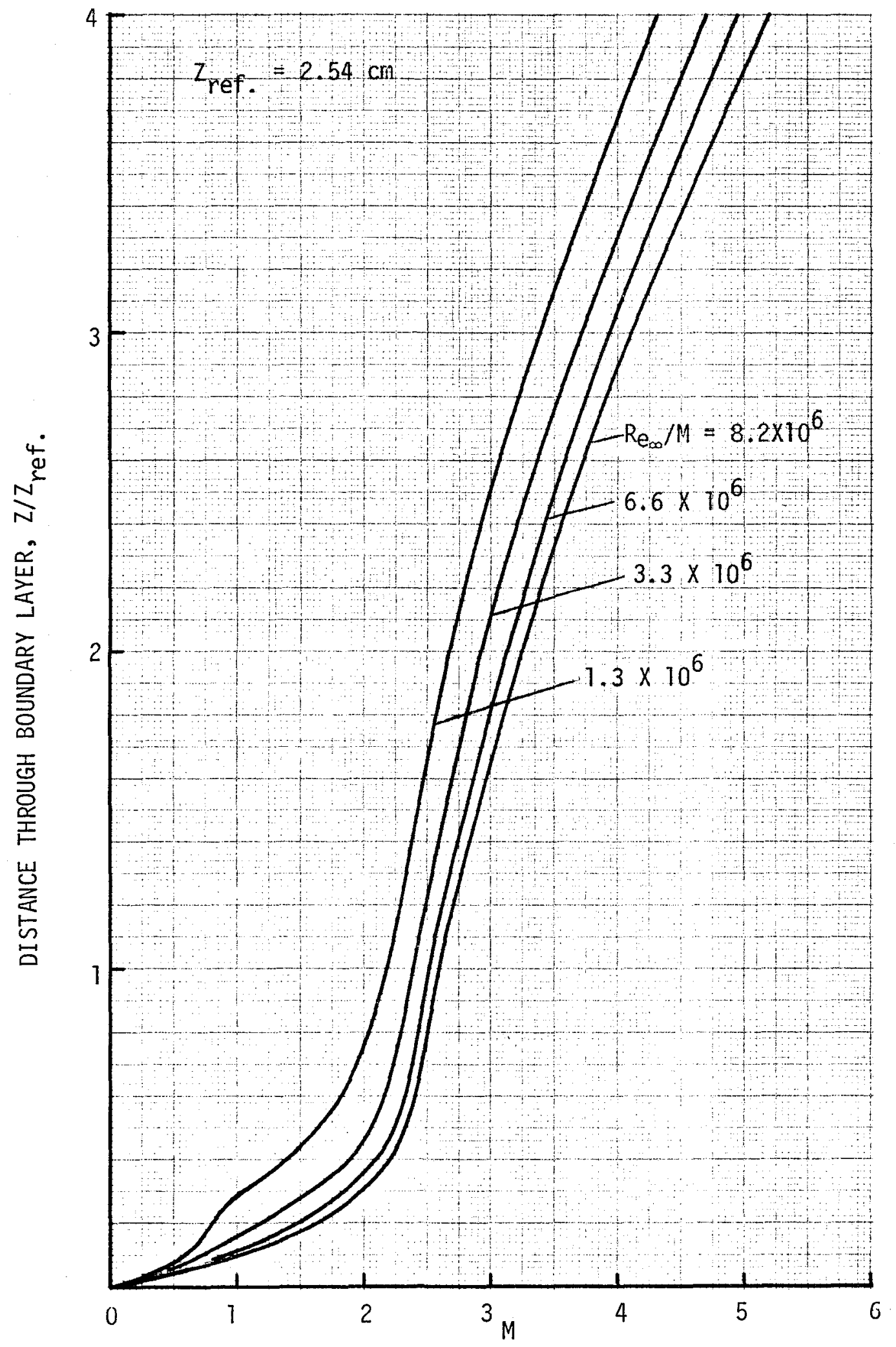

FIGURE 4-2 MACH NUMBER PROFILE IN CFHT WALL BOUNDARY LAYER 


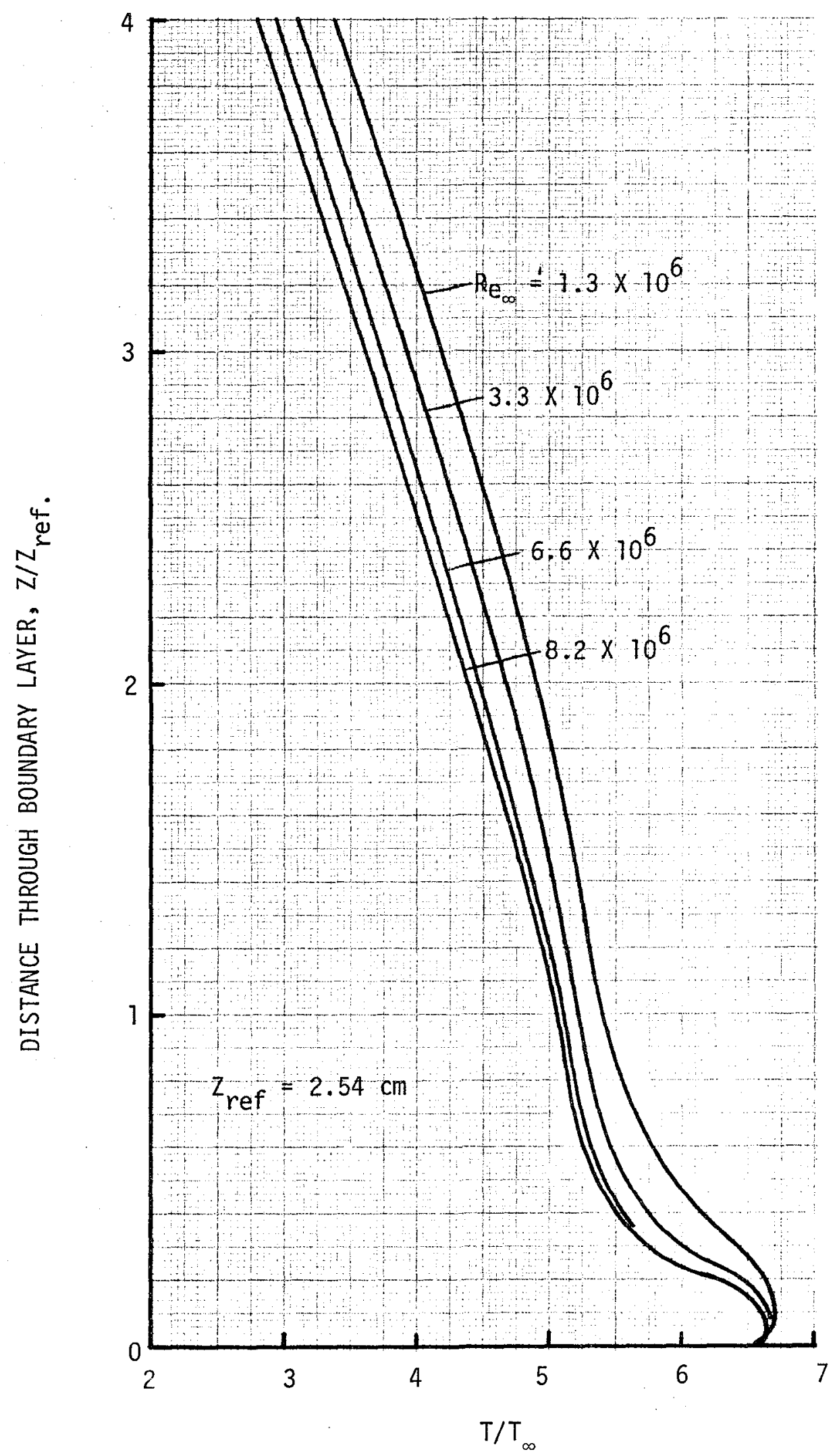

FIGURE 4-3 STATIC TEMPERATURE PROFILE IN CFHT WALL BOUNDARY LAYER 


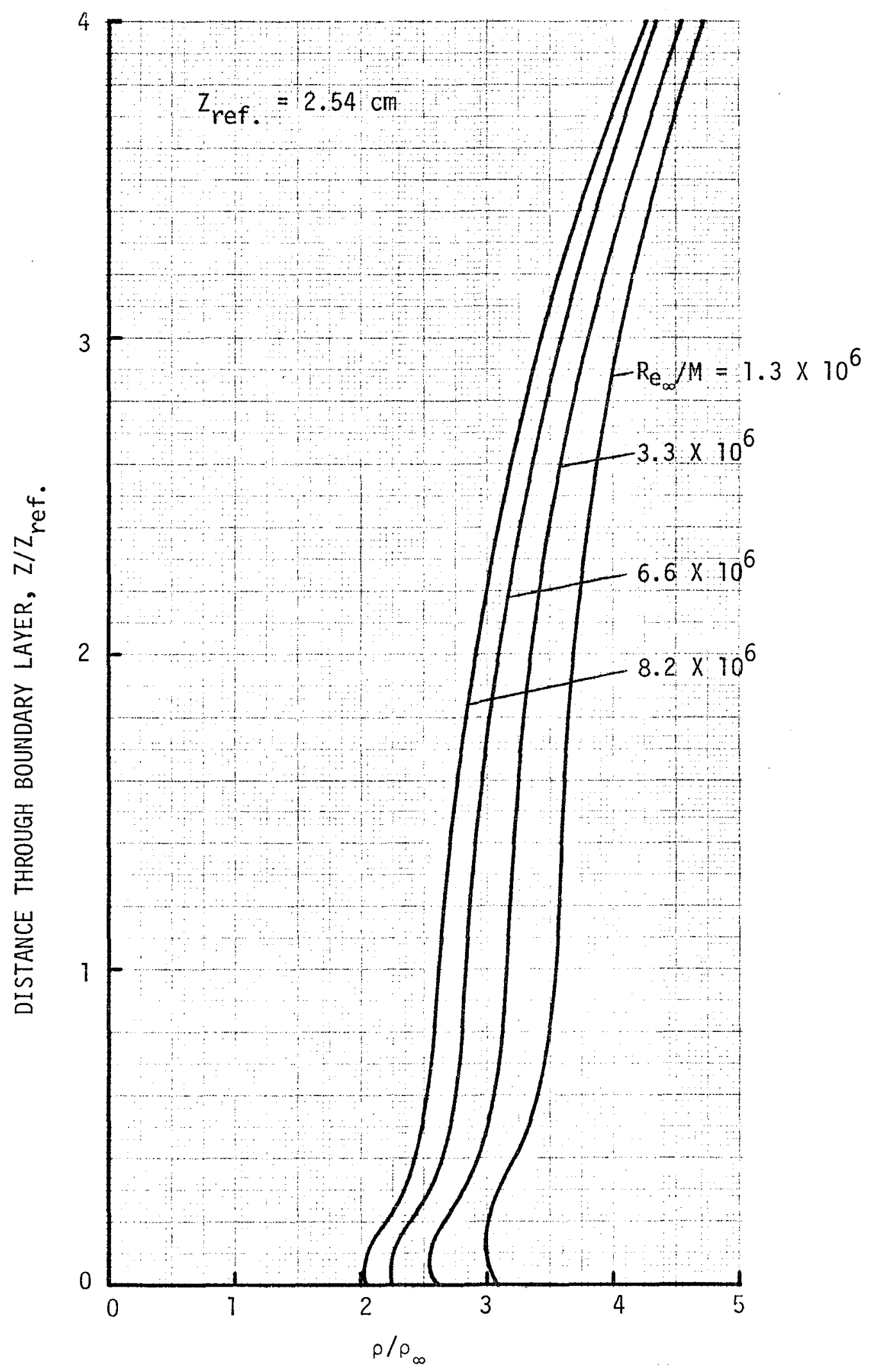

FIGURE 4-4 DENSITY PROFILE IN CFHT WALL BOUNDARY LAYER 


\subsection{EXPERIMENTAL HEATING AND PRESSURE DISTRIBUTIONS}

The heating and pressure distributions measured on the present panels $(-1,-2$, and -3 ) are used in conjunction with the previously obtained data to deduce the effect of the flow angle relative to the corrugations (corrugation angle), Mach number, Reynolds number, wave length, wave amplitude, wave surface radius, and wave scaling. Previous tests in thick turbulent boundary layers have shown that the heating and pressure distributions are relatively insensitive to the location of the wave in the train. Hence, the present study is concerned only with data in the center of the panels. Distributions over a wave in the center are representative of those over all the waves (neglecting edge effects). All the heating and pressure values appearing in this report are nondimensionalized with respect to local measured flat plate values. This is necessary due to spanwise gradients which existed on the wall of the wind tunnel. Analysis has shown that the effects of the nonuniform boundary layer are eliminated by referencing the corrugated data to the local flat plate values.

Flow Angle (Corrugation Angle) Effect - Heat transfer and pressure distributions for hypersonic flow $\left(M_{\infty}=10.3, \operatorname{Re}_{\infty} / M=6.6 \times 10^{6}\right)$ are presented in Figures 5-1 to 5-4 for panels -1 and -3 at flow angles of $0^{\circ}, 15^{\circ}, 75^{\circ}$, and $90^{\circ}$. Distributions for supersonic flow $\left(M_{\infty}=2.4, \operatorname{Re}_{\infty} / M=10 \times 10^{6}\right)$ for panel -5 at flow angles of $0^{\circ}, 15^{\circ}, 30^{\circ}, 60^{\circ}$, and $90^{\circ}$ are presented in Figures 5-5 and 5-6. For al 1 flow angles heating is much more affected by the presence of corrugations than is pressure. The largest heating and pressure increases occur when the flow is normal to the corrugations. These trends are similar to those observed in Ref. 8, $0 i l$ flow visualization indicated that these distributions were caused by flow separation in the valley and subsequent reattachment on the following wave. The greatest increase in heating over smooth wall values occurs as the flow angle increases from $0^{\circ}$ to $15^{\circ}$. However, the relative changes are more pronounced for panels -1 and -3 . The increase in heating occurring from $\emptyset=75^{\circ}$ to $90^{\circ}$ is quite small for all three panels. The greatest increase in pressure over smooth wall values occurs over the range in flow angle from $15^{\circ}$ to $75^{\circ}$. The increase in pressure from $\emptyset=75^{\circ}$ to $90^{\circ}$ is quite small for panels -1 and -3 . These heating and pressure distributions could be affected by flow angularity in the wall boundary layer which could be a function of the distance normal to the wall.

Mach Number Effect - Changes in the heating and pressure distributions on a corrugated panel due to increases in the local free-stream Mach number (while the free-stream Reynolds number is held constant) can be seen by comparing Figures 5-5 


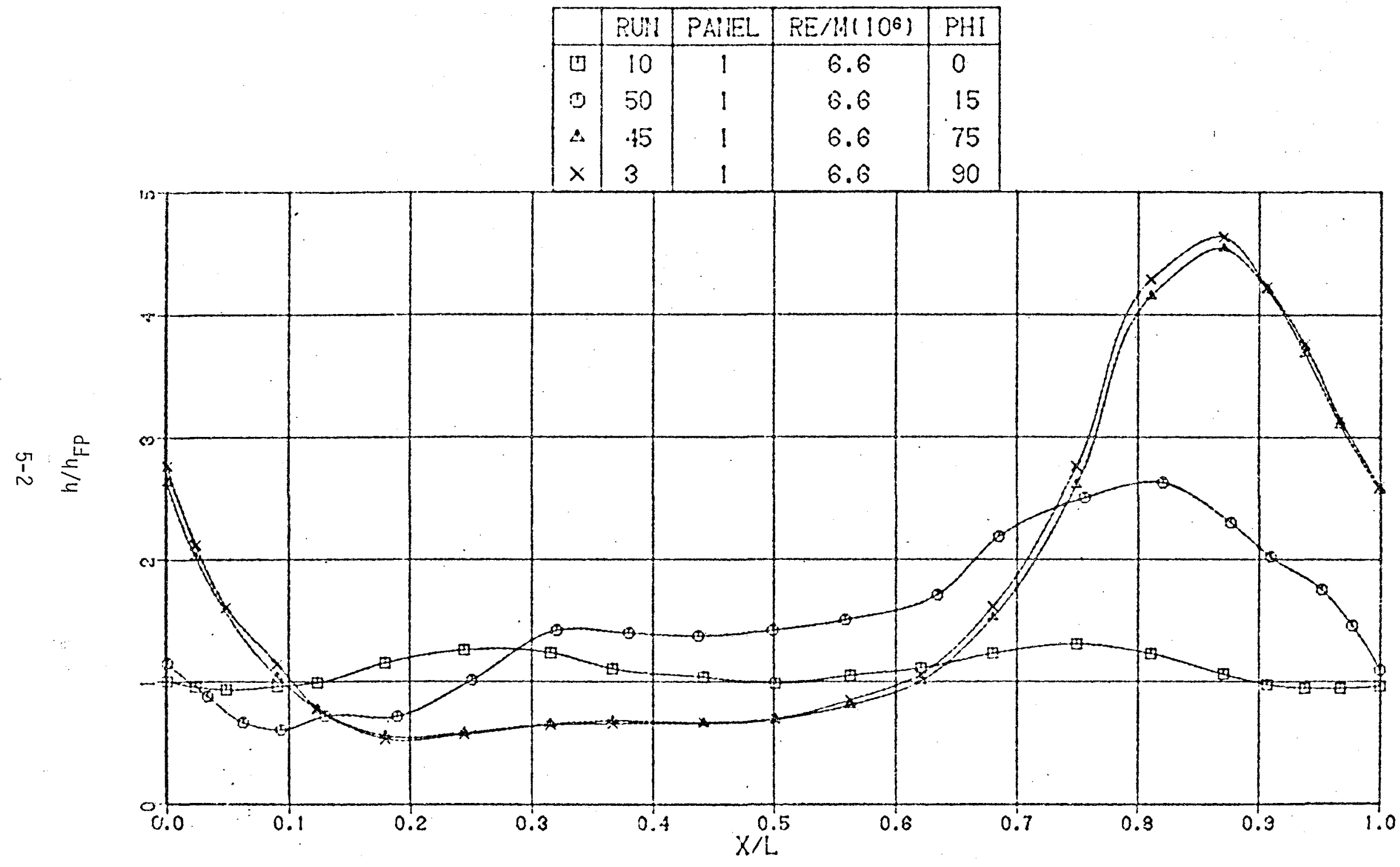

FIGURE 5- 1 EFFECT OF FLOW ANGLE ON HEATING DISTRIBUTION, $M_{\infty}=10.3$ 


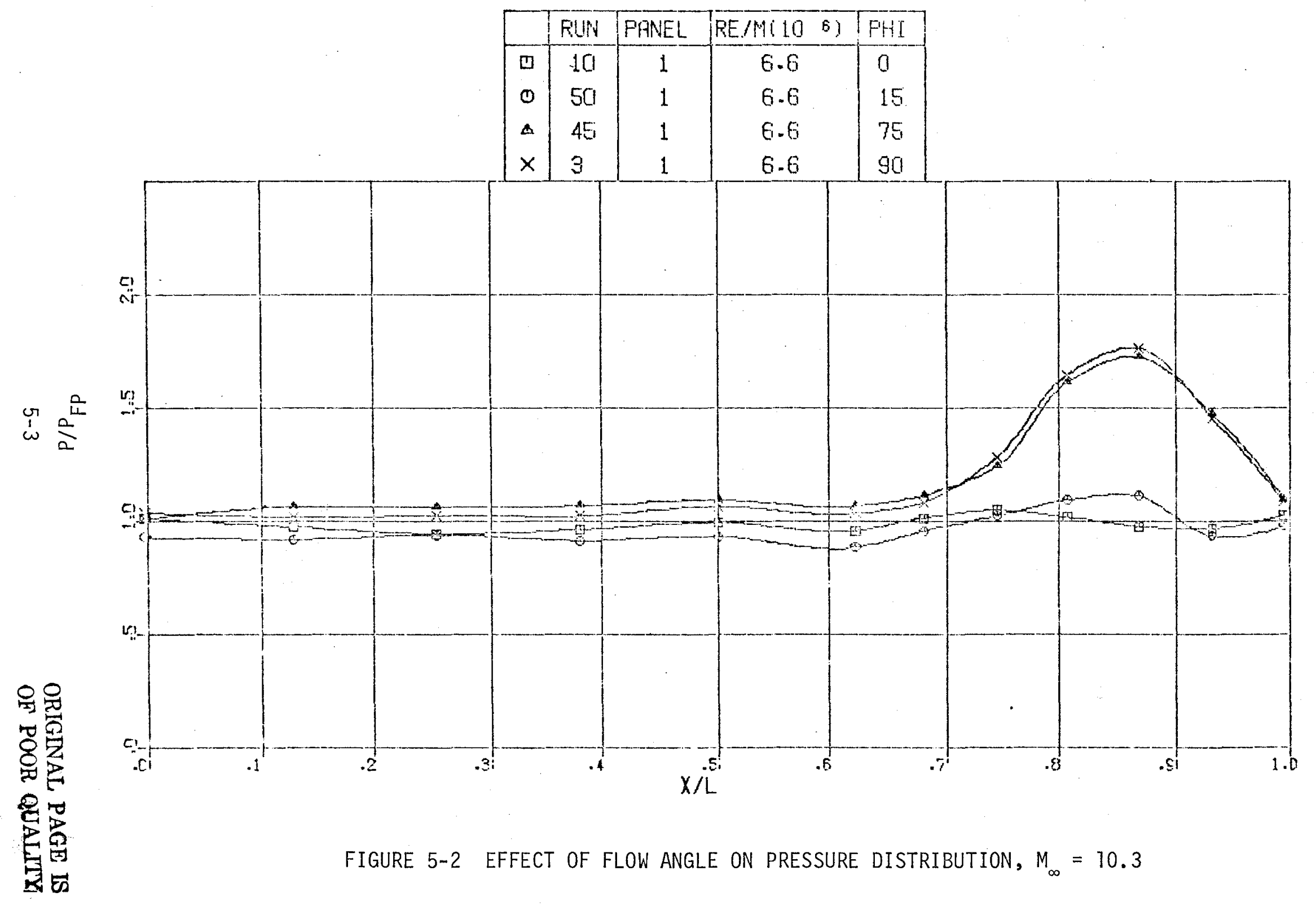




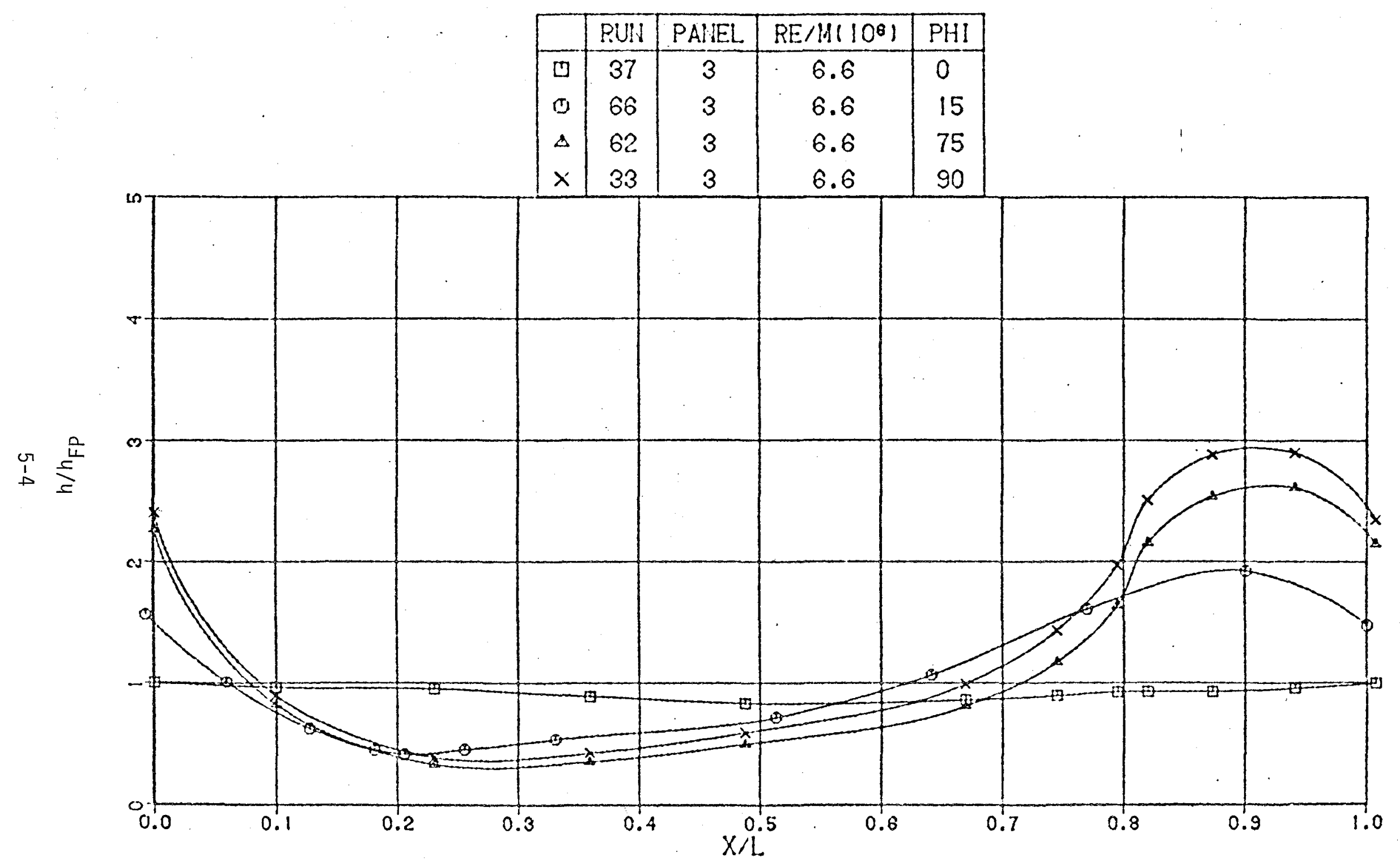

FIGURE 5-3 EFFECT OF FLOW ANGLE ON HEATING DISTRIBUTION, $M_{\infty}=10.3$ 


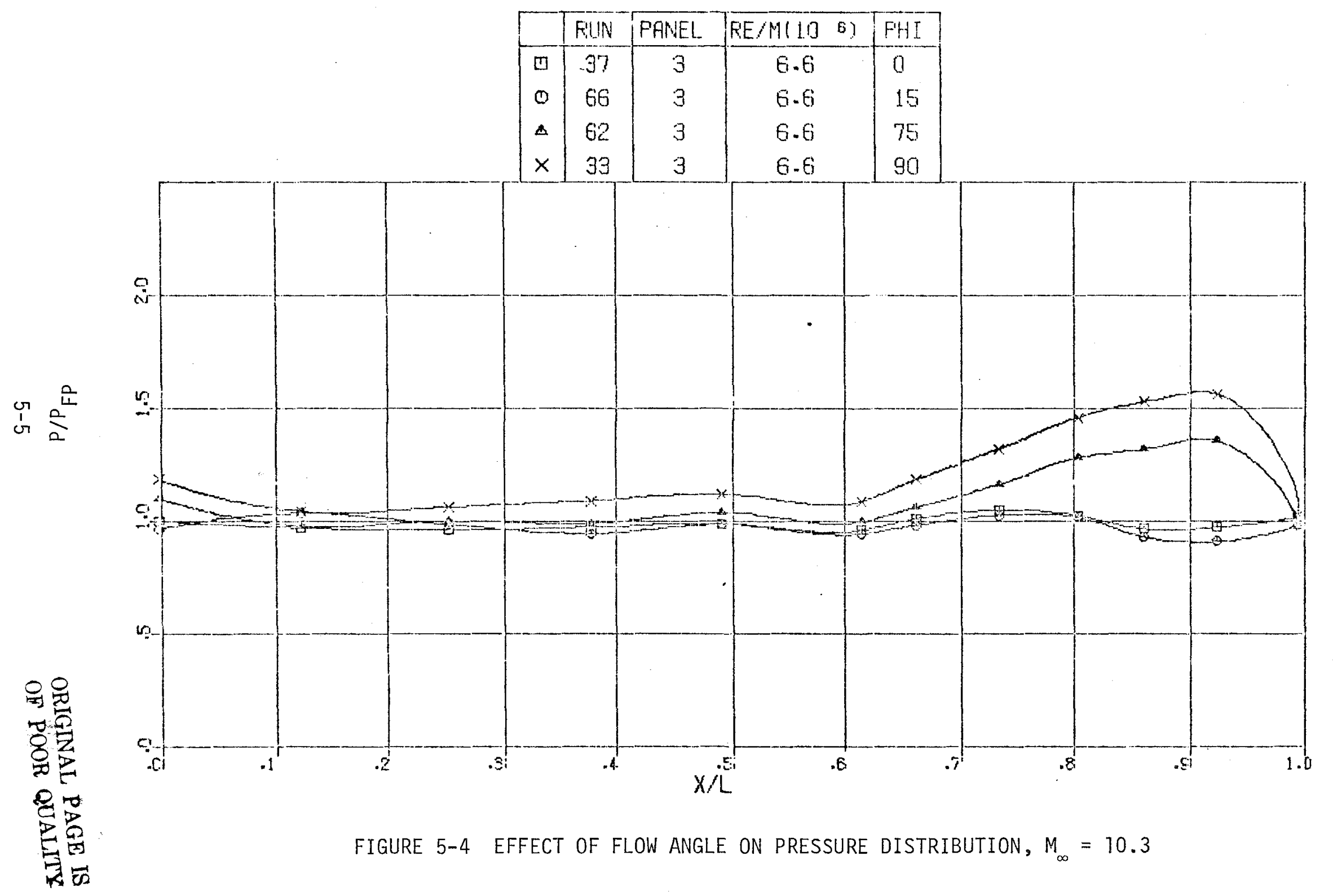




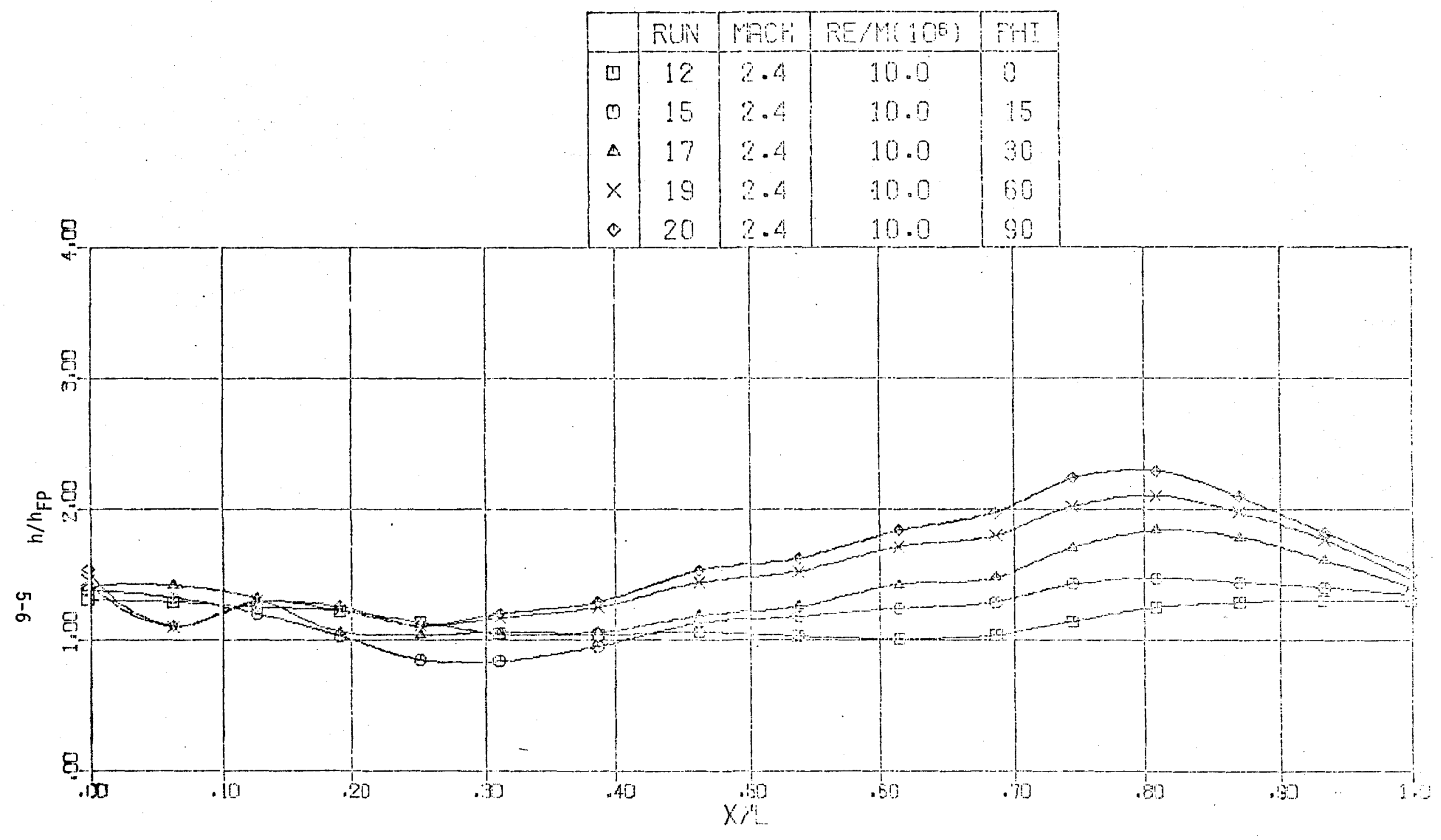

FIGURE 5-5 EFFECT OF FLOW ANGLE ON HEATING DISTRIBUTION, PANEL -6 


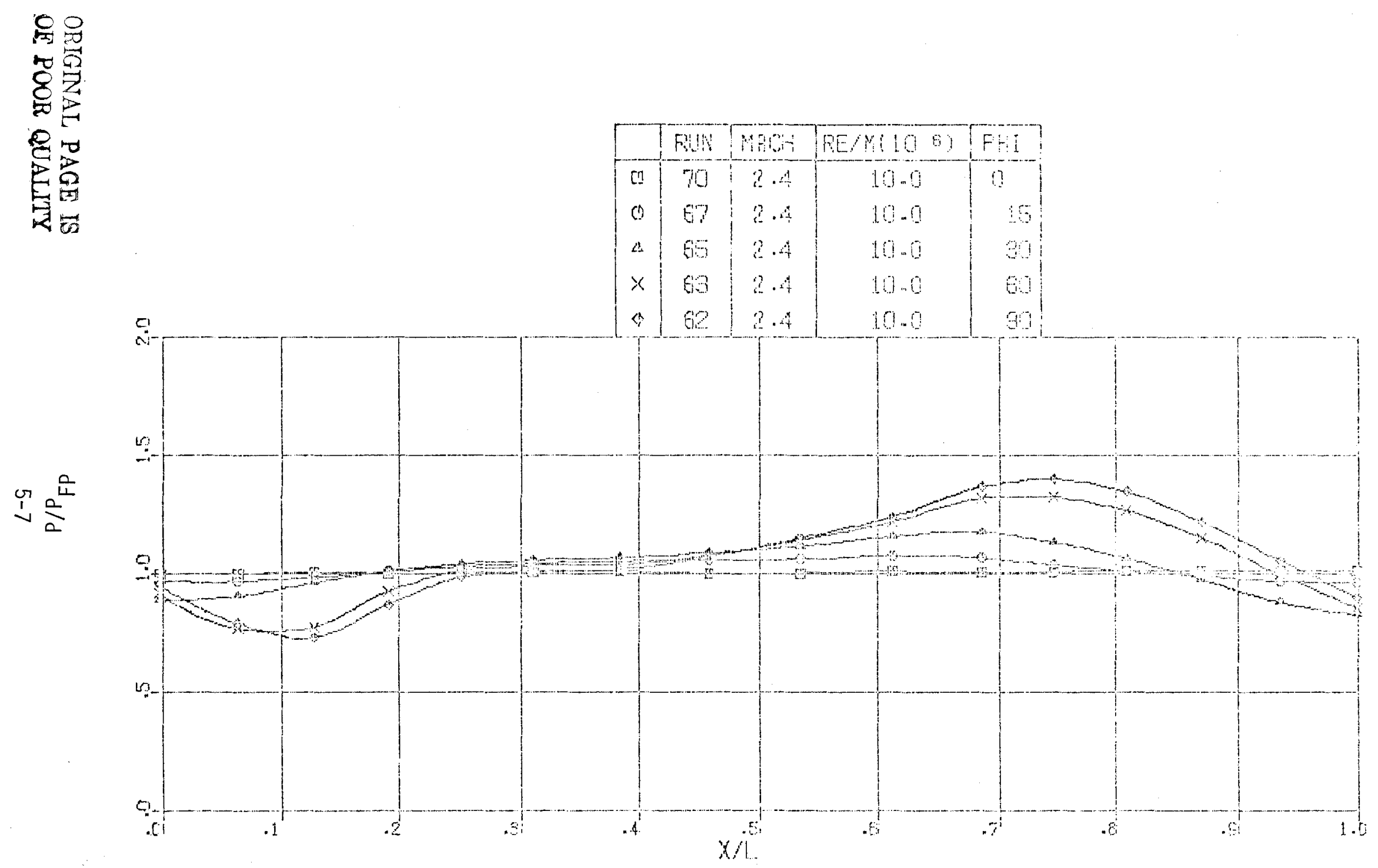

FIGURE 5-6 EFFECT OF FLOW ANGLE ON PRESSURE DISTRIBUTION, PANEL - 6 
and 5-6 with Figures 5-7 and 5-8 in which data are presented for flow angles of $0^{\circ}, 15^{\circ}, 30^{\circ}, 60^{\circ}$, and $90^{\circ}$ for $M_{\infty}=2.4$ and 4.5 for a constant free-stream Reynolds number per meter of $10 \times 10^{6}$. The Mach number has a 1 arger effect on the heating than on pressure with the importance being more pronounced at the higher flow angles. For both pressure and heating the increases over smooth wall values become greater with increasing Mach number.

Reynolds Number Effect - Previous experiments on the influence of Reynolds number on corrugated panels in thick turbulent boundary layers in hypersonic flow were conducted at $R_{e_{\infty}} / M=1.3 \times 10^{6}, 3.3 \times 10^{6}$, and $6.6 \times 10^{6}$. Results showed that peak heating and pressure increased with Reynolds number. Similar results were obtained in this study for the same Reynolds number range, as shown in Figures 5-9 and 5-10 which are for free-stream flow normal to the waves of panel -1 at a free-stream Mach number of 10.3 and $R_{e_{\infty}}=1.3,3.3,6.6$, and $8.2 \times 10^{6}$. Increasing $R_{e_{\infty}}$ increases the heating and pressure except for changes from $6.6 \times 10^{6}$ to $8.2 \times 10^{6}$ over which range the peak heating slightly decreases. Identical results were obtained for panels -2 and -3 except the heating slightly increased from $\operatorname{Re}_{\infty} / M=$ 6.6 to $8.2 \times 10^{6}$. The trends may be somewhat influenced by flow angularity in the boundary layer which could be a function of both Reynolds number and distance from the wall.

For supersonic flow $\left(M_{\infty}=2.4\right)$ over panel -6 , the effect of Reynolds number can be seen by comparing the distributions in Figures 5-11 and 5-12 with Figures 5-5 and 5-6 for flow angles of $15^{\circ}, 30^{\circ}, 60^{\circ}$, and $90^{\circ}$. As the Reynolds number increases from $3.3 \times 10^{6}$ to $10 \times 10^{6}$, the heating decreases except for $\emptyset=0^{0}$ and $15^{\circ}$ for which the heating slightly increases. The peak pressure decreases slightly with increasing Reynolds number for $\emptyset=30^{\circ}, 60^{\circ}$, and $90^{\circ}$ at approximately the same $X / L$ location on the wave. For $\emptyset=15^{\circ}$, the peak pressure also decreases slightiy with increasing Reynolds number. However, the peak pressure location for this low flow angle has moved downstream near the crest of the wave for the lower Reynolds number case.

Wave Length Effect - The wave length is one of the primary parameters considered in the design of corrugated panels. Until the present study, the effect of the wave length on the heating distributions in thick turbulent boundary layers had not been investigated. In order to investigate the wave length effect, panel -2 was constructed and tested and the results are compared with those for panel -4 which has approximately the same wave height as panel -2 and $1 / 2$ the wave length. The heating was found to be relatively insensitive to the wave length for all the flow conditions considered in this study, as demonstrated in Figures 5-13 and 5-14. 


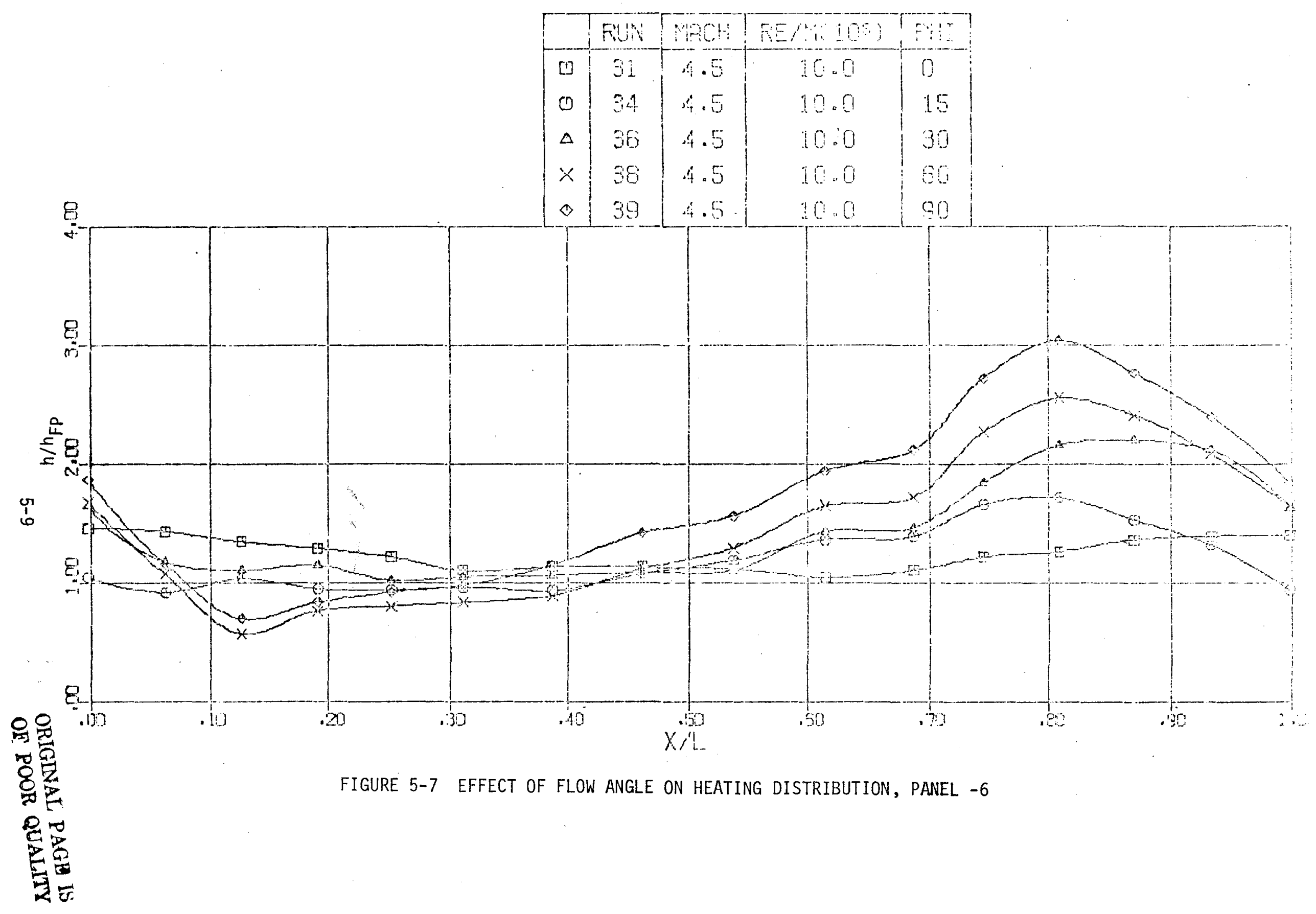




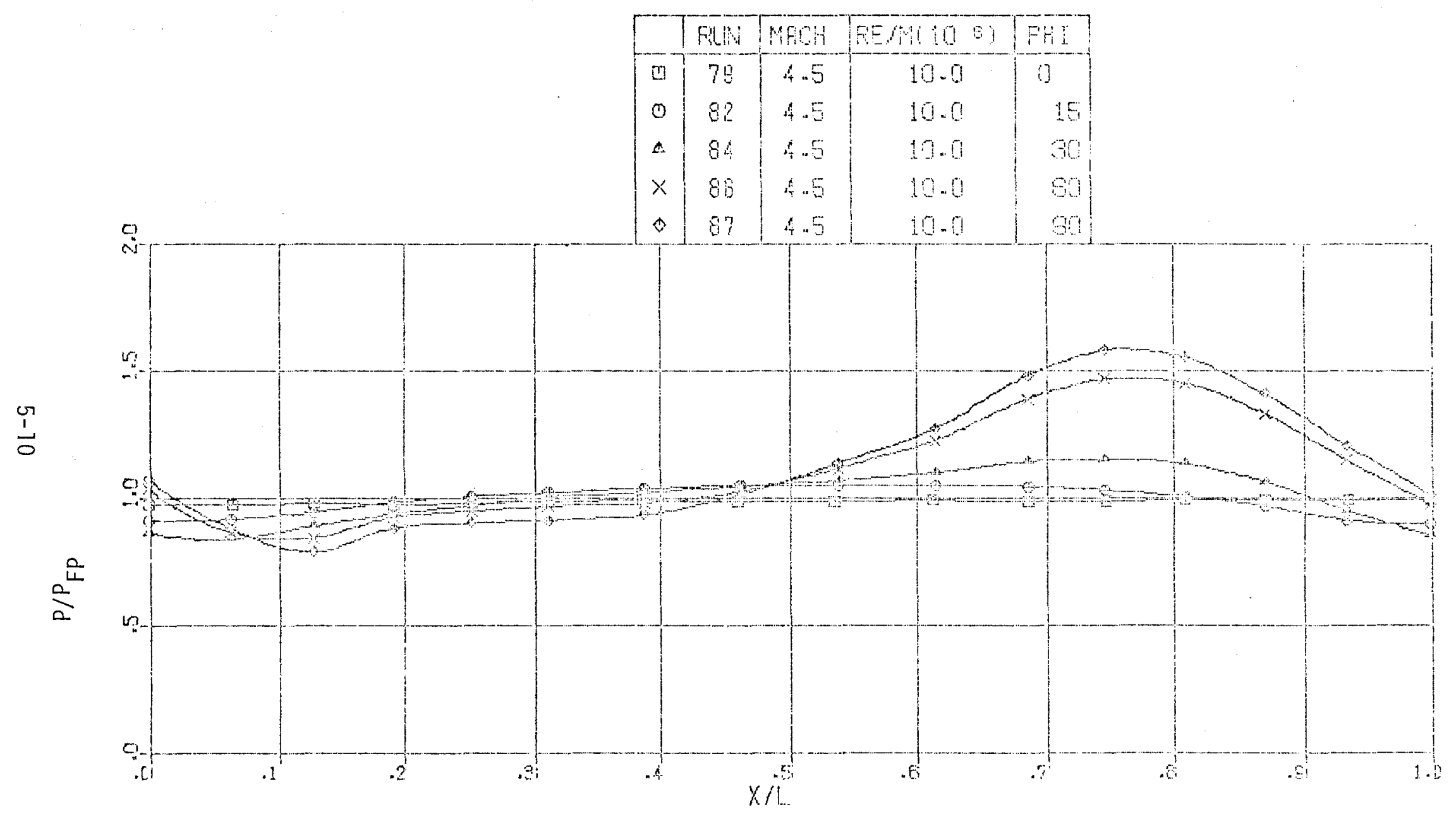

FIGURE 5-8 EFFECT OF FLOW ANGLE ON PRESSURE DISTRIBUTION, PANEL - 6 


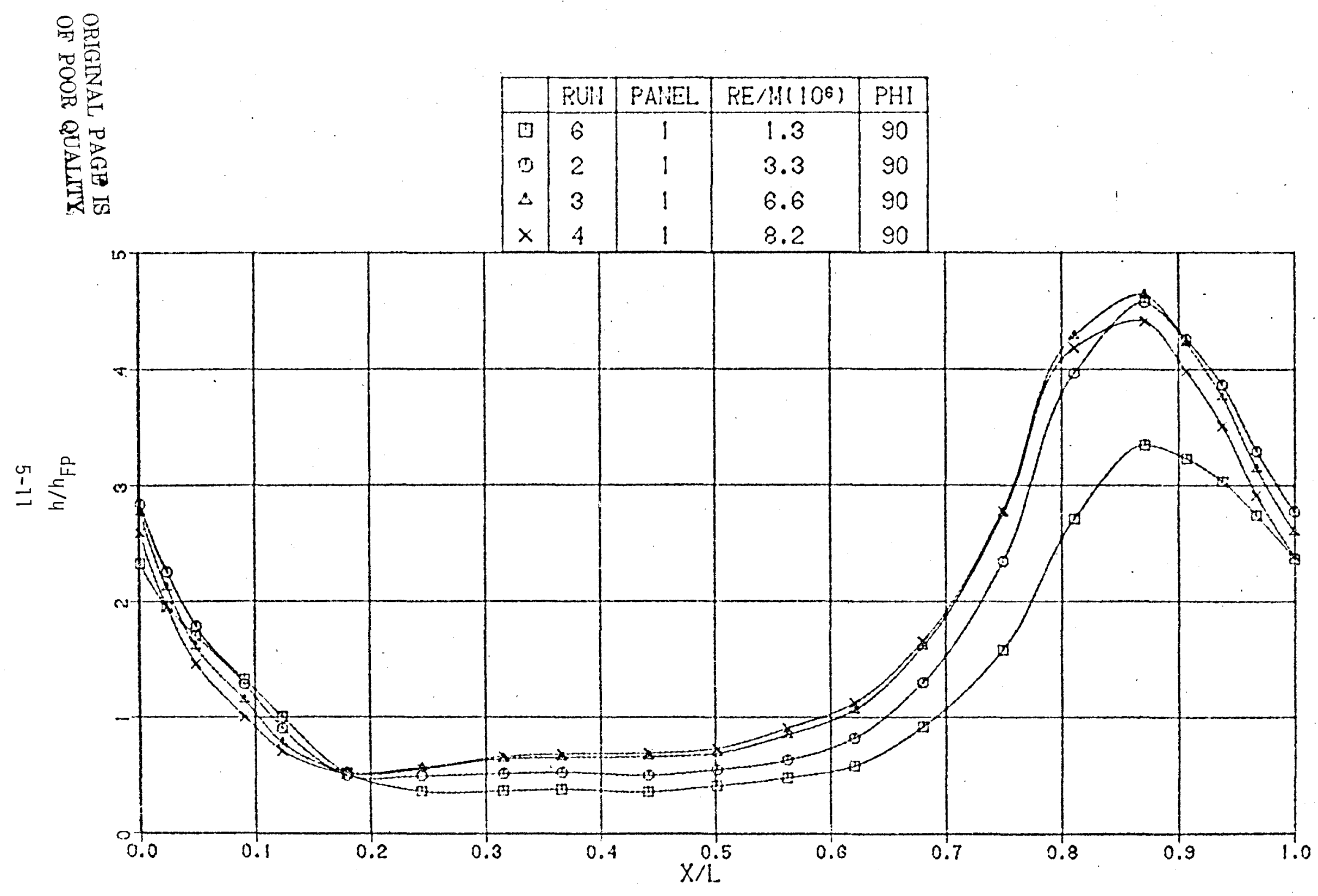

FIGURE 5-9 EFFECT OF REYNOLDS NUMBER ON HEATING DISTRIBUTION, $M_{\infty}=10.3$ 


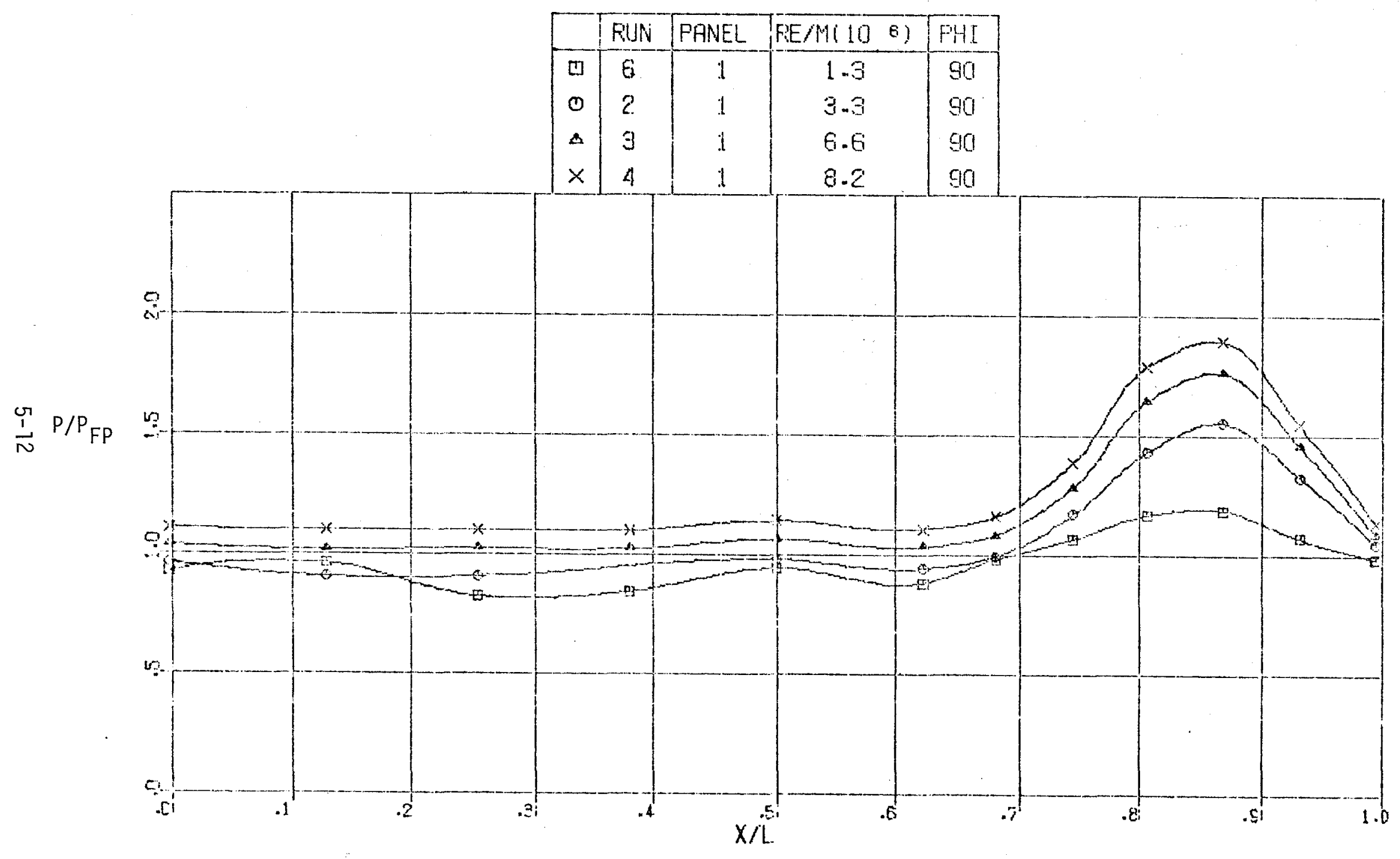

FIGURE 5-10 EFFECT OF REYNOLDS NUMBER ON PRESSURE DISTRIBUTION, $M_{\infty}=10.3$ 


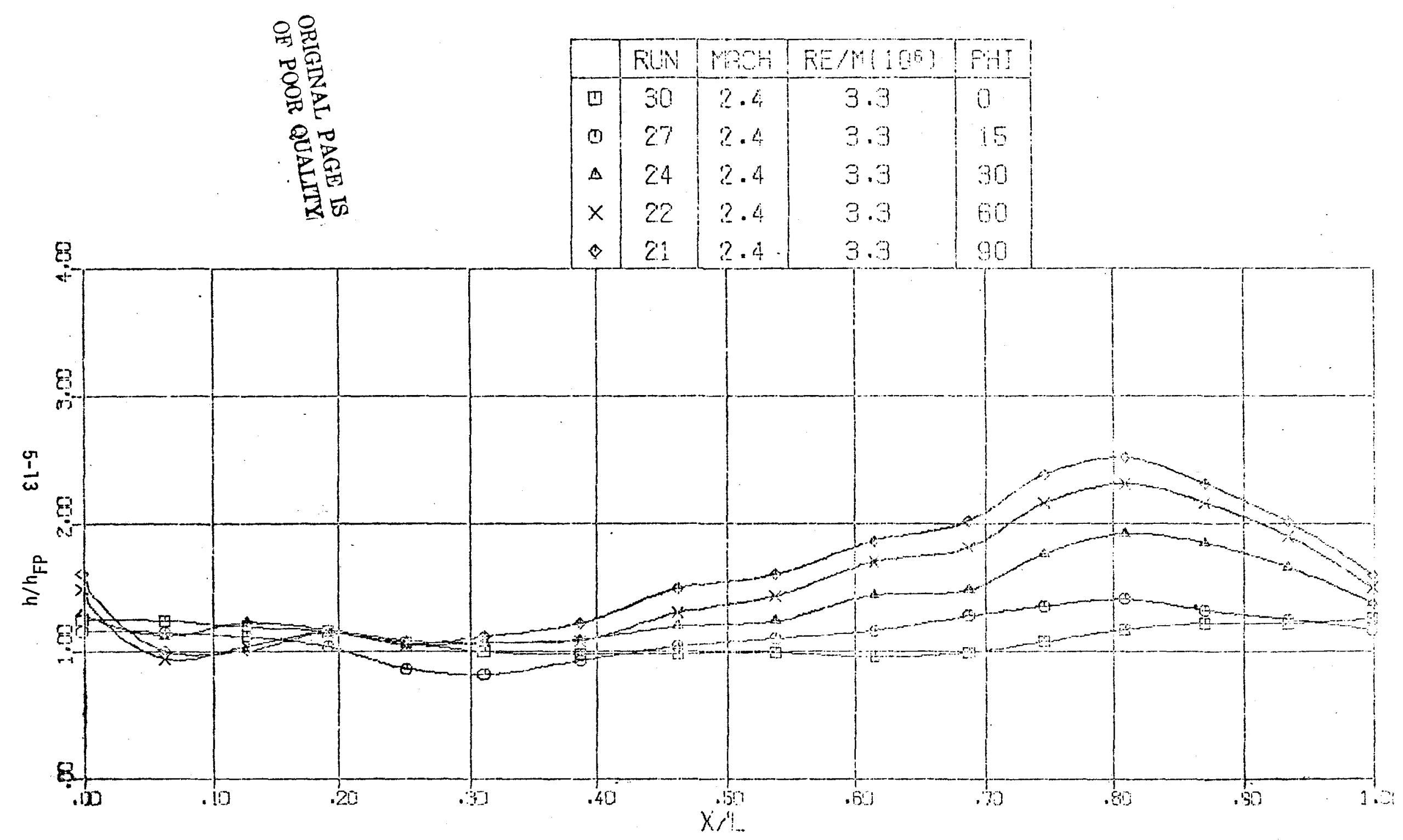

FIGURE 5-11 EFFECT OF FLOW ANGLE ON HEATING DISTRIBUTION, PANEL - 6 


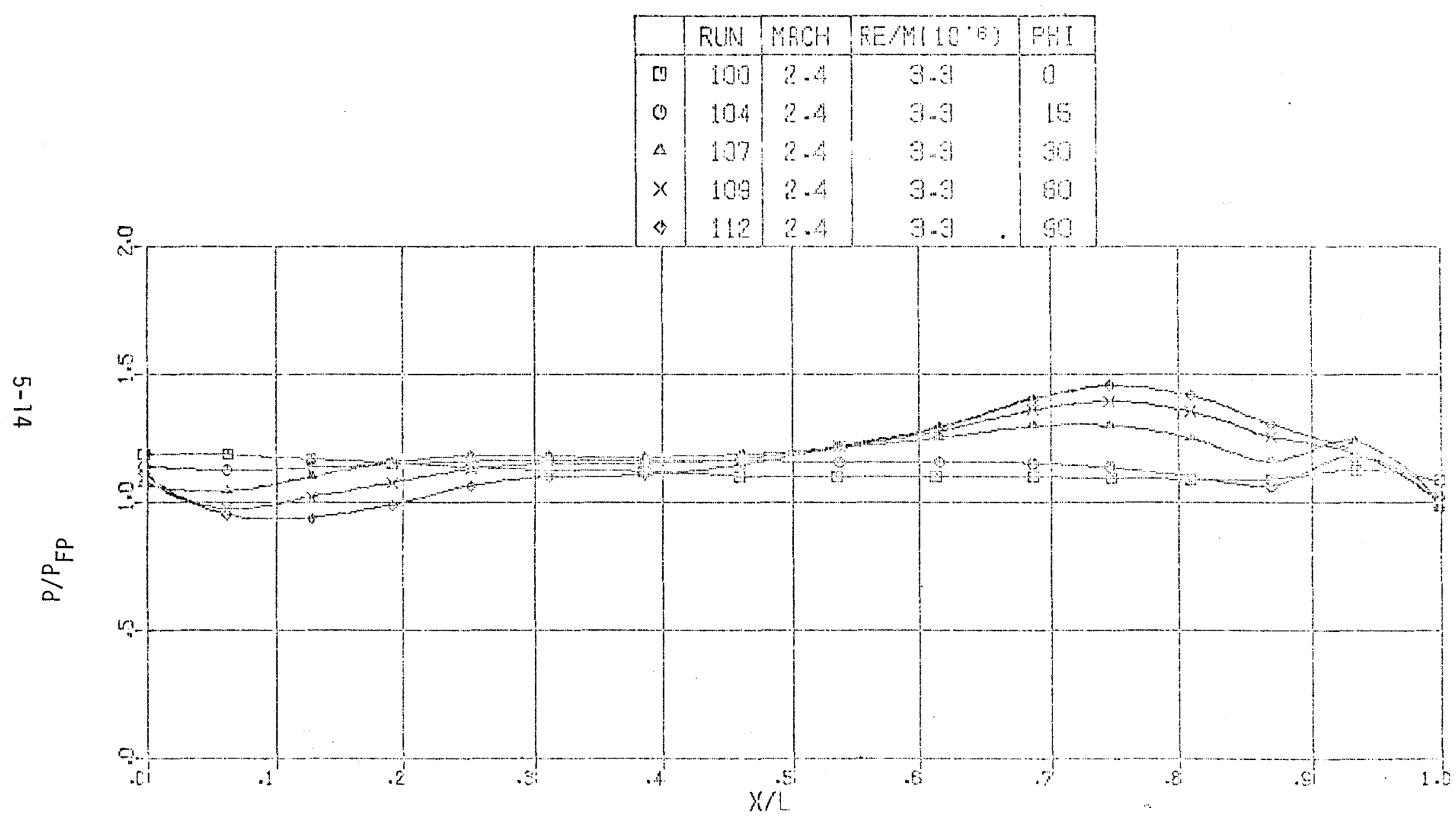

FIGURE 5-12 EFFECT OF FLOW ANGLE ON PRESSURE DISTRIBUTION, PANEL -6 


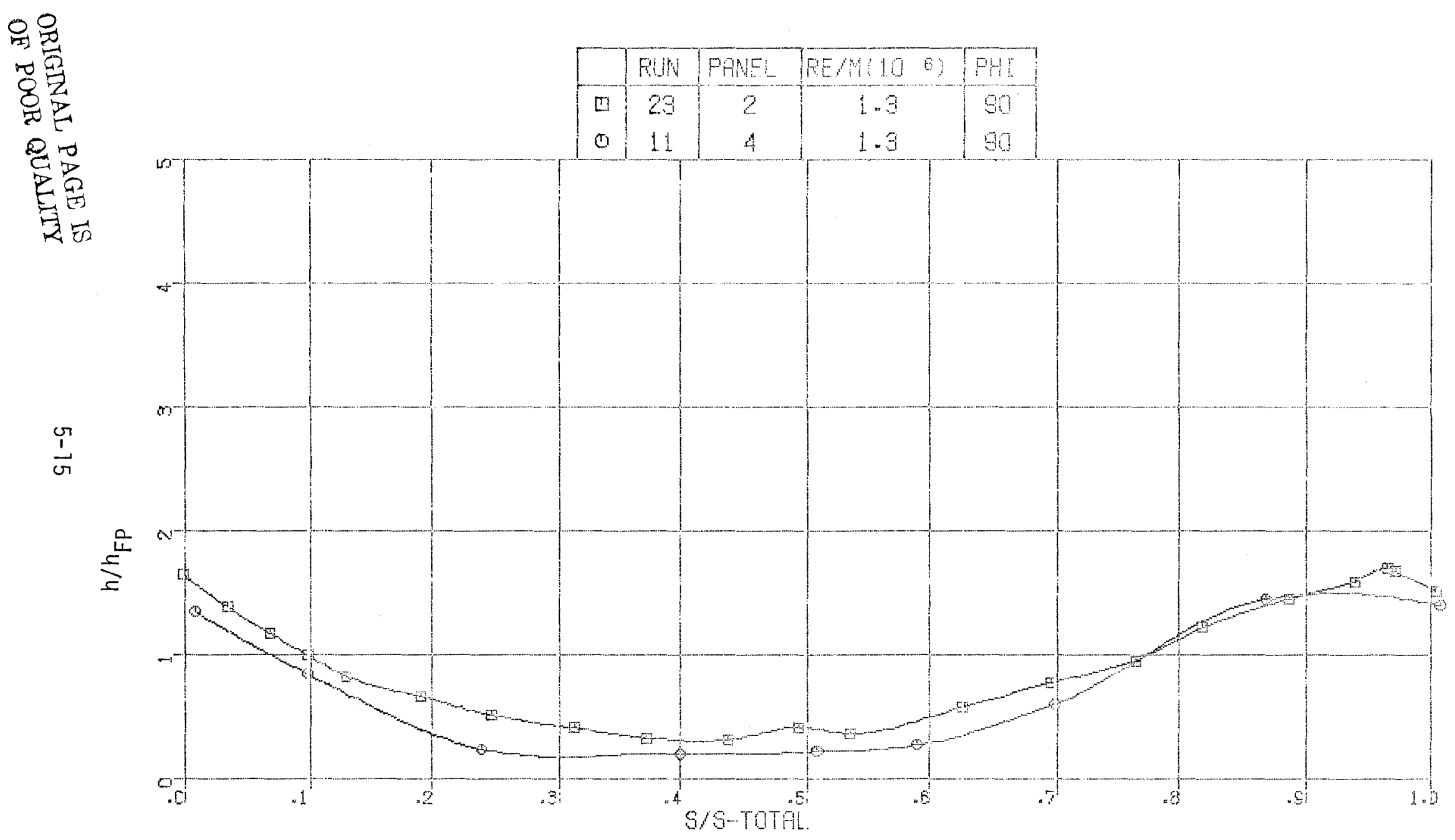

FIGURE 5-13 EFFECT OF WAVE LENGTH ON HEATING DISTRIBUTION, $M_{\infty}=10.3$ 


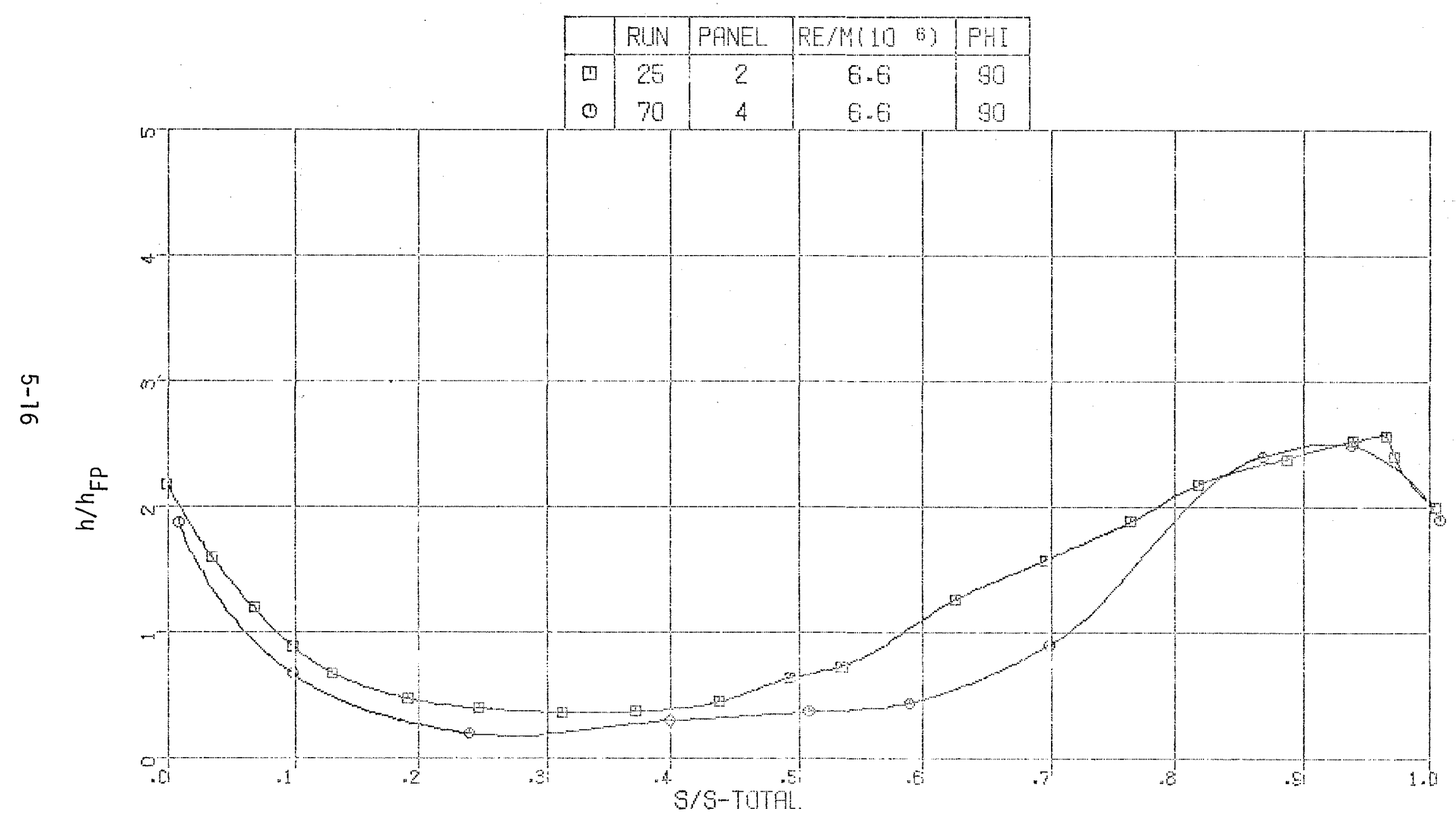

FIGURE 5-14 EFFECT OF WAVE LENGTH ON HEATING DISTRIBUTION, $M_{\infty}=10.3$ 
The heating distributions on both panels are almost identical for the three Reynolds numbers shown. For the higher Reynolds number $\left(\operatorname{Re}_{\infty} / M=6.6 \times 10^{6}\right)$, the average heating for the larger wave length panel is somewhat greater due to the increased heating along the compression surface of the wave. The present results on the effect of wave length can be very important in the design of corrugated heat shields for application in very thick boundary layers since the wave length can be significantly changed without a corresponding heating penalty.

Wave Amplitude Effect - Previous tests on the effect of corrugation height (wave amplitude) in thick turbulent boundary layers yielded results which were radically different than those for thin boundary layers. Heat transfer and pressure were found to be relatively insensitive to the wave amplitude for all flow conditions investigated. As a consequence of the previous results, panel -1 was constructed and tested to bridge the gap in the data between the very thick and thin boundary layer data. Panel -1 has a wave height which is almost twice that of panel -4 , and a wave length which is twice that of panel -4 . The heating on panels -1 and -4 are compared in Figures 5-15 and 5-16 for $R_{e_{\infty}} / M=1.3$ and $6.6 \times 10^{6}$. Unlike the previous results in thick boundary layers, the present results show that the wave height can significantly affect the peak heating on corrugated paneis if the corrugation protrudes far enough out into the boundary layer. Peak heating data for panel -5 which had an amplitude about $1 / 2$ that of -4 was very similar to data for panel -4 . However, peak heating data for panel -4 which has an amplitude about $1 / 2$ that of -1 is we 11 below the data for panel -1 . Comparison of the data for panels -2 and -4 shows that the wave length has a small influence on the peak heating, and hence the large difference between the data on panels -1 and -4 is attributed to the change in the wave height. The curves faired through the data for pane -4 ane slightly different from those presented in Ref. 8 . The present curves were generated by a computer plot routine which used a spline fit, while the previous distributions were hand faired. 


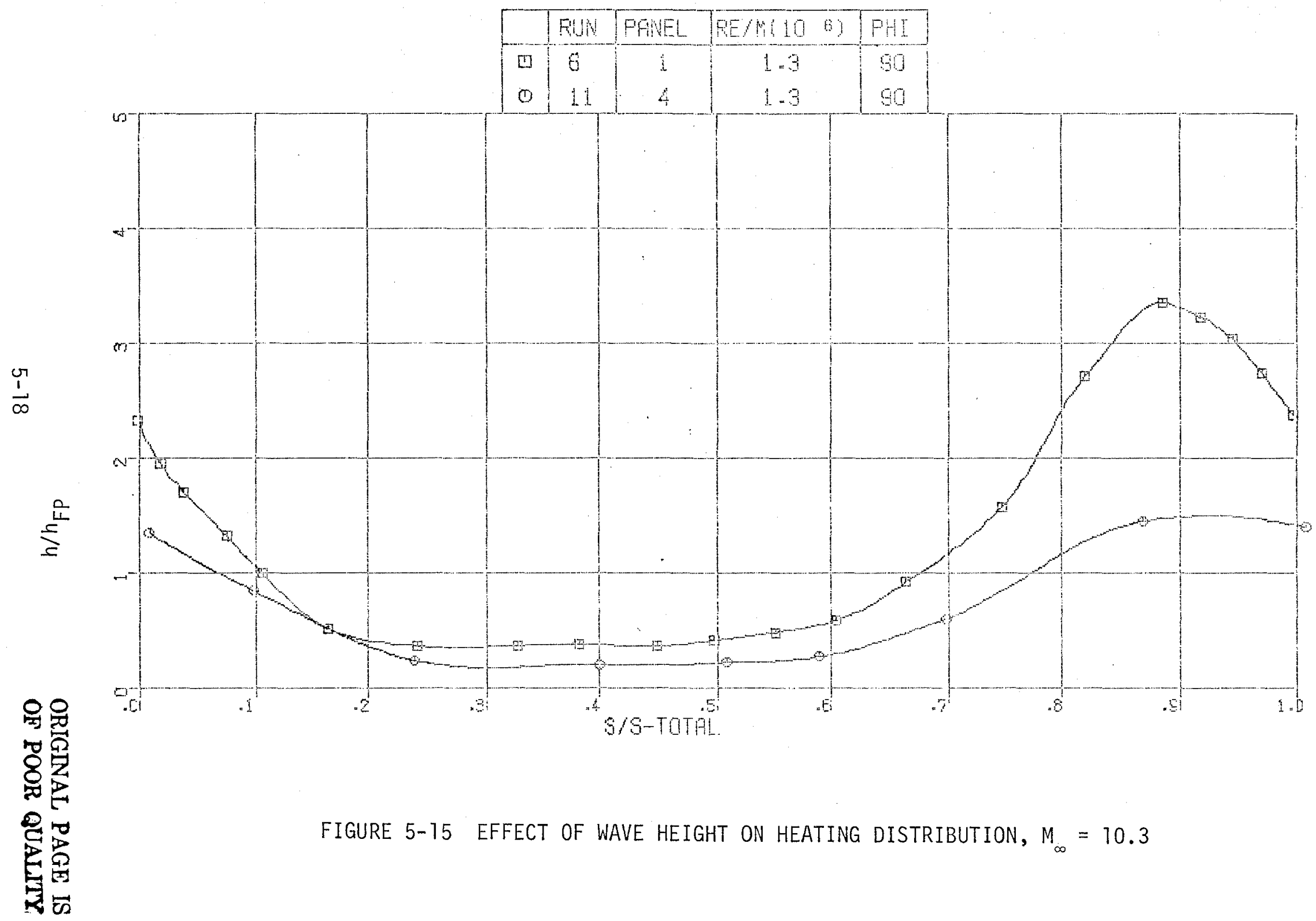




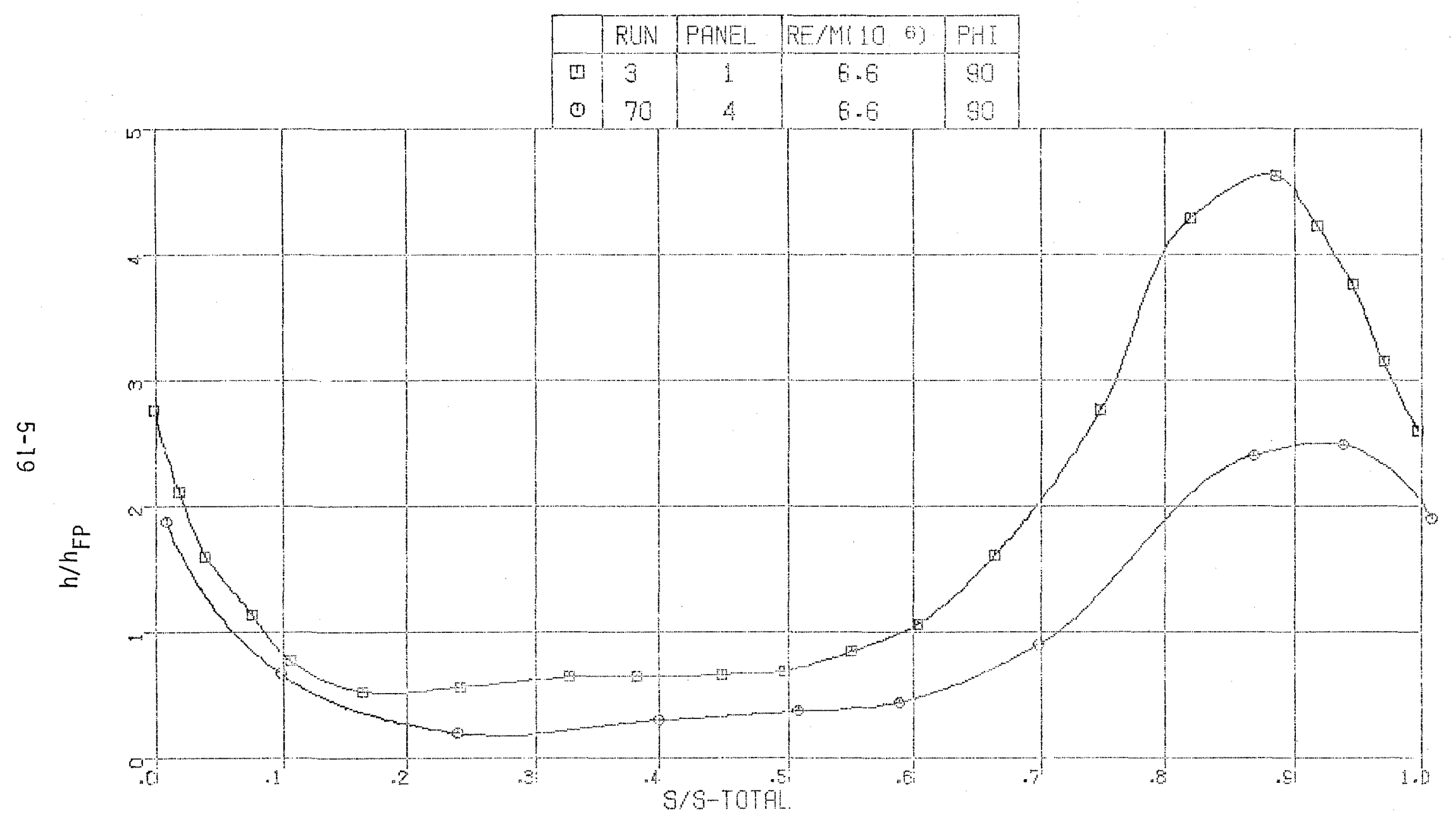

FIGURE 5-16 EFFECT OF WAVE HEIGHT ON HEATING DISTRIBUTION, $M_{\infty}=10.3$ 
Wave Radius Éffect - The panels of the present study have shapes constructed of circular arcs connected by straight lines as shown by the sketch in Figure 3-4. For a given wavelength and wave height, there is some leeway in choosing the arc radius in the panel design. Experiments were conducted with panel -3 and the results are compared with data for panel -4 to determine the importance of changing the surface radius by a factor of 2. Panel -3 has a surface radius equal to $.457 \mathrm{~cm}$ which is $1 / 2$ the radius of panel -4 . Both panels have the same wave length $(3.66 \mathrm{~cm})$. Panel -3 was designed to have the same wave height as panel -4 . However, due to spring back in the metal during construction, panel -3 has a wave height of $.406 \mathrm{~cm}$ compared to $.61 \mathrm{~cm}$ for panel -4 . Heating on the two panels is quite similar considering the surface radii are different by a factor of two, as shown in Figures 5-17 and 5-18. The peak and average heating are slightly higher on pane -3 which has the smaller wave radius. Similar results were found for other flow angles at Mach 10.3. The increased heating on the sharper wave probably would have been more pronounced if its wave height had been exactly equal to that of panel -4 . Wave Scaling - The shape of panel -1 is scaled up from panel -4 by a factor of about 2. (Again, the wave height is not quite to scale due to the spring back problem encountered during construction.) The two wave shapes are geometrically similar in that the wave shape for panel - 1 can be obtained by uniformly increasing all the dimensions of panel -4 , and the two profiles have identical surface deflection angles along the waves. However, comparison of the data obtained on panels -1 and -4 (Figures $5-15$ and 5-16) shows that the heating distributions are not similar in that the distribution on panel -4 cannot be uniformly increased to obtain the distribution on panel -1. Therefore, a known heating distribution on a given panel shape cannot be used to determine the heating distribution on a geometrically similar panel by uniformly changing the heating on the compression and expansion surfaces by a constant value. The heating on the first panel can only serve as a guide to the distribution which can be expected on the second panel. Undoubtedly, a complex function of geometric, inviscid flow, internal boundary layer, and bulk boundary layer parameters relates the heating distributions on different panels whether or not the panels are geometrically similar. This type of function was not considered in this present study for the heating distributions. However, such a function was explored for maximum heating and is discussed in the correlation section of this report. 


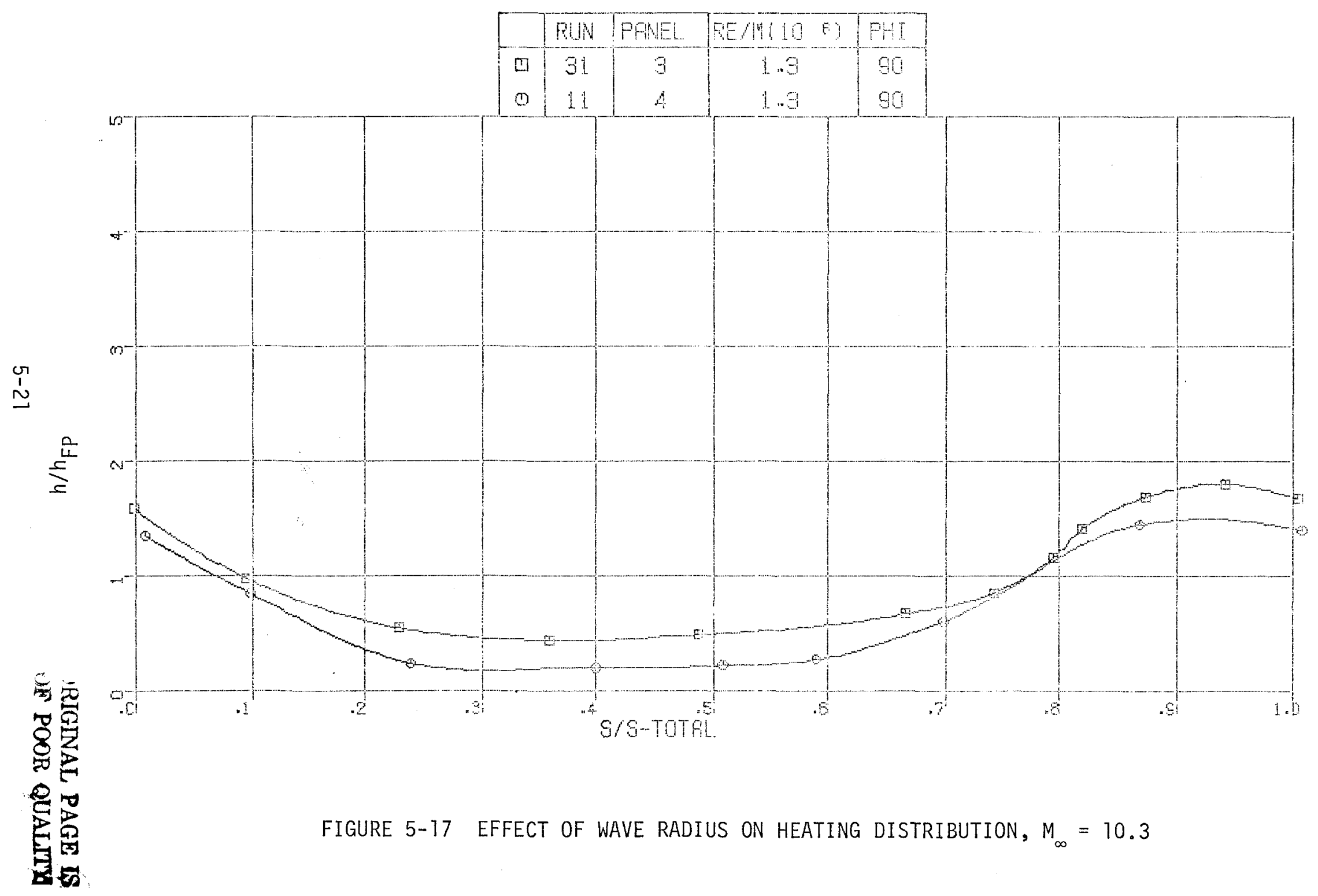




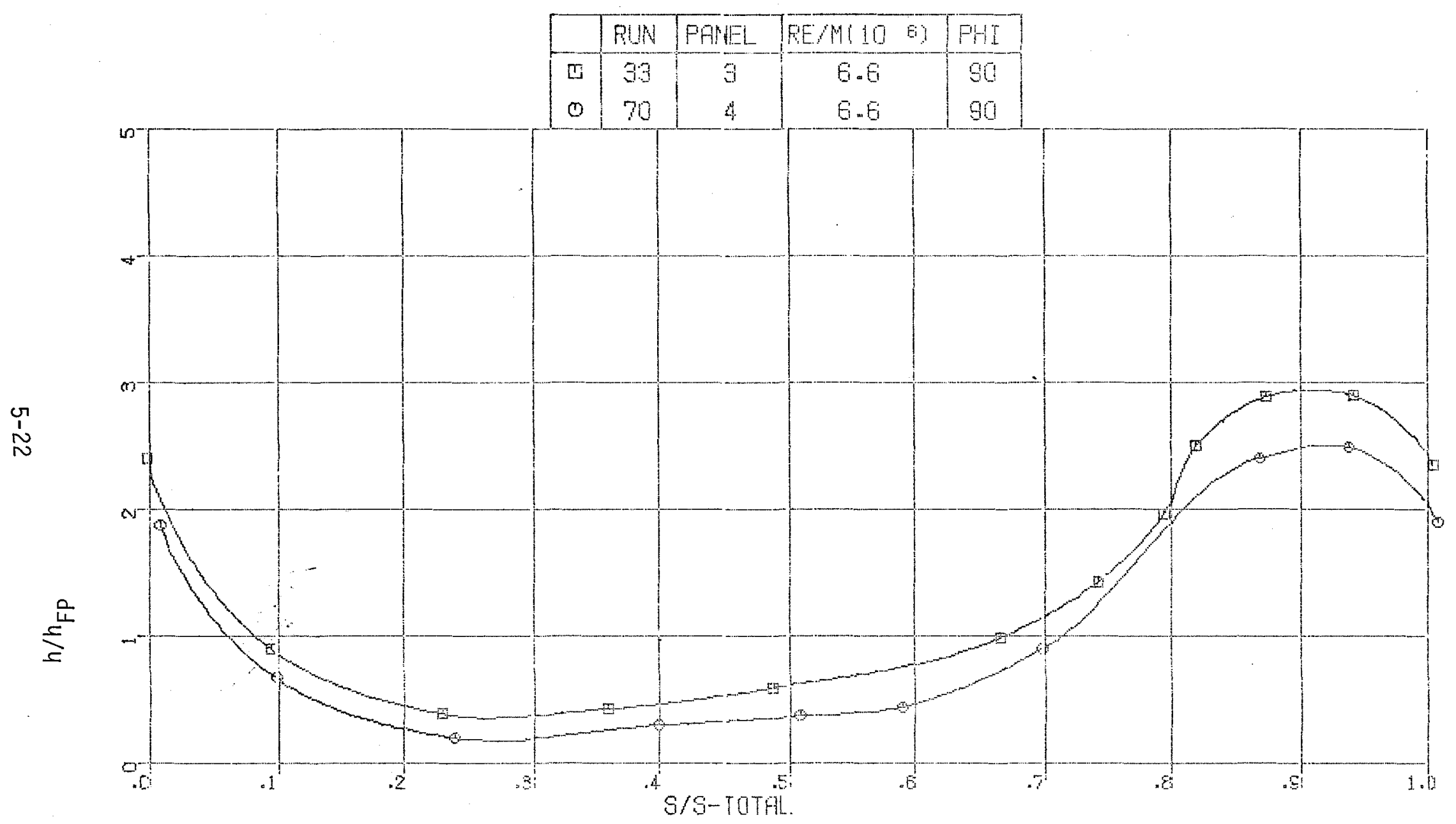

FIGURE 5-18 EFFECT OF WAVE RADIUS ON HEATING DISTRIBUTION, $M_{\infty}=10.3$ 


\subsection{CORRELATION OF WIND TUNNEL DATA}

The maximum and average wave heating measured during the study on panels -1 , -2 , and -3 are summarized in Tables 6-I and 6-II. The pressure drag coefficients measured on the panels are given in Table 6-111. The maximum heating values represent the highest measured values. The average values were obtained by integrating the heating distributions, and the pressure drag was computed by integrating the measured pressure distributions. The drag data for hypersonic flow are not correlated herein because the values were extremely low and the effect of the increased drag due to the corrugations would be insignificant in the hypersonic range. The maximum and average pressures measured on the panels are listed in Tables 6-IV and 6- $V$. Data obtained by Sawyer, Ref. 10, on panel -6 are also presented in Tables 6-I, 6-II, 6-IV, and 6-V and Figures 8-3 and 8-4 for comparison.

For supersonic flow over panel -6 , the average heating values are always greater than the corresponding flat plate value. For hypersonic flow, panels -2 and -3 have average values less than flat plate values for some conditions. However, the average heating for the largest amplitude panel $(\varepsilon=1.06 \mathrm{~cm})$ are all greater than the flat plate values. The changes in average heating with increasing corrugation angle are not consistent with the maximum heating trends in that average heating actually decreases with increasing flow angle for many conditions.

Correlation of Maximum Pressure

A detailed description of the flow field occurring over a wave of a corrugated panel is beyond the scope of the present investigation. Such a description would require a turbulent mixing solution with imbedded shocks coupled with a technique that predicts flow separation and the corresponding reattachment region. However, some effort was directed toward developing an understanding of the flow field over a wave using an elementary flow analysis.

A simple flow model was investigated to determine if the maximum surface pressure could be predicted. In this model the local internal flow* at the wave height is assumed to expand isentropically over the expansion surface, pass through a separation shock (assumed to be a normal shock), and then be compressed isentropically at the stagnation point on the compression surface. The total pressure behind the imbedded shock would then represent the maximum surface pressure which could be recovered on the compression surface. Two cases were considered for which the separation and reattachment points were determined from oil flows. For both cases the flow was normal to the corrugations. The first case was supersonic flow $\left(M_{\infty}=2.4\right)$ over panel -6 and the second case was hypersonic flow $\left(M_{\infty}=10.3\right)$ over

\footnotetext{
${ }^{*} \prod_{\varepsilon}$ is the Mach number at the wave maximum height determined in the flat plate
} boundary layer surveys. 
TABLE 6-I MAXIMUM WAVE HEATING

\begin{tabular}{|c|c|c|c|c|c|c|}
\hline $\mathrm{Re}_{\infty} / \mathrm{M}$ & $M_{\infty}$ & $\phi(D E G)$ & $\begin{array}{l}\text { PANEL } \\
(\varepsilon=1 . \\
h_{\operatorname{MAX}} / \mathrm{h}\end{array}$ & & $\begin{array}{l}\text { PANEL }-2 \\
(\varepsilon=.525 \mathrm{~cm}) \\
\mathrm{h}_{\text {MAX }} / \hat{h}_{\mathrm{fp}}\end{array}$ & $\begin{array}{l}\text { PANEL }-3 \\
(\varepsilon=.405 \mathrm{~cm}) \\
h_{\text {MAX }} / h_{\mathrm{fp}}\end{array}$ \\
\hline$\downarrow^{1.3 \times 10^{6}}$ & 10.3 & $\begin{array}{r}0 \\
15 \\
75 \\
90\end{array}$ & $\begin{array}{l}1.45 \\
3.66 \\
3.33 \\
3.35\end{array}$ & & $\begin{array}{l}1.18 \\
1.51 \\
1.50 \\
1.70\end{array}$ & $\begin{array}{l}1.32 \\
1.57 \\
1.88 \\
1.80\end{array}$ \\
\hline$\downarrow^{3.3 \times 10^{6}}$ & & $\begin{array}{r}0 \\
15 \\
75 \\
90\end{array}$ & $\begin{array}{l}1.36 \\
3.44 \\
4.36 \\
4.57\end{array}$ & & $\begin{array}{l}1.01 \\
1.55 \\
2.11 \\
2.15\end{array}$ & $\begin{array}{l}1.12 \\
1.69 \\
2.09 \\
2.40\end{array}$ \\
\hline$\underbrace{6.6 \times 10^{6}}$ & & $\begin{array}{r}0 \\
15 \\
75 \\
90\end{array}$ & $\begin{array}{l}1.31 \\
2.63 \\
4.54 \\
4.63\end{array}$ & & $\begin{array}{l}.874 \\
1.47 \\
2.40 \\
2.56\end{array}$ & $\begin{array}{l}1.00 \\
1.92 \\
2.61 \\
2.90\end{array}$ \\
\hline$\psi^{8.2 \times 10^{6}}$ & $\downarrow$ & $\begin{array}{r}0 \\
15 \\
75 \\
90\end{array}$ & $\begin{array}{l}1.31 \\
2.43 \\
4.38 \\
4.41\end{array}$ & & $\begin{array}{l}.870 \\
1.37 \\
2.34 \\
2.46\end{array}$ & $\begin{array}{l}.981 \\
1.90 \\
2.70 \\
2.98\end{array}$ \\
\hline $\operatorname{Re}_{\infty} / M$ & $\varepsilon(\mathrm{cm})$ & $M_{\infty}$ & \multicolumn{3}{|c|}{$\phi(D E G)$} & $\begin{array}{l}\text { PANEL -6 } \\
h_{\max } / h_{f p}\end{array}$ \\
\hline$\sqrt[3.3 \times 10^{6}]{1}$ & .79 & $\overline{2.4}$ & & $\begin{array}{r}0 \\
15 \\
30 \\
60 \\
90\end{array}$ & & $\begin{array}{l}1.26 \\
1.41 \\
1.92 \\
2.32 \\
2.52\end{array}$ \\
\hline $10 . \times 10^{6}$ & & $\phi$ & & $\begin{array}{r}0 \\
15 \\
30 \\
60 \\
90\end{array}$ & & $\begin{array}{l}1.31 \\
1.48 \\
1.84 \\
2.10 \\
2.30\end{array}$ \\
\hline 1 & $\vee$ & $i_{1}^{4.5}$ & & $\begin{array}{r}0 \\
15 \\
30 \\
60 \\
90\end{array}$ & & $\begin{array}{l}1.46 \\
1.72 \\
2.20 \\
2.56 \\
3.04\end{array}$ \\
\hline
\end{tabular}


TABLE 6-II AVERAGE WAVE HEATING

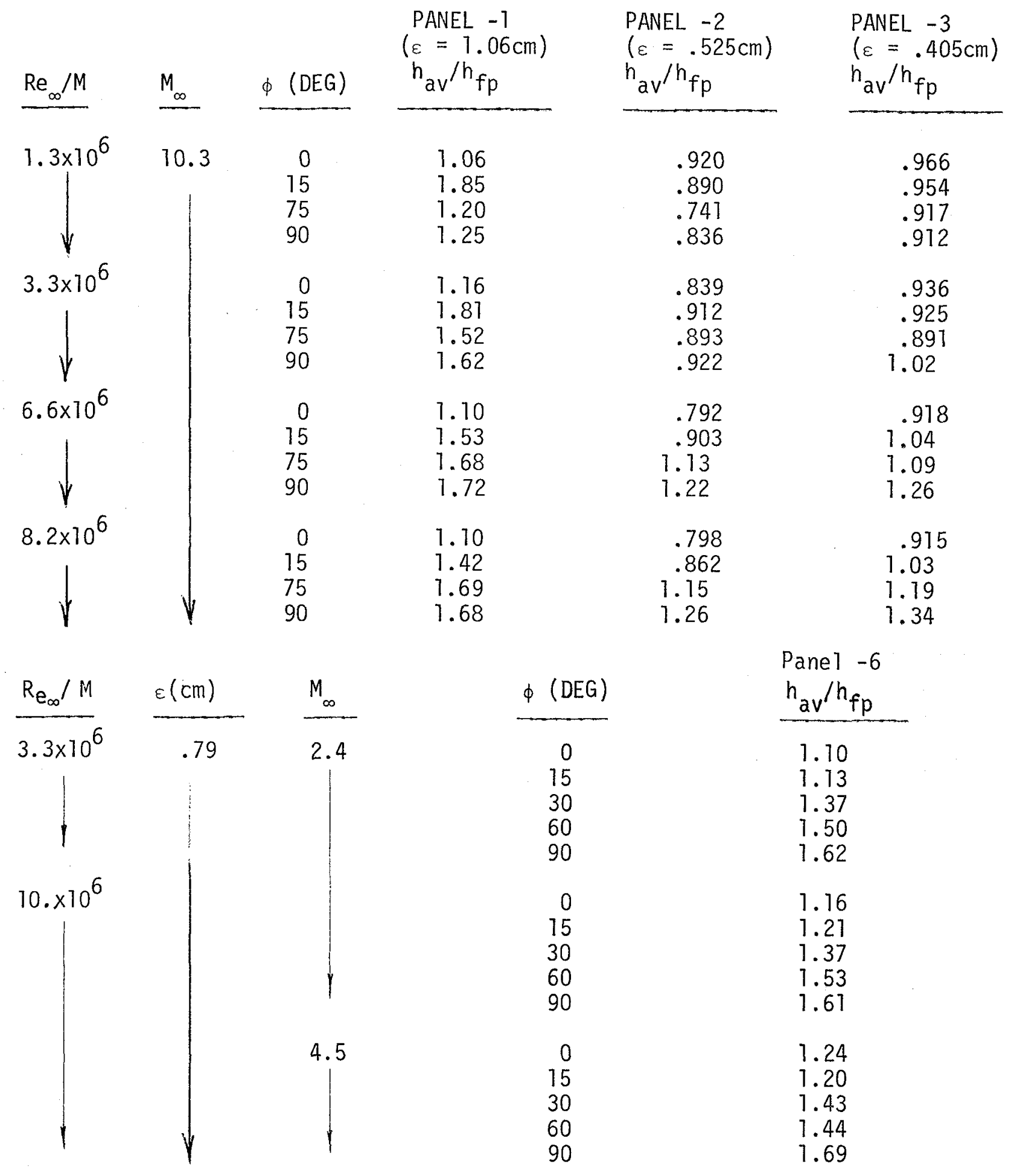


TABLE 6-III

\section{PRESSURE DRAG COEFFICIENTS}

TOR CFHT DATA

\begin{tabular}{|c|c|c|c|c|}
\hline PANEL 1 & $\operatorname{Re}_{\infty} / M=1.3 \times 10^{6}$ & $3.3 \times 10^{6}$ & $6.6 \times 10^{6}$ & $8.2 \times 10^{6}$ \\
\hline$\phi=15^{\circ}$ & $3.57 \times 10^{-5}$ & $1.82 \times 10^{-5}$ & $1.60 \times 10^{-5}$ & $1.55 \times 10^{-5}$ \\
\hline $75^{\circ}$ & .00182 & .00126 & .00120 & .00118 \\
\hline $90^{\circ}$ & .00128 & .00216 & .00143 & .00141 \\
\hline
\end{tabular}

PANEL 2

\begin{tabular}{rrrrr}
\hline$=15^{\circ}$ & $-7.55 \times 10^{-7}$ & $-7.66 \times 10^{-7}$ & $-7.10 \times 10^{-6}$ & $-1.15 \times 10^{-5}$ \\
$75^{\circ}$ & $2.08 \times 10^{-4}$ & $1.62 \times 10^{-4}$ & $2.35 \times 10^{-4}$ & $2.72 \times 10^{-4}$ \\
$90^{\circ}$ & $2.09 \times 10^{-4}$ & $2.63 \times 10^{-4}$ & $3.58 \times 10^{-4}$ & $3.94 \times 10^{-4}$
\end{tabular}

PANEL 3

$\begin{array}{cllll}\phi=15^{\circ} & 4.40 \times 10^{-6} & 1.27 \times 10^{-6} & 9.63 \times 10^{-7} & 8.20 \times 10^{-7} \\ 75 & 4.72 \times 10^{-4} & 3.18 \times 10^{-4} & 3.68 \times 10^{-4} & 4.19 \times 10^{-4} \\ 90^{\circ} & 3.91 \times 10^{-4} & 4.73 \times 10^{-4} & 5.41 \times 10^{-4} & 5.77 \times 10^{-4} \\ C_{d}=\frac{F_{\text {PRES. }}}{\frac{1}{2} \rho_{\infty} U_{\infty}^{2}(A)} \text { Based on wavelength in freestream flow direction }\end{array}$


TABLE 6-IV MAXIMUM WAVE PRESSURE

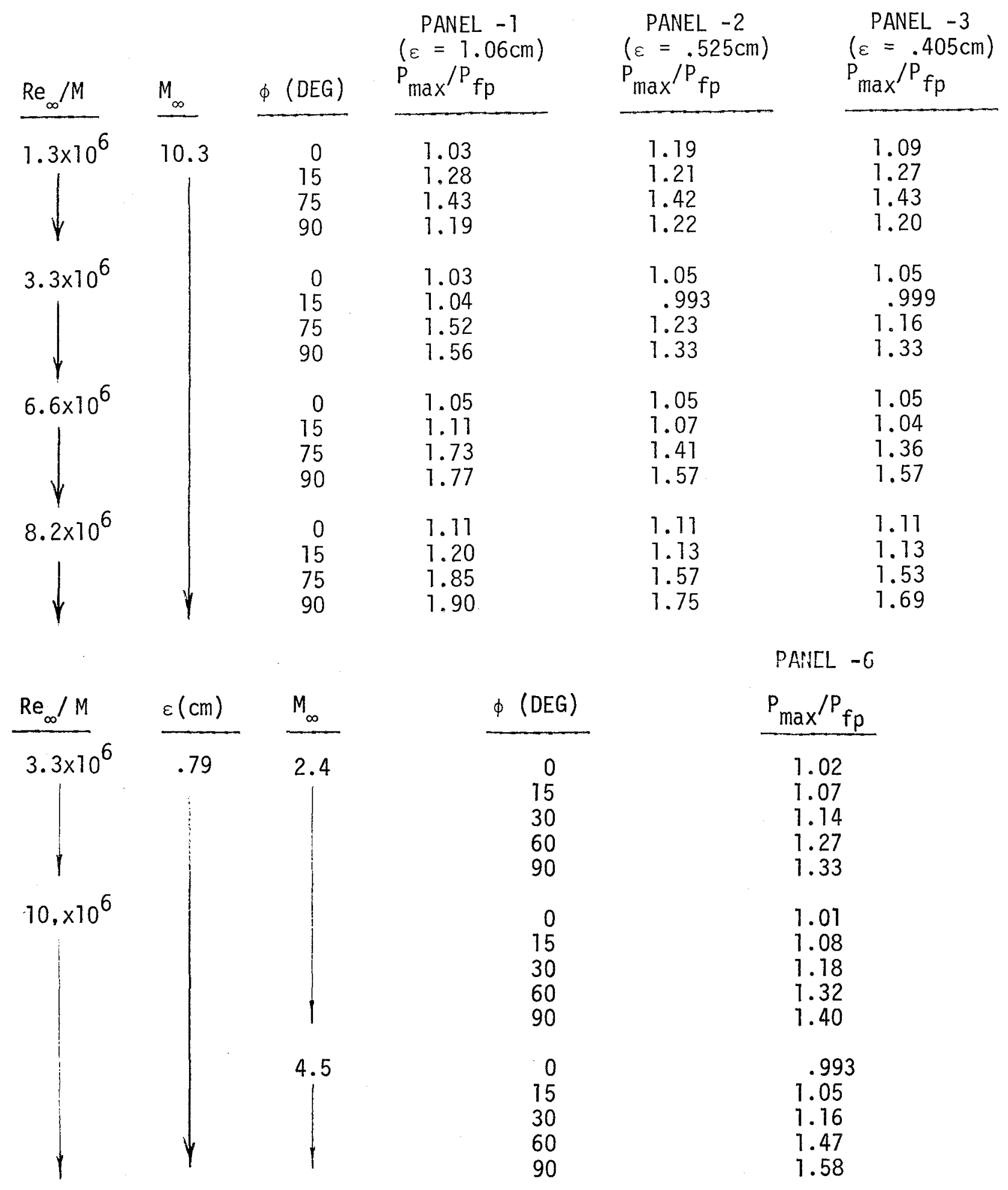


TABLE 6-V AVERAGE WAVE PRESSURE

\begin{tabular}{|c|c|c|c|c|c|}
\hline $\operatorname{Re}_{\infty}$ & $M_{\infty}$ & $\Phi(D E G)$ & $\begin{array}{l}\text { PANEL }-1 \\
(\varepsilon=1.06 \mathrm{~cm}) \\
\mathrm{P}_{\mathrm{av}} / \mathrm{P}_{\mathrm{fp}}\end{array}$ & $\begin{array}{l}\text { PANEL }-2 \\
(\varepsilon=.525 \mathrm{~cm}) \\
P_{\mathrm{av}} / P_{\mathrm{fp}}\end{array}$ & $\begin{array}{l}\text { PANEL }-3 \\
(\varepsilon=.405 \mathrm{~cm}) \\
\mathrm{P}_{\mathrm{av}} / \mathrm{P}_{\mathrm{fp}}\end{array}$ \\
\hline $1.3 \times 10^{6}$ & $\begin{array}{c}10.3 \\
1\end{array}$ & $\begin{array}{r}0 \\
15 \\
75 \\
90\end{array}$ & $\begin{array}{c}.874 \\
.929 \\
1.00 \\
.959\end{array}$ & $\begin{array}{l}.965 \\
.928 \\
.951 \\
.972\end{array}$ & $\begin{array}{l}.926 \\
.962 \\
1.04 \\
1.01\end{array}$ \\
\hline$\underbrace{3.3 \times 10^{6}}$ & & $\begin{array}{r}0 \\
15 \\
75 \\
90\end{array}$ & $\begin{array}{l}.939 \\
.904 \\
1.07 \\
1.05\end{array}$ & $\begin{array}{l}.931 \\
.922 \\
.978 \\
1.03\end{array}$ & $\begin{array}{l}.944 \\
.911 \\
.993 \\
1.09\end{array}$ \\
\hline$\underbrace{6.6 \times 10^{6}}$ & & $\begin{array}{r}0 \\
15 \\
75 \\
90\end{array}$ & $\begin{array}{l}.982 \\
.953 \\
1.18 \\
1.16\end{array}$ & $\begin{array}{r}.969 \\
.971 \\
1.06 \\
1.14\end{array}$ & $\begin{array}{l}.984 \\
.976 \\
1.08 \\
1.19\end{array}$ \\
\hline $\begin{array}{l}8.2 \times 10^{6} \\
\downarrow\end{array}$ & $\downarrow$ & $\begin{array}{r}0 \\
15 \\
75 \\
90\end{array}$ & $\begin{array}{l}1.04 \\
1.02 \\
1.27 \\
1.25\end{array}$ & $\begin{array}{l}1.04 \\
1.03 \\
1.15 \\
1.25\end{array}$ & $\begin{array}{l}1.05 \\
1.06 \\
1.18 \\
1.29\end{array}$ \\
\hline $\mathrm{Re}_{\infty} / \mathrm{M}$ & $\varepsilon(\mathrm{cm})$ & $M_{\infty}$ & $\phi(D E G)$ & \multicolumn{2}{|c|}{$\begin{array}{l}\text { PANEL -6 } \\
P_{\mathrm{av}} / \mathrm{P}_{\mathrm{fp}}\end{array}$} \\
\hline $3.3 \times 10^{6}$ & .79 & 2.4 & $\begin{array}{r}0 \\
15 \\
30 \\
60 \\
90\end{array}$ & \multicolumn{2}{|c|}{$\begin{array}{l}1.01 \\
1.03 \\
1.04 \\
1.06 \\
1.07\end{array}$} \\
\hline $10 . \times 10^{6}$ & & 1 & $\begin{array}{r}0 \\
15 \\
30 \\
60 \\
90\end{array}$ & \multicolumn{2}{|c|}{$\begin{array}{l}1.01 \\
1.02 \\
1.04 \\
1.07 \\
1.08\end{array}$} \\
\hline 1 & $\downarrow$ & $i^{4.5}$ & $\begin{array}{r}0 \\
15 \\
30 \\
60 \\
90\end{array}$ & \multicolumn{2}{|c|}{$\begin{array}{l}.987 \\
1.00 \\
1.02 \\
1.11 \\
1.13\end{array}$} \\
\hline
\end{tabular}


panel -1. The results of the calculations are presented in Figures 6-1 and 6-2. For both cases it was found that the maximum surface pressure could be predicted. For the supersonic case, a value of $P_{\max } / P_{F P}=1.36$ is predicted compared to measured ratios of 1.34 and 1.4 for $\mathrm{Re}_{\infty} / M=3.3 \times 10^{6}$ and $10 \times 10^{6}$, respectively. For hypersonic flow a maximum value of 1.57 is predicted compared to an experimental value of 1.60 for $\operatorname{Re}_{\infty} / M=3.3 \times 10^{6}$. However, the flow fields required for the prediction of the pressures are inconsistent with the measured results. For $M_{\infty}=2.4$, the flow at the top of the wave is required to expand through an angle of $35^{\circ}$ over the wave to a static pressure value into the shock of $P_{j} / P_{F P}=.125$, and for $M_{\infty}=10.3$ the required static pressure value is .101 for an expansion angle of $33^{\circ}$. The measured separation angles are $5.2^{\circ}$ for $M_{\infty}=2.4$ and $28^{\circ}$ for 10.3 . Hence, the necessary separation angles are much less than detected by experiment. In addition the extremely low static pressures required for the flow into the shock wave are much less than the measured values which were on the order of $P_{1} / P_{F P}=1$. Hence, the peak pressures measured on the compression surface of the waves cannot be explained on the basis of the local internal flow passing through a shock wave.

An interesting feature of the flow field over shallow waves in thick turbulent boundary layers is that the incoming flow adjusts almost instantaneously from wave to wave. This was first detected in Ref. 8 in which the heating distributions were found to be essentially independent of wave cycle. In order to further investigate this phenomenon, a total pressure rake was placed behing the last wave of panel -1 , for $\emptyset=90^{\circ}$ as shown in Figure 6-3. Total pressures obtained from the rake data are compared with maximum pressures measured on a wave in the center of the panel as a function of Reynolds number in this figure. The total pressures from the rake data were obtained at the measured reattachment height on the wave. As shown in Figure 6-3, the two pressures agree quite well which indicates that the mixing process over each wave is almost identical, and that the maximum pressure on the wave is approximately equal to the total pressure of the streamline that stagnates on the compression surface.

Based on these results, it was decided to determine if the maximum surface wave pressure could be related to the total pressure associated with the streamline at the wave height. It was found that the ratio of the maximum surface pressure to the total pressure of the streamline at the wave height is a function of the Mach number of the streamline at the wave height, as shown in Figure 6-4. Hence, the ratio $P_{\max } / P_{t_{\varepsilon}}$ can be considered a total pressure loss associated with the 


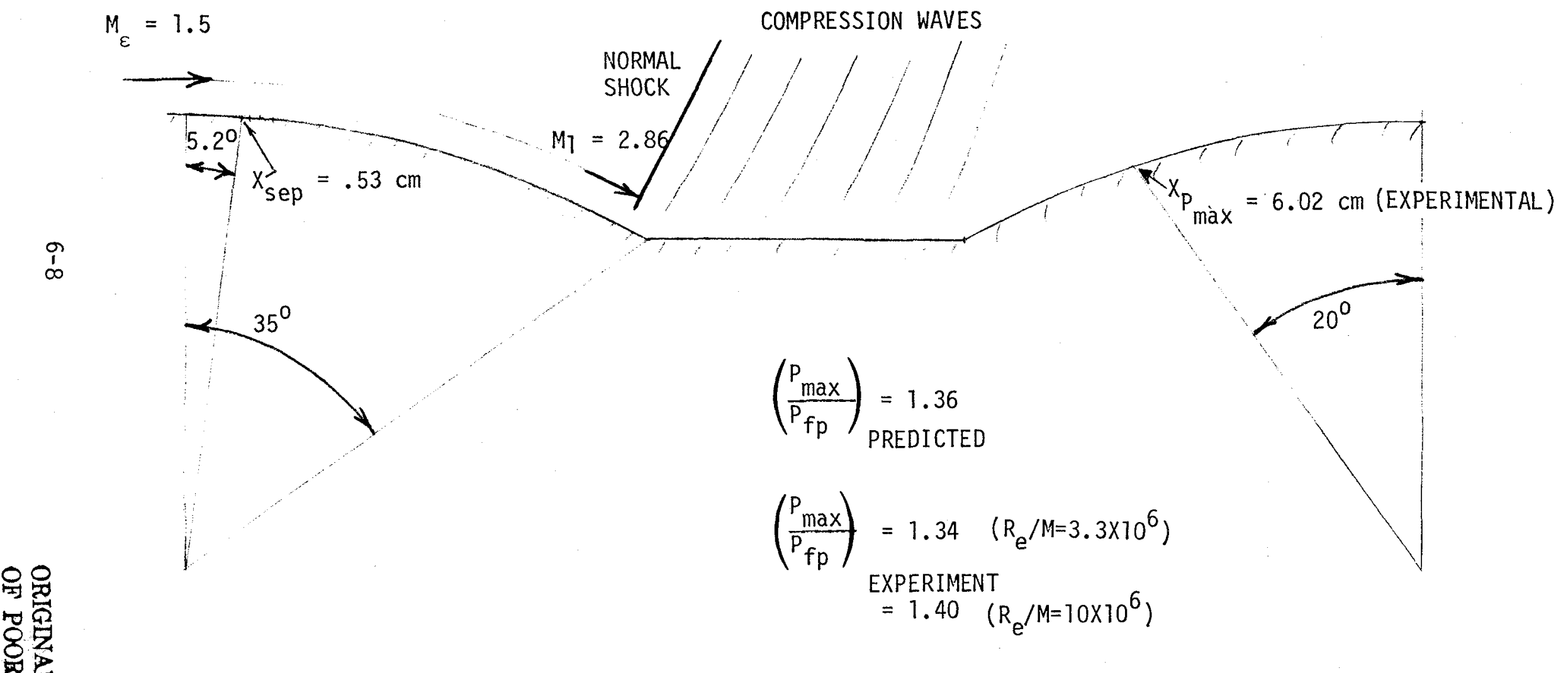

FIGURE 6-1 IMBEDDED SHOCK FLOW MODEL FOR PANEL $-6, M_{\infty}=2.4, \emptyset=90^{\circ}$ 


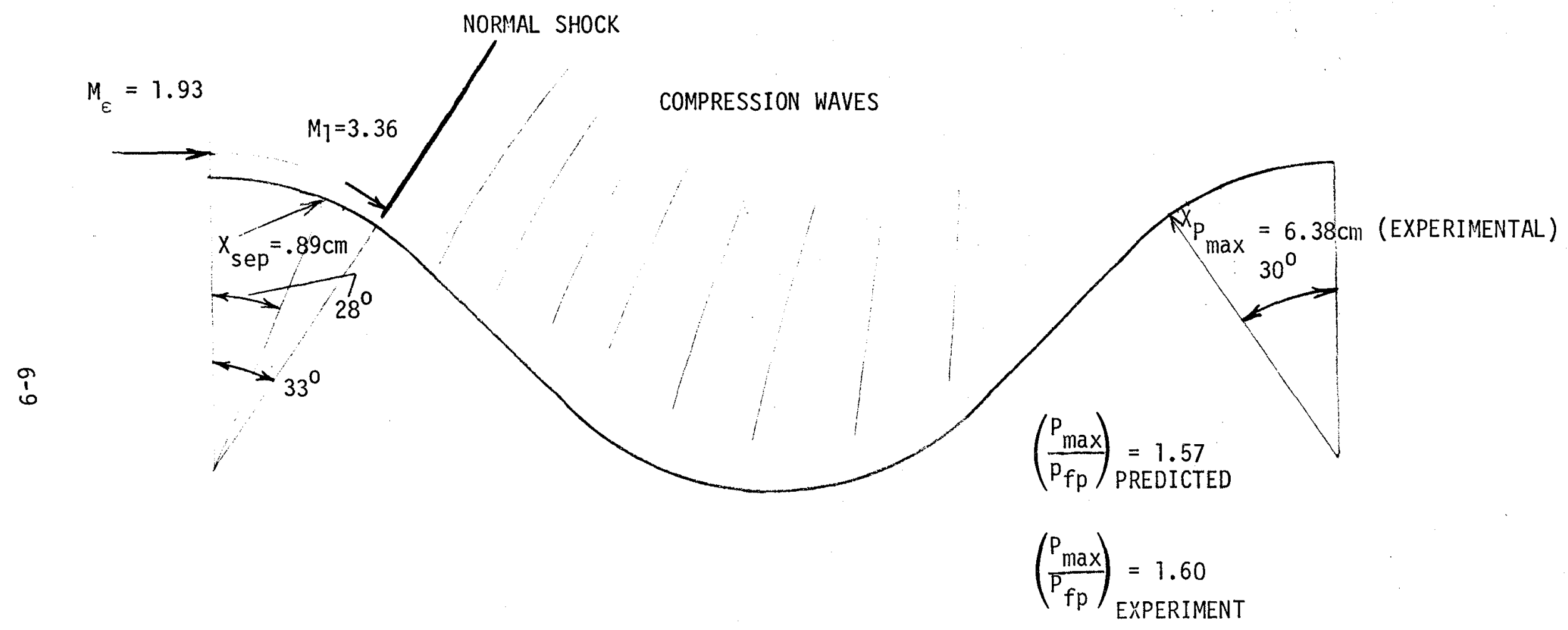

FIGURE 6-2 IMBEDDED SHOCK FLOW MODEL FOR

PANEL - $7, M_{\infty}=10.3, R_{e_{\infty}} / M=3.3 \times 10^{6}, \emptyset=90^{\circ}$ 


$\begin{array}{ccc}R_{e_{\infty}} / M \times 10^{-6} & \left(\mathrm{p}_{\mathrm{t}}^{\prime} / \mathrm{P}_{\mathrm{fp}}\right)^{*} & \frac{\mathrm{P}_{\mathrm{max}} / \mathrm{P}_{\mathrm{fp}}}{1.3} \\ 3.3 & 1.24 & 1.19 \\ 6.6 & 1.43 & 1.56 \\ 8.2 & 1.60 & 1.77 \\ \text { *PRESSURE AT REATTACHMENT HEIGHT } & \end{array}$
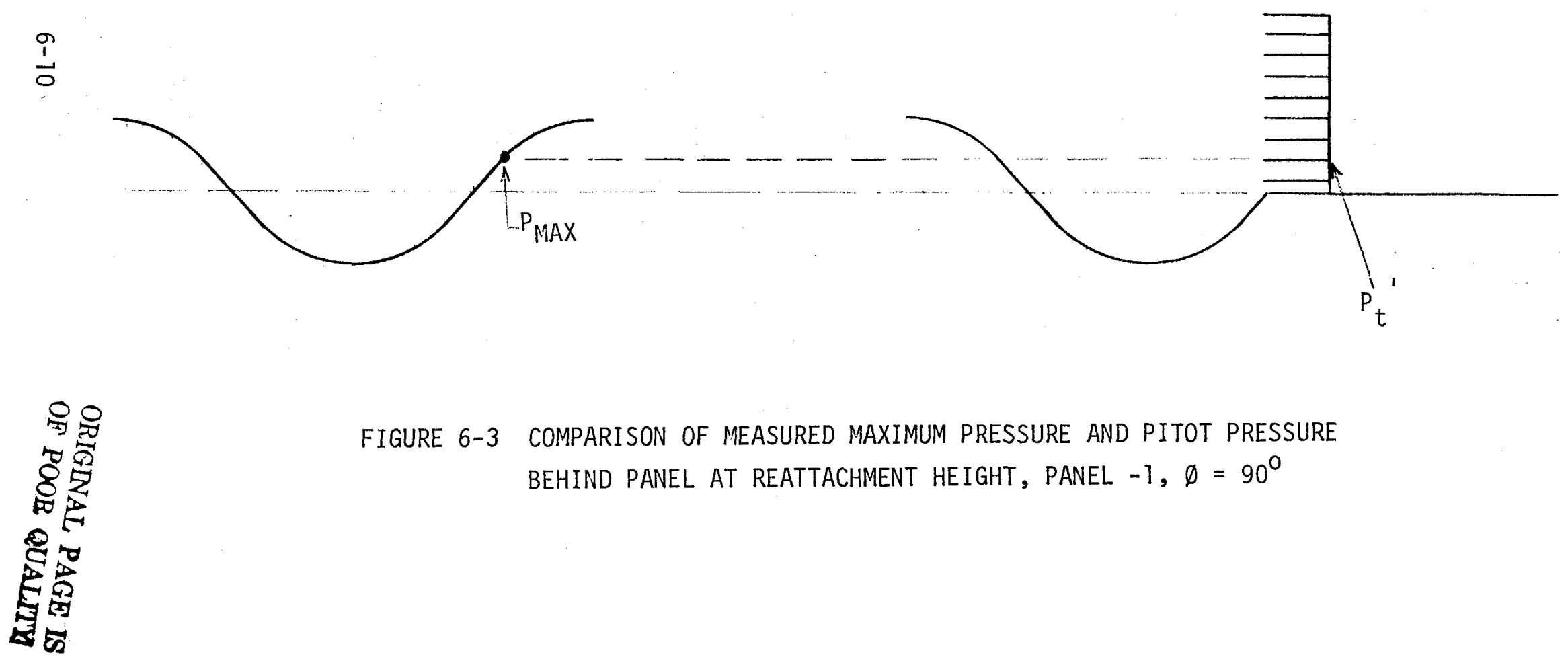

FIGURE 6-3 COMPARISON OF MEASURED MAXIMUM PRESSURE AND PITOT PRESSURE BEHIND PANEL AT REATTACHMENT HEIGHT, PANEL $-1, \emptyset=90^{\circ}$ 


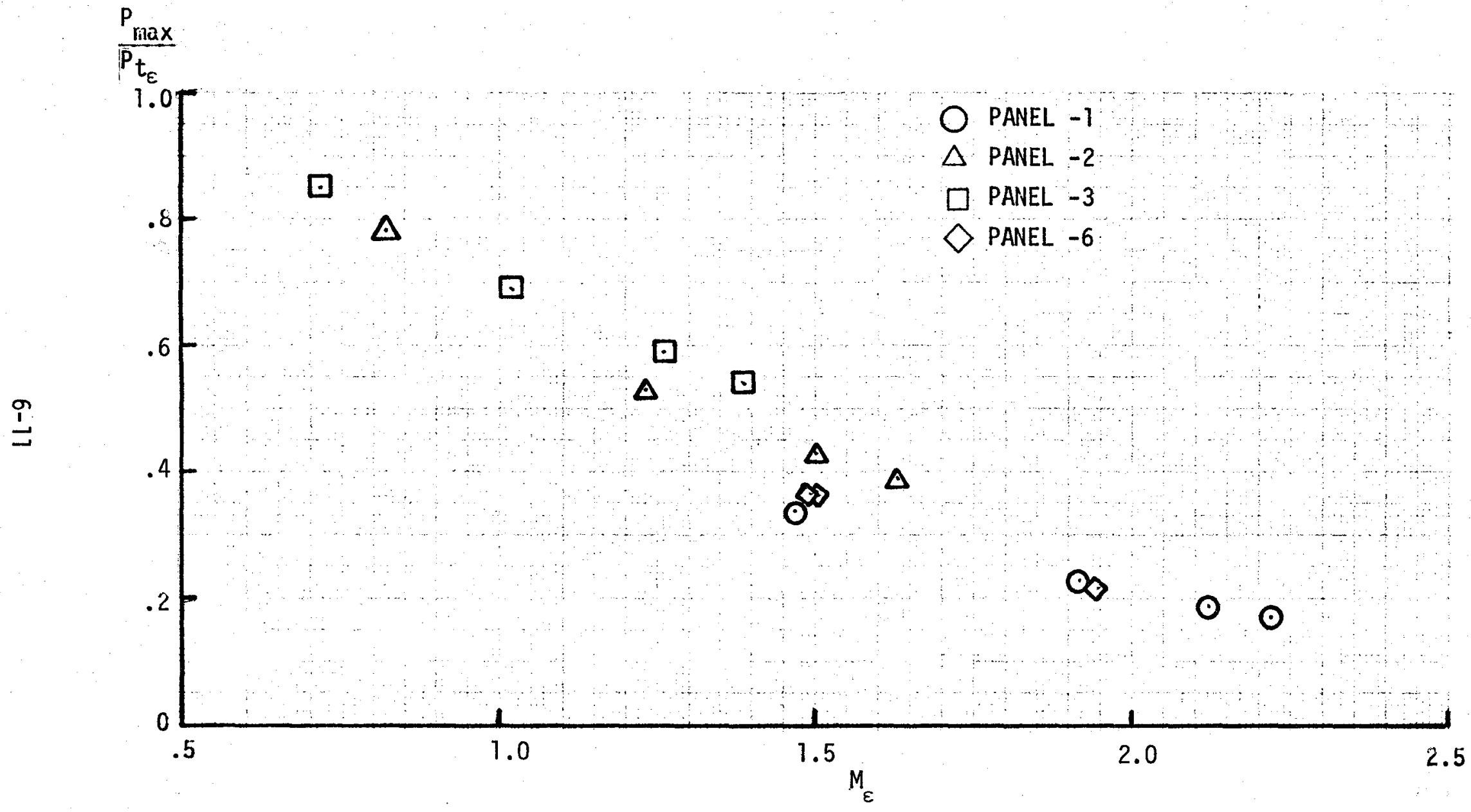

FIGURE $6-4$ CORRELATION OF MAXIMUM PRESSURE FOR $\emptyset=90^{\circ}$ 
turbulent mixing process over the wave. It is not surprising that the pressure ratio is such a strong function of Mach number. The Mach number is known to strongly affect the total pressure loss in turbulent jets and wakes. Shift in Peak Heating and Pressure

The panels considered in the present study were instrumented in much more detail than those previously tested. As a result the measured heating and pressure distributions on panels $-1,-2,-3$, and -6 are much more exact than those on panels -4 and -5 . Due to the more detailed instrumentation, certain features of the data have been detected that were not noticeable in the previous study. For example, consider the peak heating and peak pressure locations for $\emptyset=90^{\circ}$ on panels $-1,-2$, -3 , and -6 as shown in Table 6-VI. For panels -2 and -3 there is a large shift in the peak pressure location. These data are for hypersonic flow at the lowest Reynolds number tested. Table 6-VI shows that several flow parameters have distinct changes for these conditions which could result in this shift. The shift occurs when the Mach number at the wave height becomes subsonic. For supersonic flow at the wave height a separation shock could occur just downstream of the wave peak. For subsonic flow at the wave height the flow could expand further in the valley before separation occurred. In addition to the Mach number change, the sublayer thickness becomes greater than the wave height, and the hydraulic diameter, $\mathrm{d}_{h}$, of the wave shape becomes less than two times the laminar sublayer thickness when there is a shift in the peak pressure location. The changes in the 1ater two ratios could affect the manner in which the flow field develops over a wave. The results presented in Table 6-VI show that a definite change in the flow field over the waves has been detected as a function of changes in the local flow conditions. The mechanism controlling these changes needs further investigation. It should not be ruled out that nonuniformity in the wall boundary layer flow as a function of Reynolds number could account for some of these changes. The shift occurred only for pressure, and the peak heating location was not affected by the aforementioned changes in the flow conditions.

Large shifts in peak pressure locations were also detected for other flow angles for the low Reynolds number data, as shown in Figures 6-5 and 6-6 for panel -1 for $\emptyset=15^{\circ}$ and $75^{\circ}$ as a function of Reynolds number. Hence, there is a definite shift in peak pressure location even for supersonic flow at the wave height for certain wave shapes. Similar results have been detected by Howell (Ref. 14) in his study of flow over notches. Howell found that the separation point for notch flow was both a function of the notch shape and the local edge Mach number.

*The hydraulic diameter, $d_{h}$, is described in Table 6-VII. 


\begin{tabular}{|c|c|c|c|c|c|c|c|c|}
\hline PANEL & $M_{\infty}$ & $\mathrm{Re}_{\mathrm{e}_{\infty}} / \mathrm{M}^{\times 10^{-6}}$ & $\delta_{s}(\mathrm{~cm})$ & $\underline{M}_{\varepsilon}$ & $\frac{\delta_{s}}{\varepsilon}$ & $\frac{d_{h}}{2 \delta s}$ & $P_{\max }$ & $!_{\max }$ \\
\hline$\gamma$ & 10.3 & $\begin{array}{l}1.3 \\
3.3 \\
6.6 \\
8.2\end{array}$ & $\begin{array}{l}.737 \\
.381 \\
.279 \\
.203\end{array}$ & $\begin{array}{l}1.44 \\
1.93 \\
2.13 \\
2.23\end{array}$ & $\begin{array}{l}.70 \\
.36 \\
.26 \\
.19\end{array}$ & $\begin{array}{l}1.31 \\
2.53 \\
3.45 \\
4.74\end{array}$ & .87 & 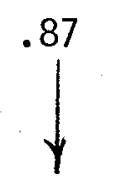 \\
\hline$j^{2}$ & & $\begin{array}{l}1.3 \\
3.3 \\
6.6 \\
8.2\end{array}$ & $\begin{array}{l}.737 \\
.381 \\
.279 \\
.203\end{array}$ & $\begin{array}{l}.81 \\
1.20 \\
1.48 \\
1.68\end{array}$ & $\begin{array}{r}1.41 \\
.73 \\
.53 \\
.39\end{array}$ & $\begin{array}{r}.69 \\
1.34 \\
1.83 \\
2.52\end{array}$ & $\begin{array}{l}.75 \\
.82 \\
.82 \\
.82\end{array}$ & 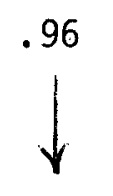 \\
\hline 3 & $V$ & $\begin{array}{l}1.3 \\
3.3 \\
6.6 \\
8.2\end{array}$ & $\begin{array}{l}.737 \\
.381 \\
.279 \\
.203\end{array}$ & $\begin{array}{l}.73 \\
1.00 \\
1.27 \\
1.43\end{array}$ & $\begin{array}{r}1.82 \\
.94 \\
.69 \\
.50\end{array}$ & $\begin{array}{r}.52 \\
1.01 \\
1.38 \\
1.89\end{array}$ & $\begin{array}{l}.73 \\
.92 \\
.97 \\
.90\end{array}$ & $\begin{array}{l}.93 \\
.93 \\
.91 \\
.90\end{array}$ \\
\hline $\begin{array}{l}6 \\
\downarrow\end{array}$ & $\begin{array}{l}2.4 \\
2.4 \\
4.5\end{array}$ & $\begin{array}{r}3.3 \\
10.0 \\
10.0\end{array}$ & $\begin{array}{l}.028 \\
.013 \\
.062\end{array}$ & $\begin{array}{l}1.5 \\
1.5 \\
1.95\end{array}$ & $\begin{array}{l}.035 \\
.017 \\
.079\end{array}$ & $\begin{array}{c}7.89 \\
17.0 \\
3.57\end{array}$ & $\begin{array}{l}.75 \\
.75 \\
.76\end{array}$ & $\begin{array}{l}.81 \\
.80 \\
.81\end{array}$ \\
\hline
\end{tabular}

TABLE 6 -Vi PARAMETERS AFFECTING PEAK heATING AND PRESSURE LOCATIONS, $\varphi=90^{\circ}$ 

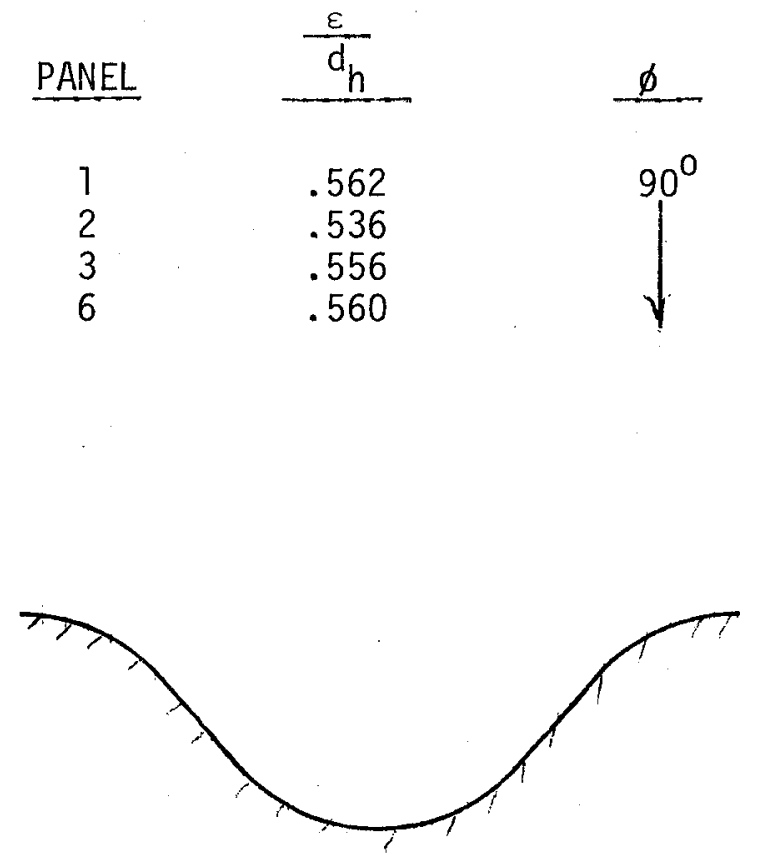

$d_{h}=4 \frac{\text { (AREA ENCLOSED BY WAVE) }}{\text { (PERIMETER OF WAVE SURFACE) }}$

TABLE 6-VII DEFINITION OF HYDRAULIC DIAMETER 


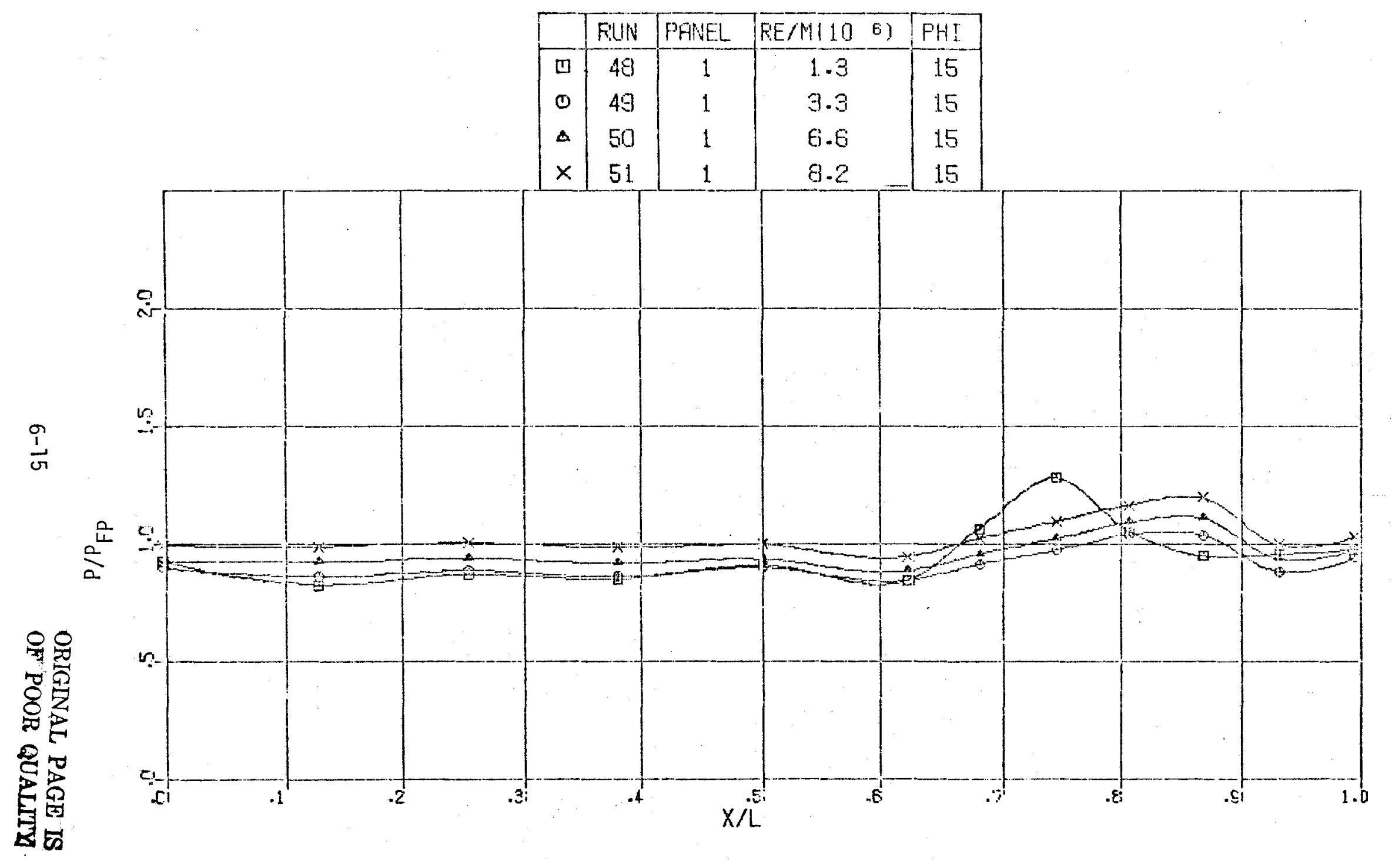

FIGURE 6-5 SHIFT IN PEAK PRESSURE LOCATION, $M_{\infty}=10.3$ 


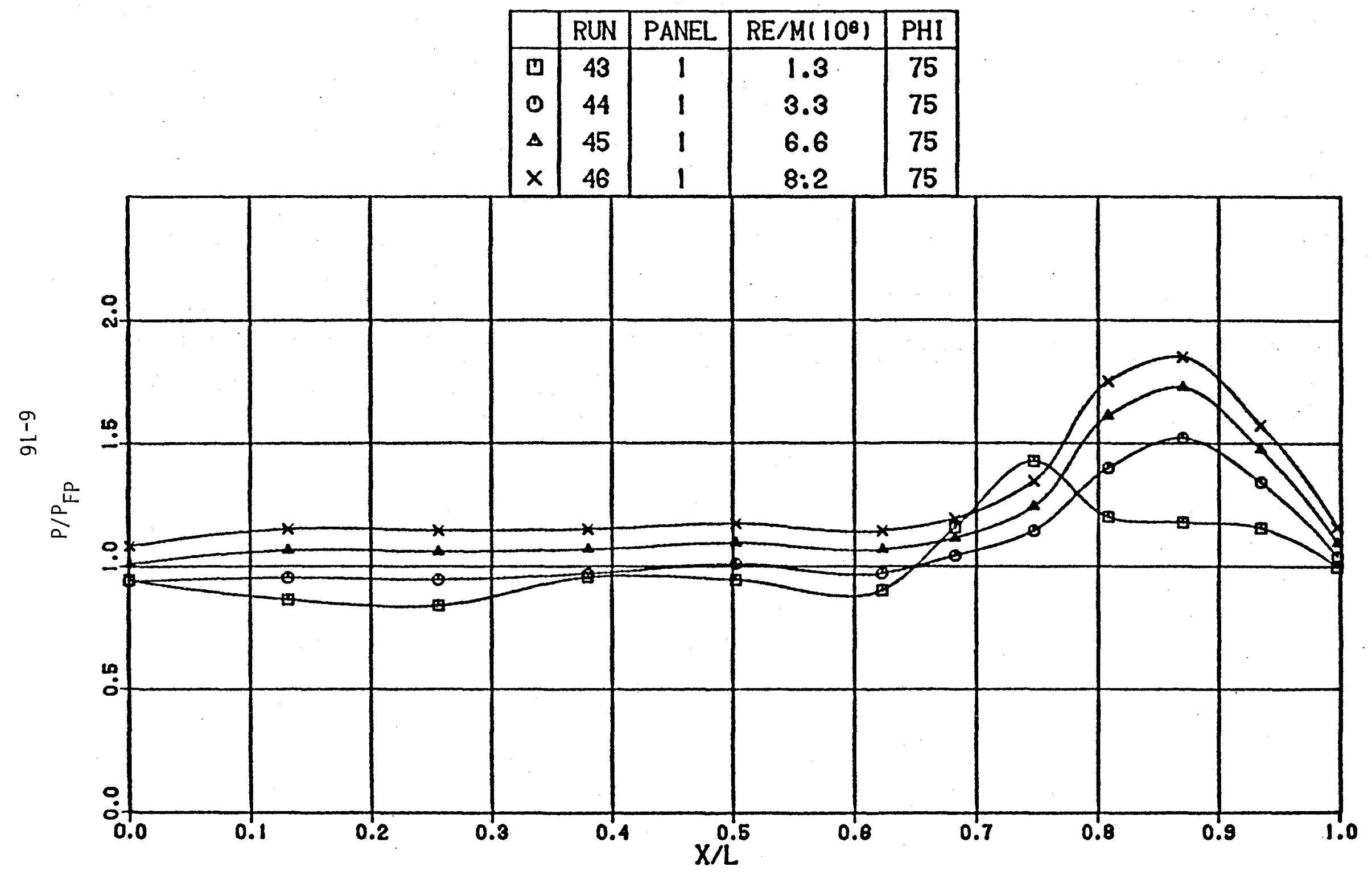

FIGURE 6-6 SHIFT IN PEAK PRESSURE LOCATION, $M_{\infty}=10.3$ 
Howe11's correlation of the separation point is shown in Figure 6-7 in which the data are given as a function of the Mach number and notch angle. For a given notch angle and subsonic flow, the separation point moves upstream as the Mach number increases. The separation distance reaches a minimum for sonic flow, and then increases as the Mach number becomes supersonic. For a given local edge Mach number, the separation distance decreases as the notch angle is increased.

A similar plot of the present data for corrugated shapes is shown in Figure 6-8. In plotting these data, the separation point on the expansion surface was assumed to be the mirror image of the measured reattachment point (point of surface peak pressure) on the compression surface. Judgement was used in constructing the faired distributions due to the lack of data in the subsonic and sonic flow range. Nonetheless, these distributions seem reasonable considering Howe 11's measured distributions. Hence, it appears that the Mach number at the wave height controls the separation point location on a corrugated shape in a thick turbulent boundary layer. For a given Mach number at the wave height, the separation distance decreases as the parameter $\frac{r L}{\varepsilon^{2}}$ is decreased.

Correlation of Peak*Heating

The previous study, Refs. (8) and (9), served as a guide in choosing the parameters which would be useful in developing the peak heating correlations. An automated multiple regression technique designed to fit multiple variables was employed to help determine the importance of the input parameters and obtain consistent nonbiased correlating equations. The computer program, which is described in detail in Ref. 15, is a stepwise Multiple Regression Analysis (MRA) which provides information as to the adequacy of candidate correlation functions and the equation coefficients. The MRA computes a series of multiple 1 inear regression equations in a stepwise manner. At each step, one parameter is added to the equation. The variable that is added is the one which makes the greatest reduction in the variance about the mean.

Formulation of the first peak heating correlation consisted in developing a good analytical fit to all the thick turbulent boundary layer data obtained on panels $-1,-2,-3,-4,-5$, and -6 . These maximum heating data ranged from a value of 1.37 to 4.63 . This range includes all the peak heating data except for corrugation angles of $0^{\circ}$. Several good fits were formulated. The best fit of the data has a standard error of estimate of .324 and is given by the equation: 


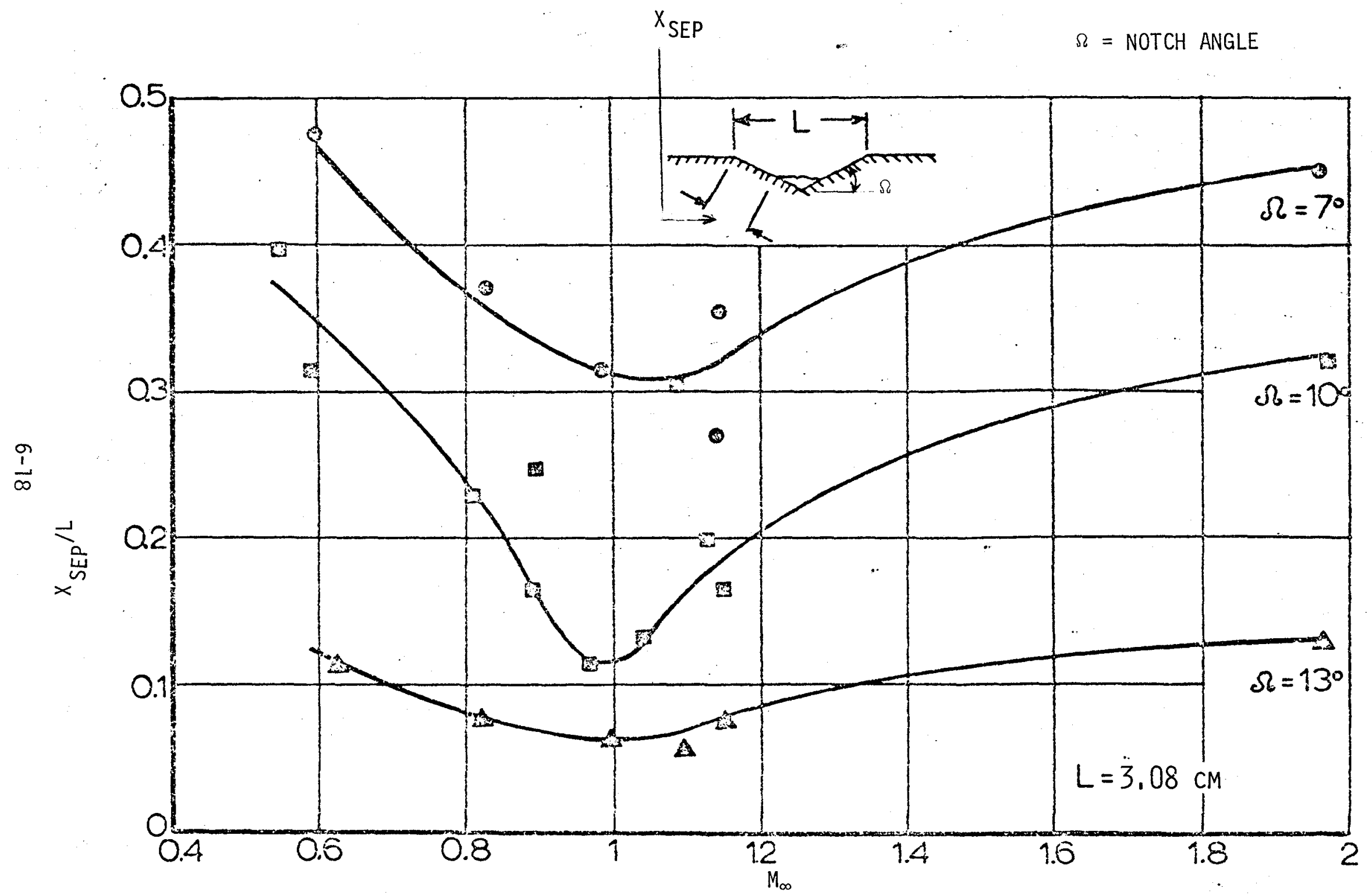

FIGURE 6-7 SELF ADJUSTMENT OF THE SEPARATION POINT FOR THIN TURBULENT BOUNDARY LAYER FLOW OVER NIOTCH 


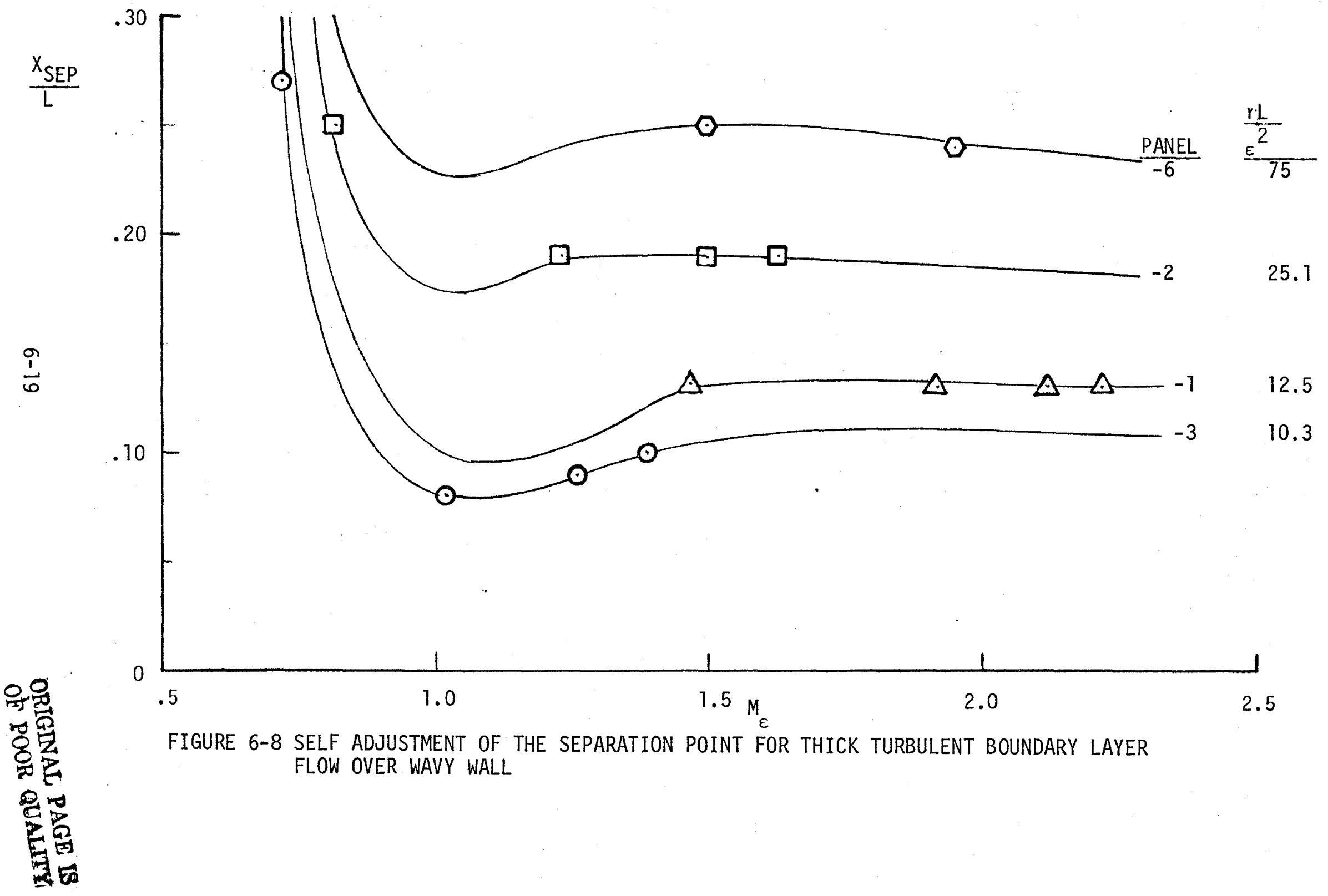




$$
\frac{h_{\max }}{h_{F P}}=1+C_{1}\left(\sin \alpha_{\gamma}\right) \cdot \frac{M_{\varepsilon}{ }^{1.077} \dot{R}_{e_{\varepsilon}}^{.329}\left(\frac{\delta}{\varepsilon}\right)^{.677}\left(\frac{\theta}{L}\right){ }^{.196}\left(\sin \alpha_{\max }\right)^{.325}}{\left(\frac{\varepsilon}{L}\right)^{.158}\left(\frac{\delta}{L}\right)^{.222}}
$$

where $C_{1}=e^{-.677}$

During the course of developing this correlation equation, it was discovered that several of the terms could be eliminated without greatly reducing the accuracy of the resulting correlation. Removing the displacement thickness, momentum thickness, and the maximum wave surface angle, the following correlation equation was obtained for the peak heating for all the thick turbulent boundary layer data:

$$
\frac{h_{\max }}{h_{\mathrm{FP}}}=1+c_{2}\left(\sin \alpha_{\gamma}\right)^{.240} M_{\varepsilon}^{1.316}\left(\frac{\delta_{s}}{\varepsilon}\right)^{.204}\left(\frac{\varepsilon}{L}\right)^{.231}
$$

where $C_{2}=e^{.951}$. This simpler equation has a standard error of estimate of .350 .

Equation (1) is compared with all the thick turbulent boundary layer data in Figure 6-9. Equation (2) is not graphically compared with the data. However, the agreement would be comparable since the standard error of estimate is about the same for both equations.

Prior analysis (Ref. 8) using the MRA solution for peak heating showed that good data fits for thick turbulent boundary layer data were in poor agreement with data sets for thin turbulent boundary layers. As an extension of the previous correlation activity, a11 the thin boundary layer data were incorporated into the data bank containing the thick boundary layer data. The MRA analysis was then applied to the resulting data bank containing all the thick and thin boundary layer peak heating data. A successful correlation equation was then derived for a range in data from 1.37 to 7.6 . This equation is:

$$
\frac{h_{\max }}{h_{F P}}=\frac{1+\frac{C_{3}\left(\sin \alpha_{r}\right) M_{\varepsilon}{ }^{1.107} R_{e_{\varepsilon}} \cdot 057\left(\frac{\varepsilon}{L}\right)}{\left(\frac{\delta^{*}}{L}\right)^{.278}\left(\frac{\theta}{L}\right)^{.287} R_{e_{\varepsilon}}}}{.344}
$$




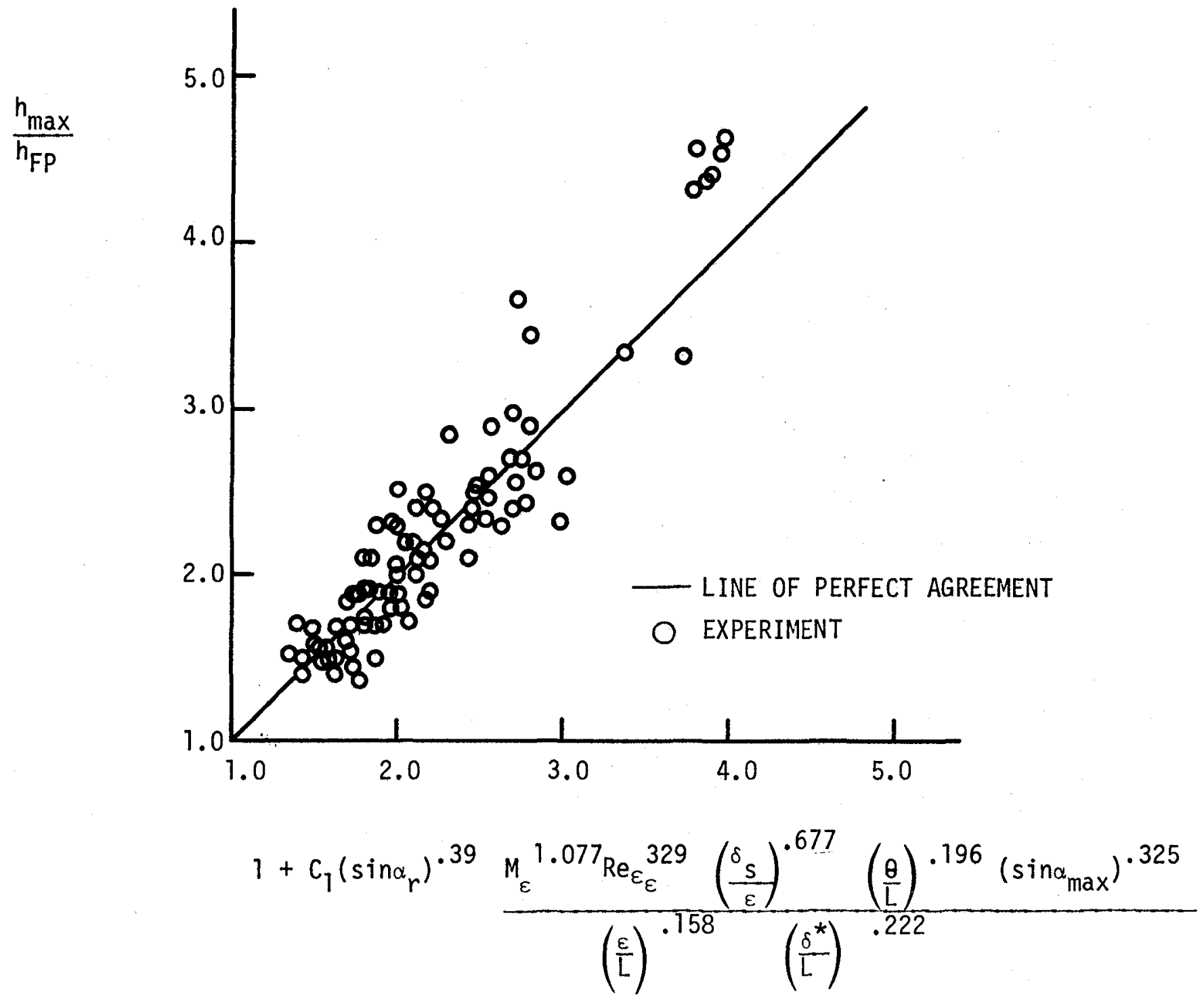

FIGURE 6-9 CORRELATION OF MAXIMUM HEATING FOR ALL THICK BOUNDARY LAYER DATA 
where $\quad c_{3}=e^{2.813}$

This correlation, which has a standard error of estimate equal to .557, is compared with all the data in Figure 6-10. The agreement between the measured and predicted values is good except for a few thin boundary layer data points at the highest heating conditions.

As with the analysis for all the thick boundary layer data, it was found that several correlating parameters could be eliminated from equation ( 3 ) in order to simplify the correlation without greatly reducing its accuracy. A simpler correlation form for all the peak heating data is:

$$
\frac{h_{\max }}{h_{F P}}=1+\frac{C_{4}\left(\sin \alpha_{r}\right) \cdot 348 M_{\varepsilon}^{1.397}\left(\frac{\varepsilon}{L}\right) .678}{\left(\frac{\delta^{*}}{L}\right)^{.492}\left(\operatorname{Re}_{\varepsilon_{\varepsilon}}\right)^{.323}}
$$

where $C_{4}=e^{4.1317}$

The standard error of estimate for this correlation is .579. Agreement between the correlation predictions and the data is comparable to that shown in Figure 6-10 because the standard errors of estimate for equations (3) and (4) are very similar. Correlation of Average Heating

An important factor which must be considered in the study of corrugated panels is the effect of surface roughness on average heating. Correlations and analyses for the prediction of average heating to rough surfaces have previously been developed for nosetip performance during reentry conditions. A correlation developed by Powars (Ref. 16) has been in widespread use for the prediction of surface roughness heating. Data obtained on all six panels of the present study are compared with Powars correlation in Figure 6-11. The equivalent sand grain roughness, $k_{e}$, used in this correlation was calculated using Dirling's analysis (Ref. 17). The data do not follow the trend of the correlation for any range of the independent variable. In general the data fall well below the correlation line for $10 \mathrm{k}_{\mathrm{e}} / \delta_{\mathrm{s}}>10$ and have considerable scatter about the correlation line for $10 \mathrm{k}_{\mathrm{e}} / \delta_{\mathrm{s}}<10$.

Another correlation for average heating to rough surfaces was developed by Grabow and White (Ref.18) using the same heating data upon which the Powars correlation is based. Data from the present study are compared with the Garbow 


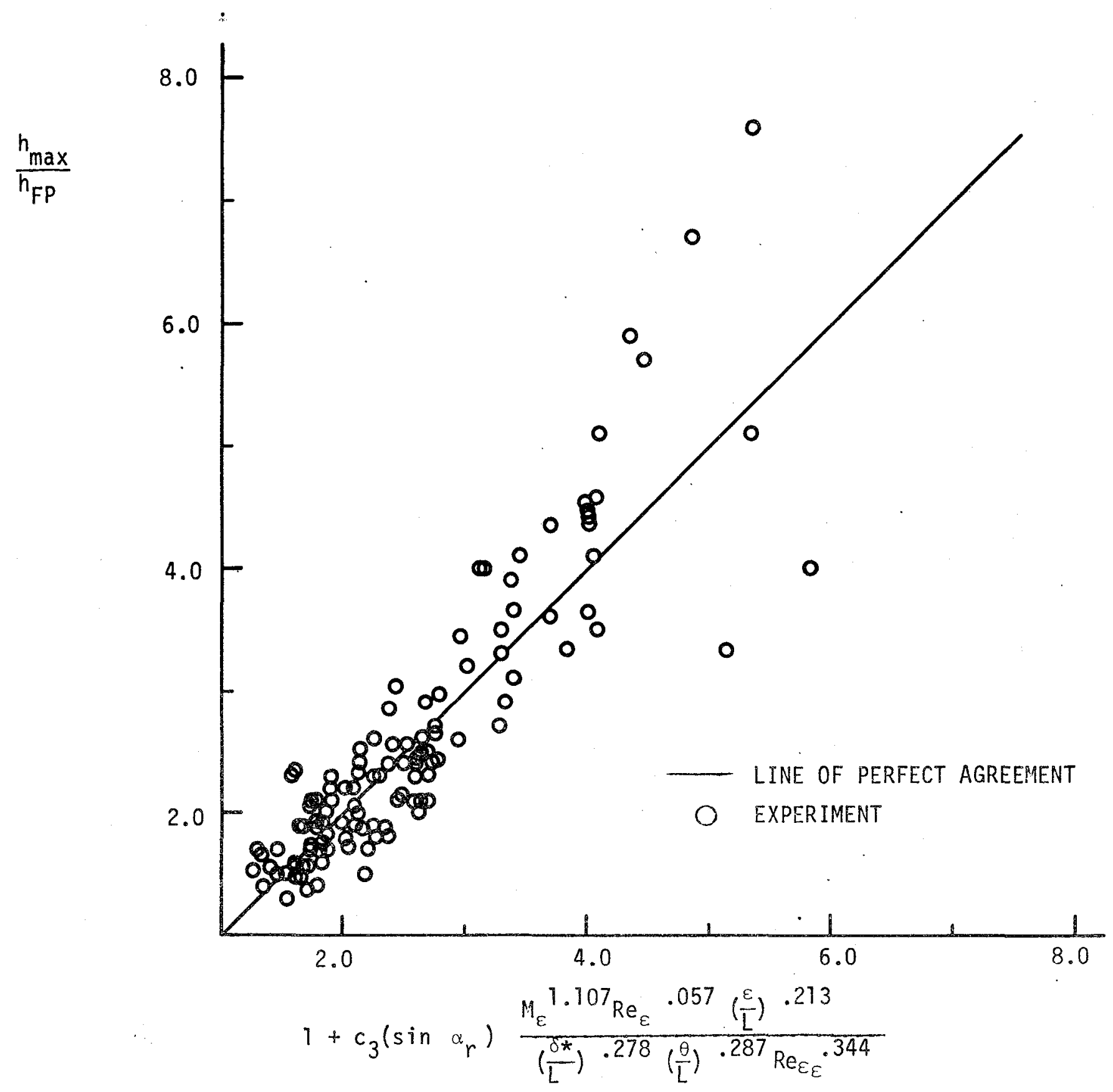

FIGURE 6-10 CORRELATION OF MAXIMUM HEATING FOR ALL THICK AND THIN BOUNDARY LAYER DATA 


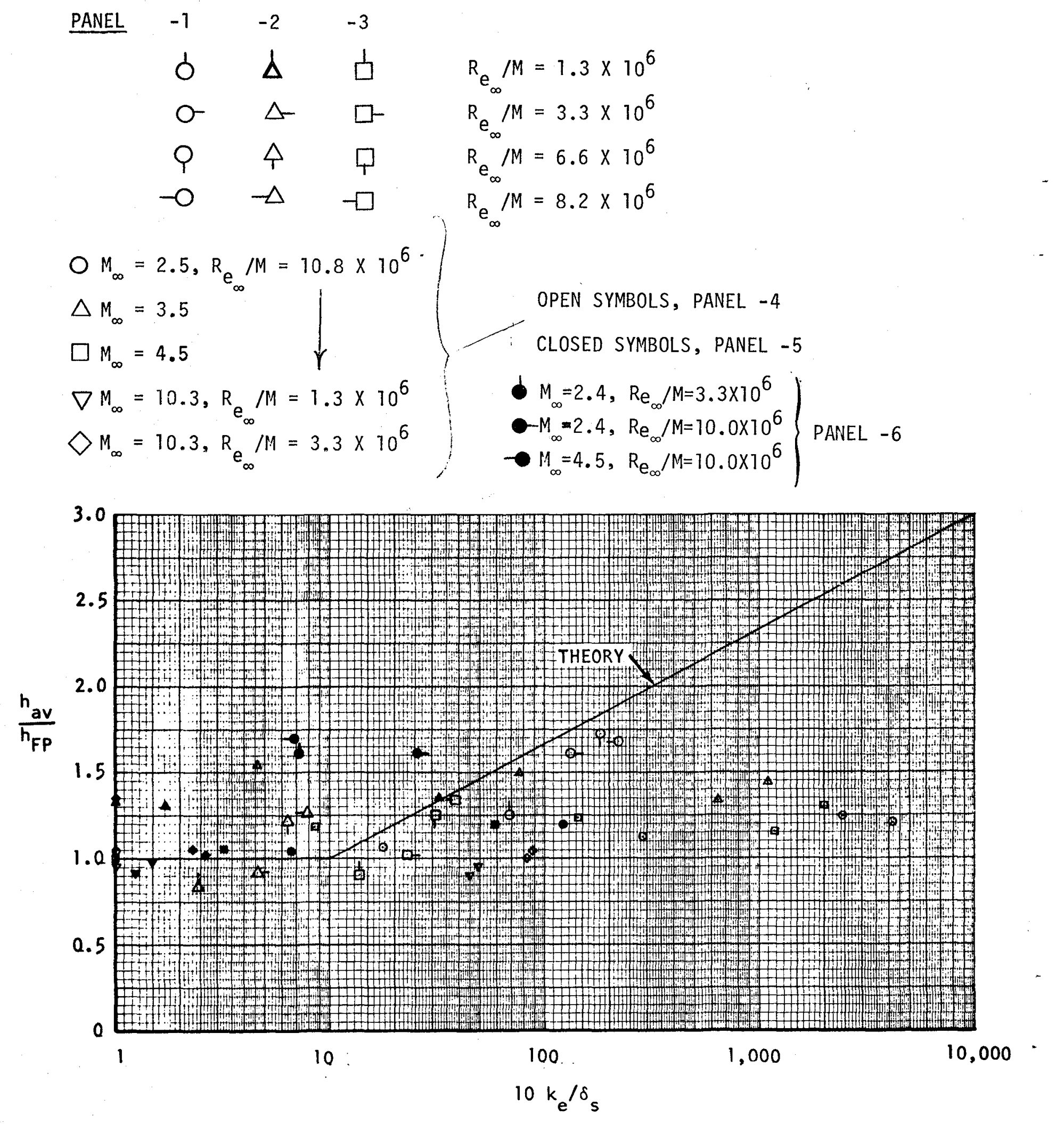

FIGURE 6-11 AVERAGE HEATING COMPARED WITH POWARS CORRELATION 
and White correlation in Figure 6-12. In this correlation the average heating is plotted versus $k_{e} / \delta *$. This correlation works quite well for $k_{e} / \delta$ greater than about 10. The present data fall in the range for $\mathrm{ke} / \delta * 1$ ess than about 1 . These data represent the range for which the roughness height is much less than the displacement thickness. The correlating parameter $\mathrm{ke}_{\mathrm{e}} / \delta^{*}$ does not represent an adequate variable which can be used in predicting the average heating for very thick turbulent boundary layers.

Based on the comparisons shown in Figures 6-11 and 6-12, it was concluded that no reliable correlation existed which could be used to represent average heating to rough surfaces in thick turbulent boundary layers. Some success had previously been obtained in Ref. 8 using Dirling's technique to predict the average heating for the flow normal to the corrugations. However, there was an uncertainty as to which geometric height (half-wave height or total wave height) must be used in order for Dirling's method to match the experimental results. The reason for the uncertainty was not understood and needed more investigation. It was felt that a detailed analysis of the present data using Dirling's approach was beyond the scope of this study. Rather, it was decided to focus effort toward developing a correlation equation using the MRA approach.

It was found that an excellent correlation of the average heating data could be obtained using the corresponding maximum heating data along with several flow and geometric parameters. This correlation is:

$$
\frac{h_{\mathrm{av}}}{h_{\mathrm{FP}}}=\frac{C_{5}\left(\frac{h_{\max }}{h_{\mathrm{FP}}}\right)^{.773} R_{\varepsilon_{\varepsilon}} \cdot{ }^{.257}\left(\frac{\delta_{s}}{\varepsilon}\right)^{.211}\left(\sin _{\max }\right)^{.085}}{M_{\varepsilon}^{.454}\left(\frac{\varepsilon}{L}\right){ }^{.174}\left(\frac{\theta}{L}\right)^{.012}\left(\frac{\delta}{L}\right)^{*} .005}
$$

where $c_{5}=e^{-2.174}$. The measured data for this correlation range from .836 to 1.85 . The correlation has a standard error of estimate of .081 . Equation (5) is compared with the present data in Figure 6-13 for al1 corrugation angles except $\emptyset=0^{0}$. The agreement between the correlation and the data is quite good.

Further analysis showed that the complexity of equation (5) could be greatly reduced by eliminating several correlating parameters without severely penalizing the accuracy of the curve-fit to the data. The best simplified correlating form 


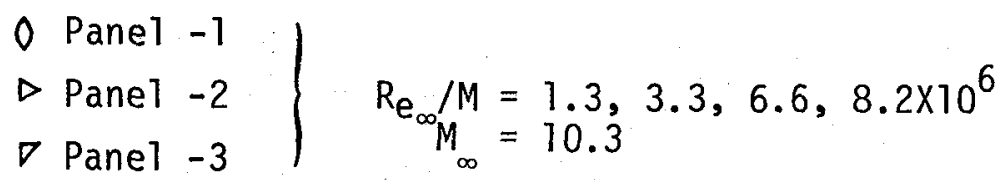

$\nabla M_{\infty}=10.3, R_{e_{\infty}} / M=1.3 \times 10^{6}$

$\Delta M_{\infty}^{\infty}=10.3, \operatorname{Re}_{\infty} / M=3.3 \times 10^{6}$

$\circ M_{\infty}=2.5, R_{\infty} / M=10.8 \times 10^{6}$

$\Delta M_{\infty}=3.5, R_{e_{\infty}} / M=10.8 \times 10^{6}$

$\square M_{\infty}=4.5, R_{e_{\infty}} / M=10.8 \times 10^{6}$

OPEN SYMBOLS, PANEL -4

CLOSED SYMBOLS, PANEL -5

$\delta M_{\infty}=2.4, R_{e_{\infty}} / M=3.3 \times 10^{6}$

$O-M_{\infty}=2.4, R_{e} / M=10 \times 10^{6}$

$Q M_{\infty}=4.5, R_{e_{\infty}} / M=10 \times 10^{6}$

Pane -6

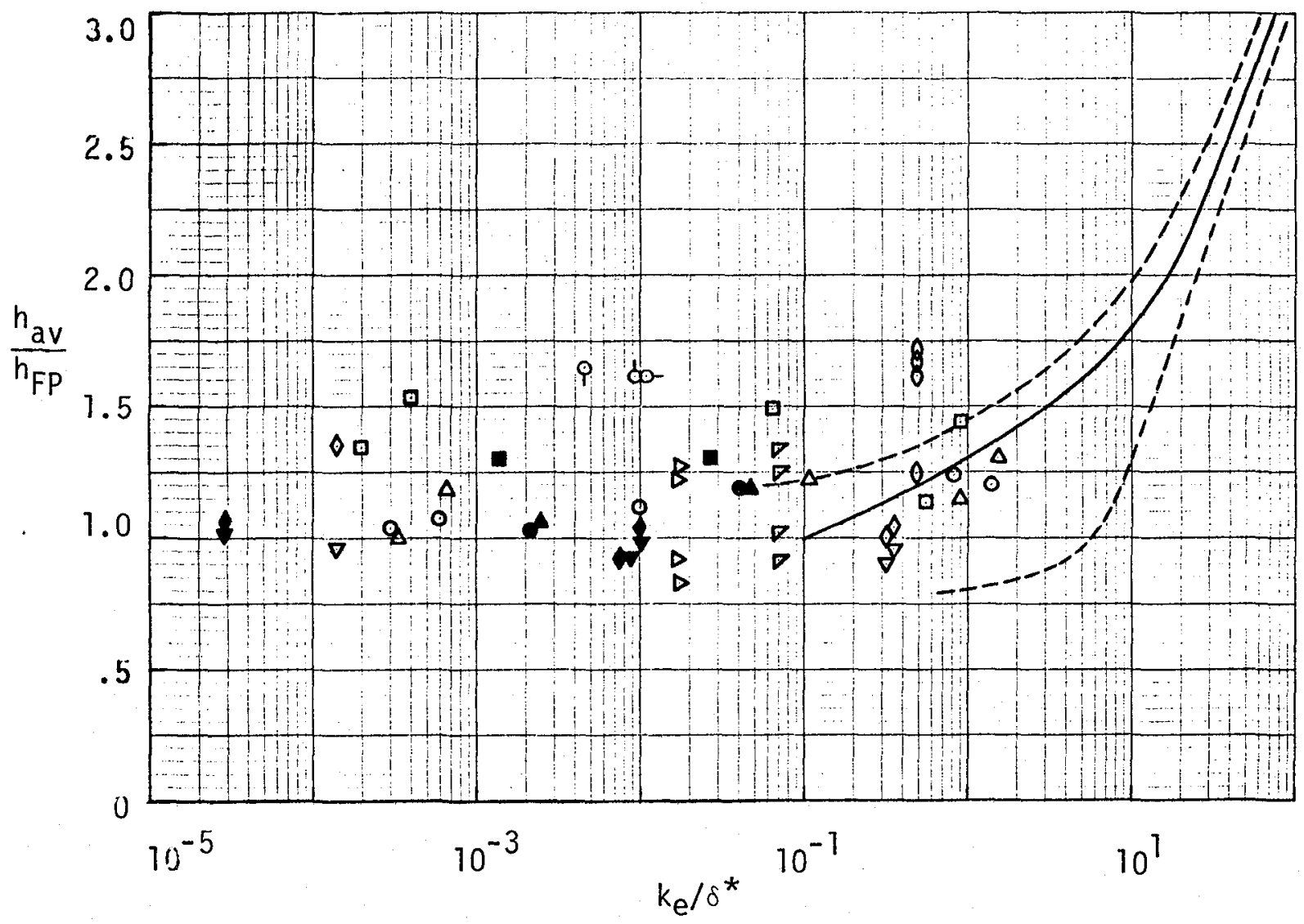

FIGURE 6-12 AVERAGE HEATING COMPARED WITH GRABOW AND WHITE CORRELATION 


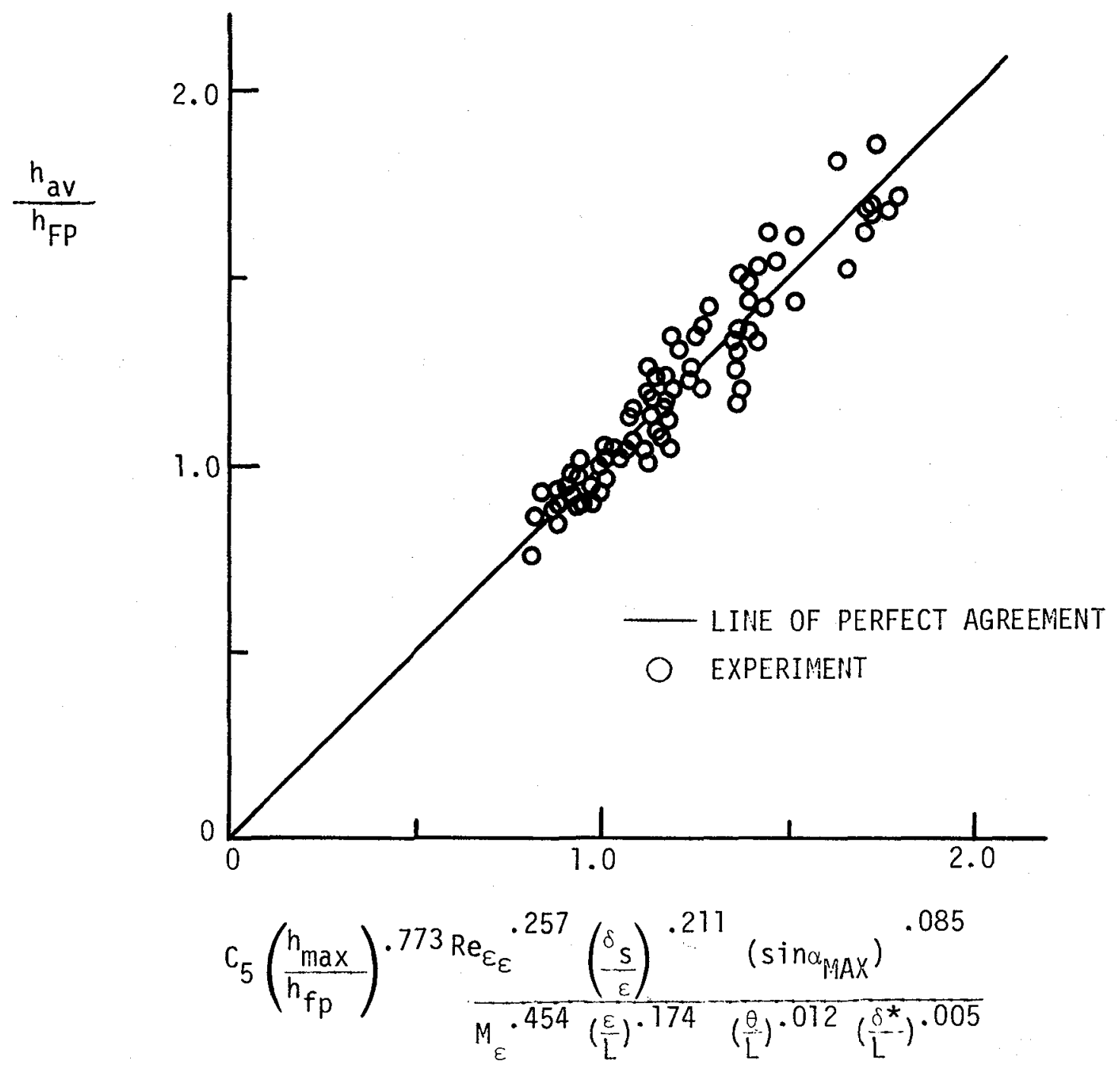

FIGURE 6-13 CORRELATION OF AVERAGE HEATING FOR ALL THICK BOUNDARY LAYER DATA 
for the average heating to rough surfaces in very thick turbulent boundary layers is:

$$
\frac{h_{a v}}{h_{F P}}=\frac{c_{6}\left(\frac{h_{\text {max }}}{h_{F P}}\right)^{.822} R_{e \varepsilon_{\varepsilon}}^{.085}}{\left(\frac{\varepsilon}{L}\right)^{.126} M_{\varepsilon}^{.286}}
$$

where $c_{6}=e^{-1.326}$. This simplified correlation has a standard error of estimate of .088. The agreement between this correlation and the data is essentially as good as that shown in Figure 6-13.

\section{Geometry of Separation Region}

Inherent in the maximum heating correlations is the assumption that the geometry of the separated flow field in the valley of a wave is known so that the local wave surface angle can be computed at the point of maximum heating. Prior to the present study, the local wave surface angle at maximum heating was assumed to be known from experiment. If the angle was not known, it was suggested that the maximum surface angle on the wave be used in order to obtain a conservative solution for the maximum heating.

In order to improve the usefulness of the developed correlations, the experimental data for the surface angle at the maximum heating point have been correlated for al1 the thick boundary layer data obtained on panels $-1,-2,-3,-4,-5$, and -6 in supersonic and hypersonic flow. The data for thin boundary layers were not included in the geometry correlations since the local angles could not be accurately computed for the data that had been published in the literature. The following equation was found to give a good fit to the thick boundary layer geometry data:

$$
\sin \alpha_{r}=\frac{C_{7} M_{\varepsilon}^{.935}\left(\frac{\varepsilon}{L}\right)^{1.43}\left(\frac{\delta^{*}}{L}\right)^{.332}}{\left(\frac{\delta_{s}}{\varepsilon}\right)^{.699} \mathrm{Re}_{\varepsilon_{\varepsilon}}{ }^{.365} \mathrm{R}_{\mathrm{e}_{\varepsilon}}^{.36}\left(\sin \alpha_{\max }\right)^{.715}\left(\frac{\theta}{\mathrm{L}}\right)^{.320}}
$$

where $c_{7}=e^{6.026}$. This correlation has a standard error of estimate equal to .073 . Again, further examination showed that the equation could be greatly simplified without reducing the accuracy of the results. Upon simplification, the following equation resulted which represents a good fit of the data: 


$$
\sin \alpha_{r}=\frac{C_{8}\left(\frac{\varepsilon}{L}\right)^{1.373} R_{e_{\varepsilon}}{ }^{.097}}{\left(\sin \alpha_{\max }\right)^{.63}}
$$

where $c_{8}=e^{1.040}$. This correlation has a standard error of estimate of .077 . Equation (7) is compared with the data in Figure 6-14. Except for a few points, the agreement between the measured and predicted results is fairly good. About the same agreement would exist between the data and equation (8). Variation of Local Heating with Pressure

In many engineering studies, a heating-pressure relationship is used to predict the maximum heating. The variation in the heating rate with the local pressure measured in this study is shown in Figure 6-15. A11 the thick boundary layer data are shown in this figure for $\emptyset=90^{\circ}$. Two separate relationships exist between pressure and heating. In the separated region, the heating increases while the pressure is fairly constant. In the vicinity of the attached flow region, the heating ratio is approximately proportional to the square of the pressure ratio. The reattachment heating for thin turbulent boundary layers varys as the pressure ratio to about the eight-tenth power. Hence, in comparison to thin boundary layers, the present results for thick turbulent boundary layers over corrugated surfaces show that the increase in heating over the corresponding flat plate value is much greater than the increase in the pressure over the flat plate value. 


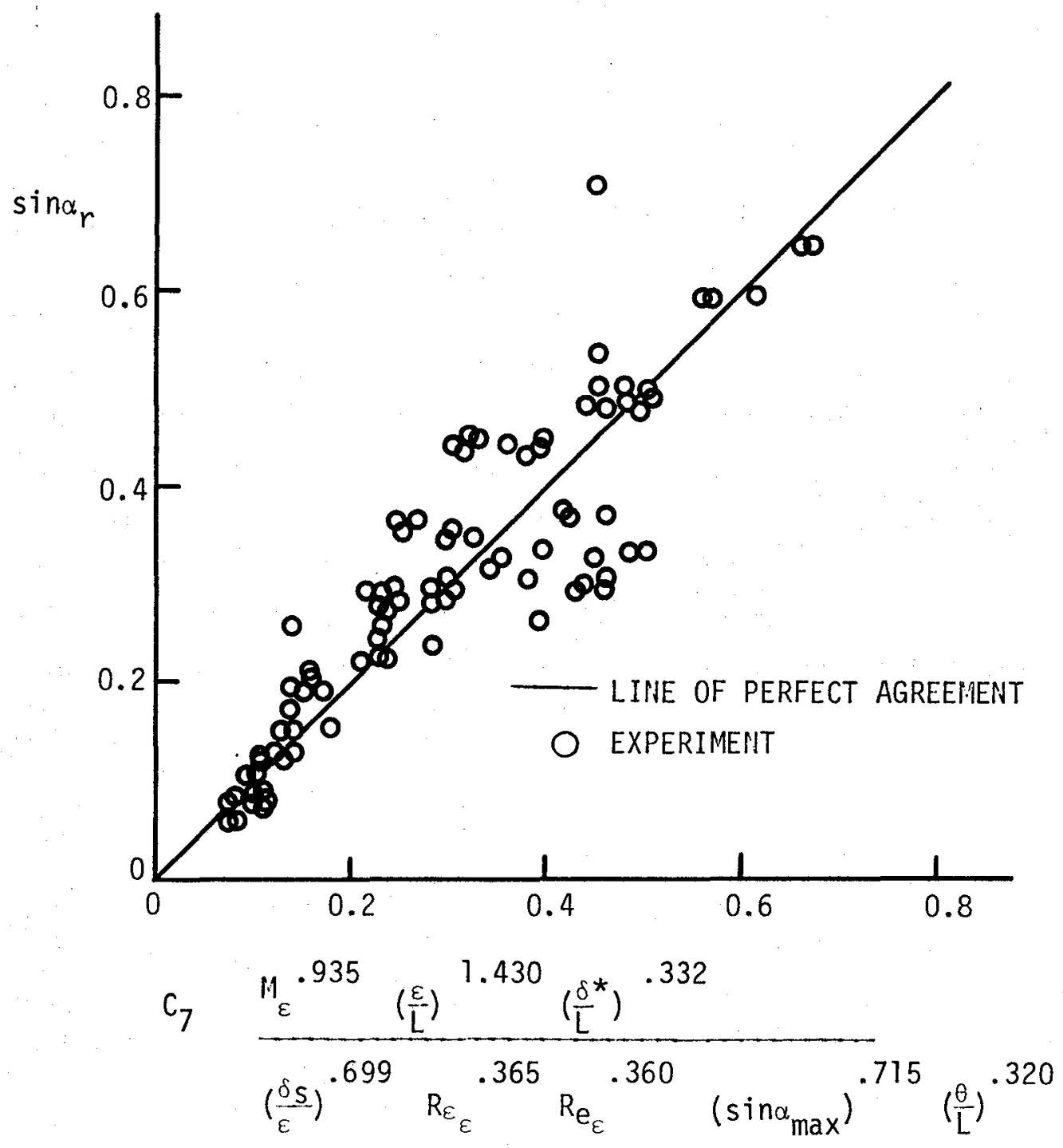

FIGURE 6-14 CORRELATION OF WAVE SURFACE AIJGLE AT REATTACHMENT FOR ALL THICK BOUNDARY LAYER DATA 


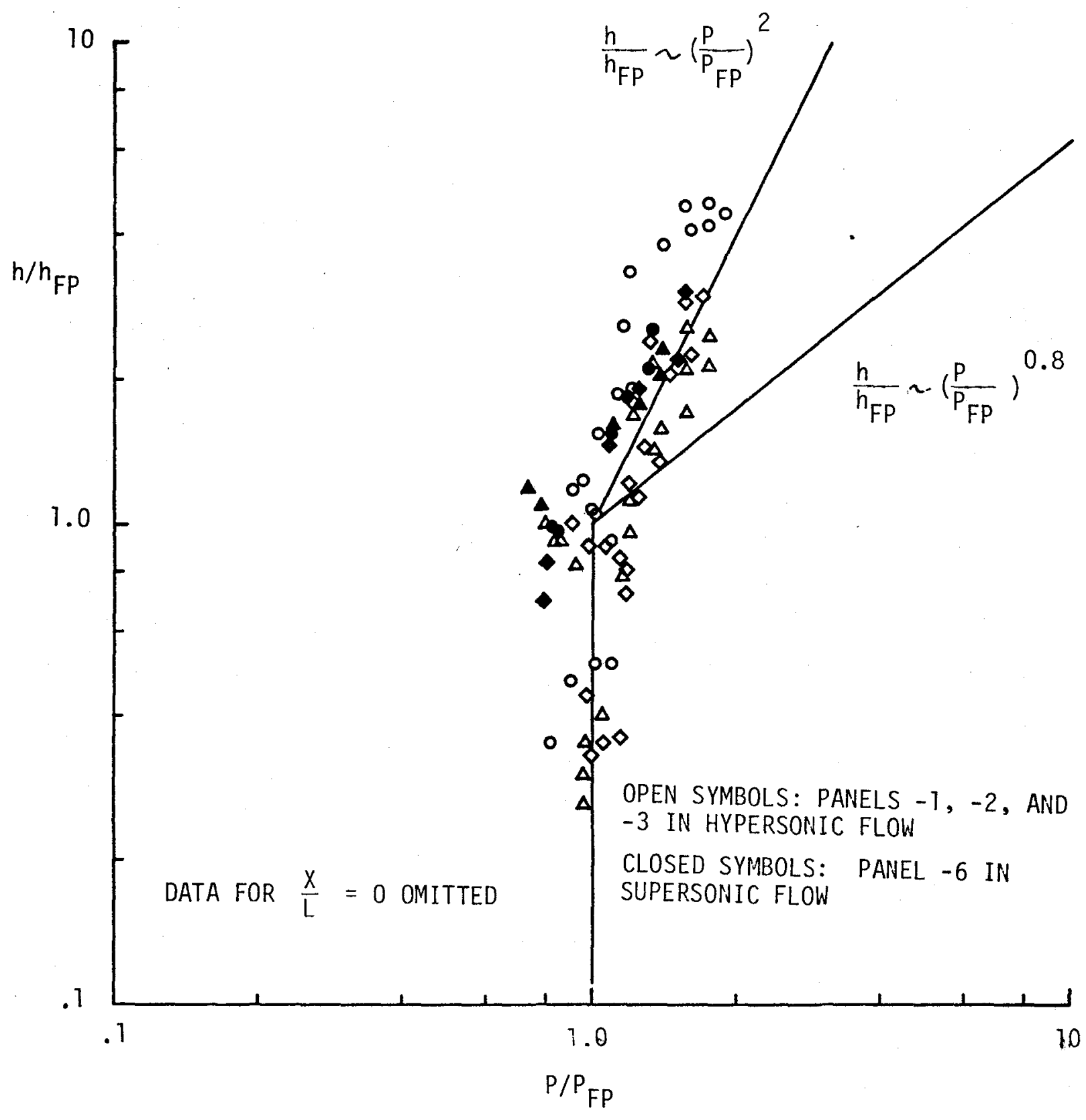

FIGURE 6-15 CORRELATION OF HEATING AND PRESSURE DATA

ORIGINAL PAGE IS

OF POOR QUALTIX 


\subsection{THERMAL FLIGHT ASSESSMENT}

Using the data and correlations described in the previous sections, this section examines the feasibility of applying surface corrugation stiffened panels to advanced space transportation system (STS) vehicles without serious risk to flight performance. Factors considered in the evaluation are the impact of corrugations on thermal response and their impact on aerodynamic performance, both within constraints established by structural dynamic criteria and materials technology. Optimization of corrugation shapes with respect to cost, weight or system performance was not considered.

Objectives of the thermal assessment were to determine, from application of the MRA correlations for peak and average corrugation heating, the peak TPS skin temperatures to be expected during reentry and the insulation thickness required to maintain a $177^{\circ} \mathrm{C}\left(350^{\circ} \mathrm{F}\right)$ limit for the primary structure temperature excursion at several representative points on the SSTO vehicle. From these results it was the further objective to gauge, by the predicted temperature and insulation thickness departures from those obtained for the corresponding smooth body case, where on the SSTO vehicle the corrugated panel TPS can be successfully applied without excessive penalties in insulation thickness or skin material requirements.

The peak corrugation temperatures were calculated by applying to the corrugated skin an assumed spatial heating distribution scaled to result in the same peak heating value as that predicted by the MRA correlations. This calculation was repeated at each location on the vehicle for two different materials (depending upon the expected temperature range) and three skin thicknesses to determine the effect of variations in lateral skin conductance upon the predicted peak temperature.

Insulation thicknesses were determined at each location on the vehicle for both the smooth body and the corrugated skin cases using, in the latter case, the correlated value for average corrugation heating to augment the smooth body value. This calculation was performed for only one skin thickness and assumed $56.1 \mathrm{~kg} / \mathrm{m}^{3}$ (3.5 $\left.\mathrm{lbm} / \mathrm{ft}^{3}\right)$. Microquartz insulation.

Throughout this analysis, the assumed corrugation shape is that shown in Figs. 7-5 and 7-6 which is the configuration recommended by the strength and structural dynamics considerations outlined in Section 9.0 .

\section{SSTO Vehicle and Trajectory}

While the study results are intended to be applicable to advanced STS vehicles in general, to facilitate the analysis a specific SSTO (Single-Stage-To-Orbit) vehicle was chosen as the focal point for the flight evaluation. The characteristics 
of this vehicle were developed in Ref. (19) and shown in Figure 7-1. The SSTO is designed to be sled-launched and to land horizontally. Its length, 63m (206 ft), and wing span, $40 \mathrm{~m}$ (13] ft), are roughly twice the corresponding dimensions of Shuttle. The reentry planform loading of SSTO is approximately $129 \mathrm{~kg} / \mathrm{m}^{2}$ (26 $\mathrm{lb} / \mathrm{ft}^{2}$ ) compared with $264 \mathrm{~kg} / \mathrm{m}^{2}\left(55 \mathrm{lb} / \mathrm{ft}^{2}\right)$ for Shuttle.

The trajectory flown by the SST0 vehicle from Ref. (19) is shown in Figure 7-2. The angle of attack is $50^{\circ}$ at the time of deorbit, decreasing to $30^{\circ} 2300$ seconds later and remaining at that value for 2700 seconds. The period of significant aerodynamic heating and peak loads occurs within the period during which the SSTO angle of attack is $30^{\circ}$. The fact that the angle of attack remains constant during this period results in simplification of the corrugated panel design evaluation.

\section{Vehicle Locations Selected}

Figure 7-3 illustrates the location of the points of interest on the SSTO for which the flow field and its effects upon corrugation heating were investigated. These locations were selected to be representative of areas in which it is expected that the corrugated panel TPS might be applicable. In addition, the points were chosen to reflect a wide range of smooth wall heating and boundary layer parameters in order to define rough limits for the application of corrugated panels on the vehicle and for the correlations developed to predict peak and average corrugation heating. An important consequence of the choice of points for the flow field evaluation is the wide variation in local flow angle relative to the vehicle axis, and thus the possible variation of the flow direction relative to the assumed axis of the TPS corrugations. As was previously noted in the data correlation, this corrugation "angle of attack" is one of the more important parameters affecting peak heat transfer to the corrugation.

Wind tunnel oil flow results for Shuttle orbiter type configurations at $30^{\circ}$ angle of attack (Figure 7-4) were used as a basis for determining the local flow angle relative to the vehicle roll axis. These suggest that flow angles for the SSTO geometry are probably less than $10^{\circ}$ near the lower body centerline, less than $20^{\circ}$ at the lower body off-center point, and $20^{\circ}$ on the lower wing. While the flow on the upper surfaces is predominantly separated and shows evidence of vortex impingment, the local flow angles appear to be no greater than $60^{\circ}$ at any point on the upper body, upper wing or side body forward of the wing. 


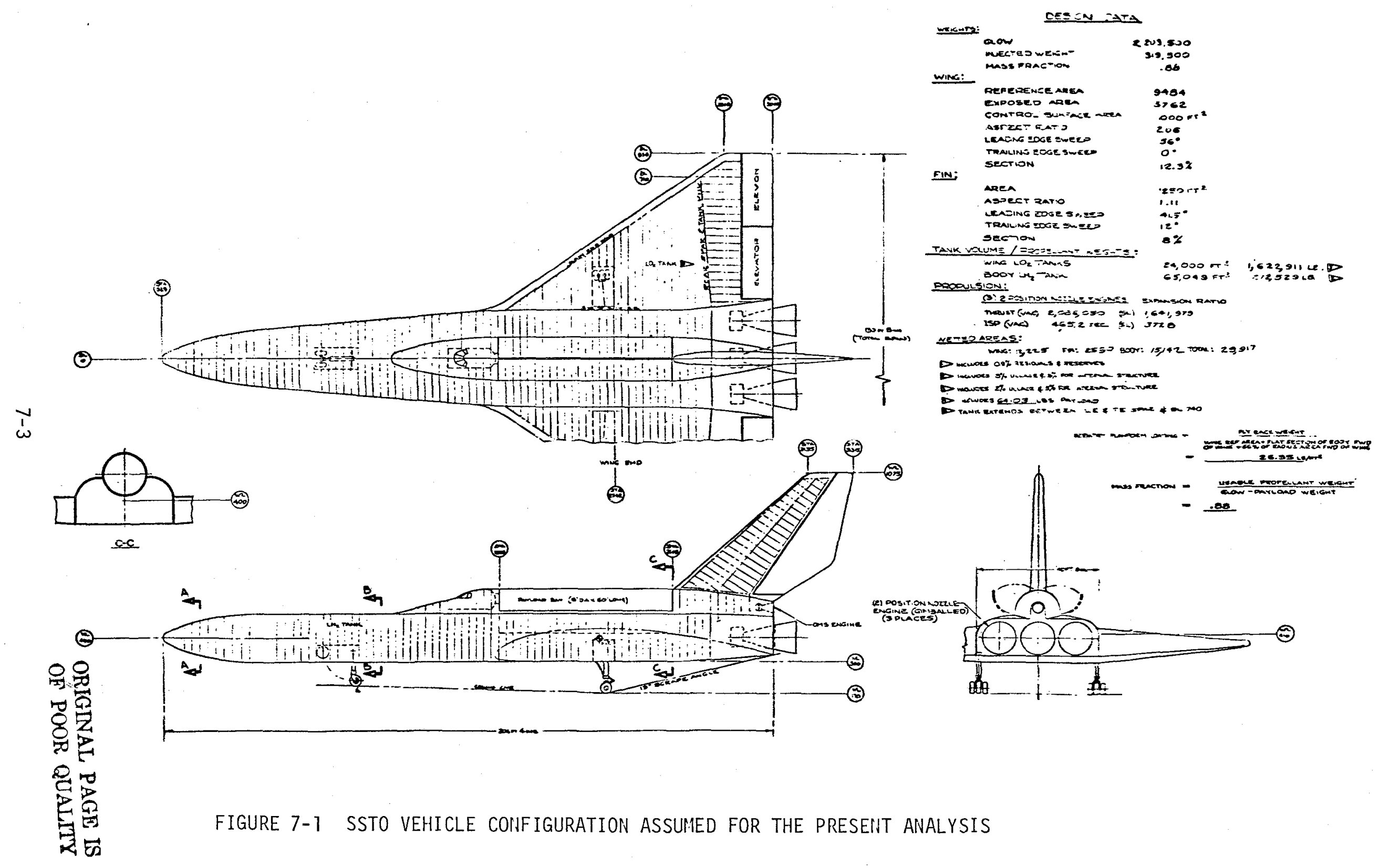




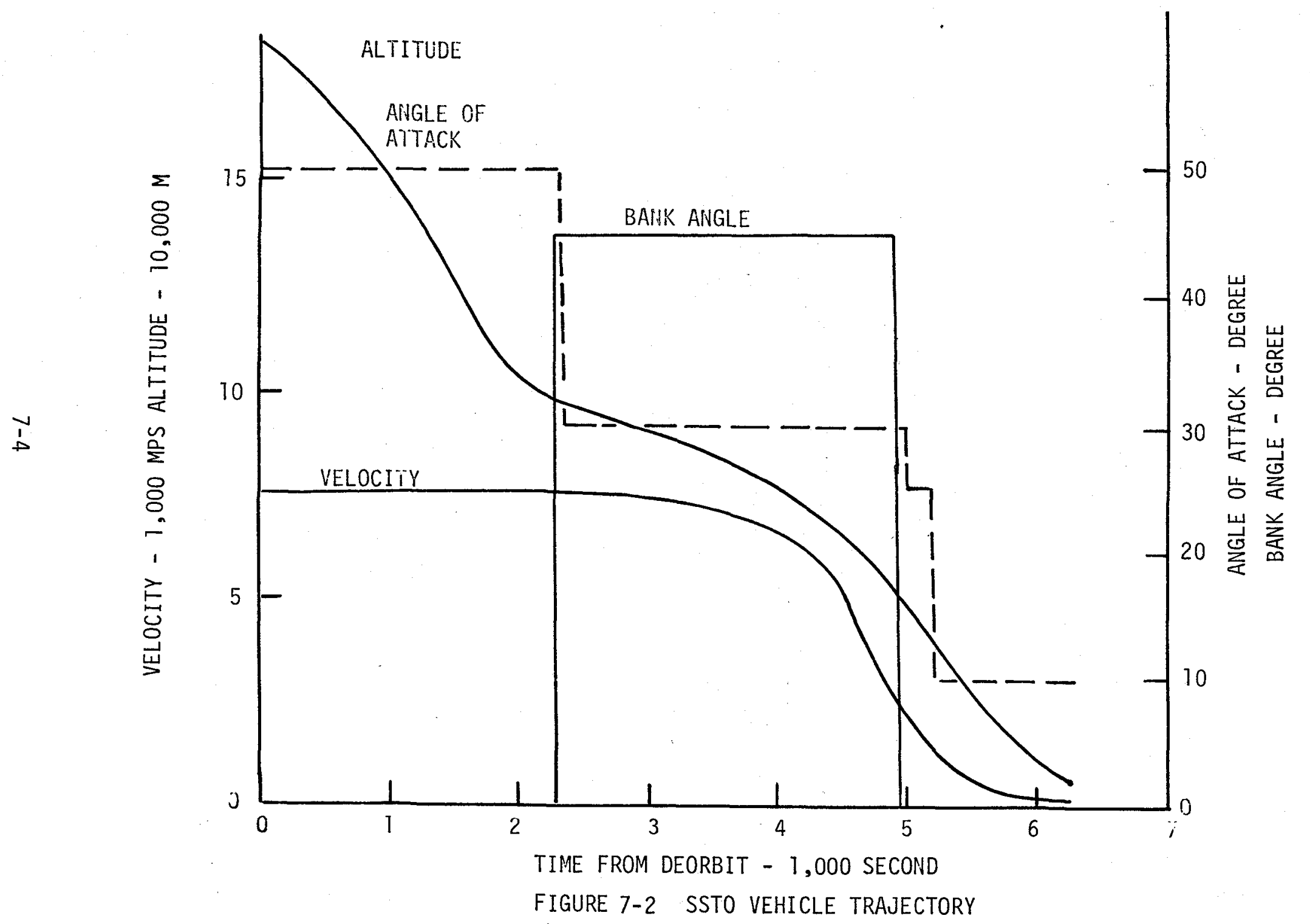


UPPER AND LOWER WIMG

50\% SPAN, 20\% AND 60\% CHORD

SIDE FUSELAGE

(3i3) $50 \% \mathrm{~L}$

$\longrightarrow$ 工

(20)

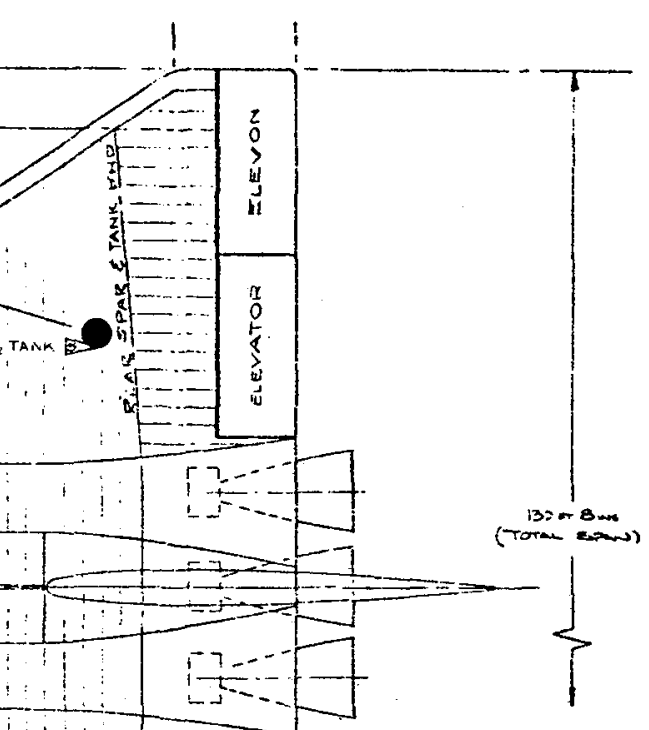

ì

L.OWER FUSELAGE

OFF CENTER, $75 \% \mathrm{~L}$

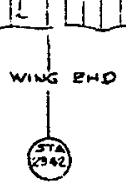

UPPER AND LOWER FUSELAGE

$50 \%$ ANSD 75\% L

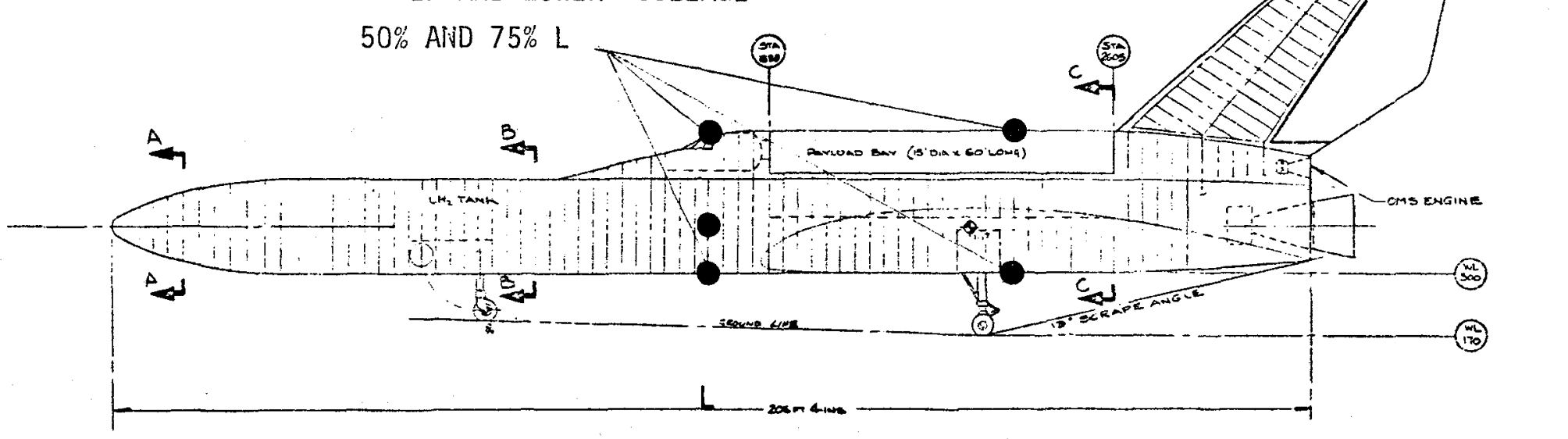

FIGURE 7-3 VEHICLE LOCATIONS CONSIDERED FOR APPLICATION OF THE CORRUGATED PANEL TPS 

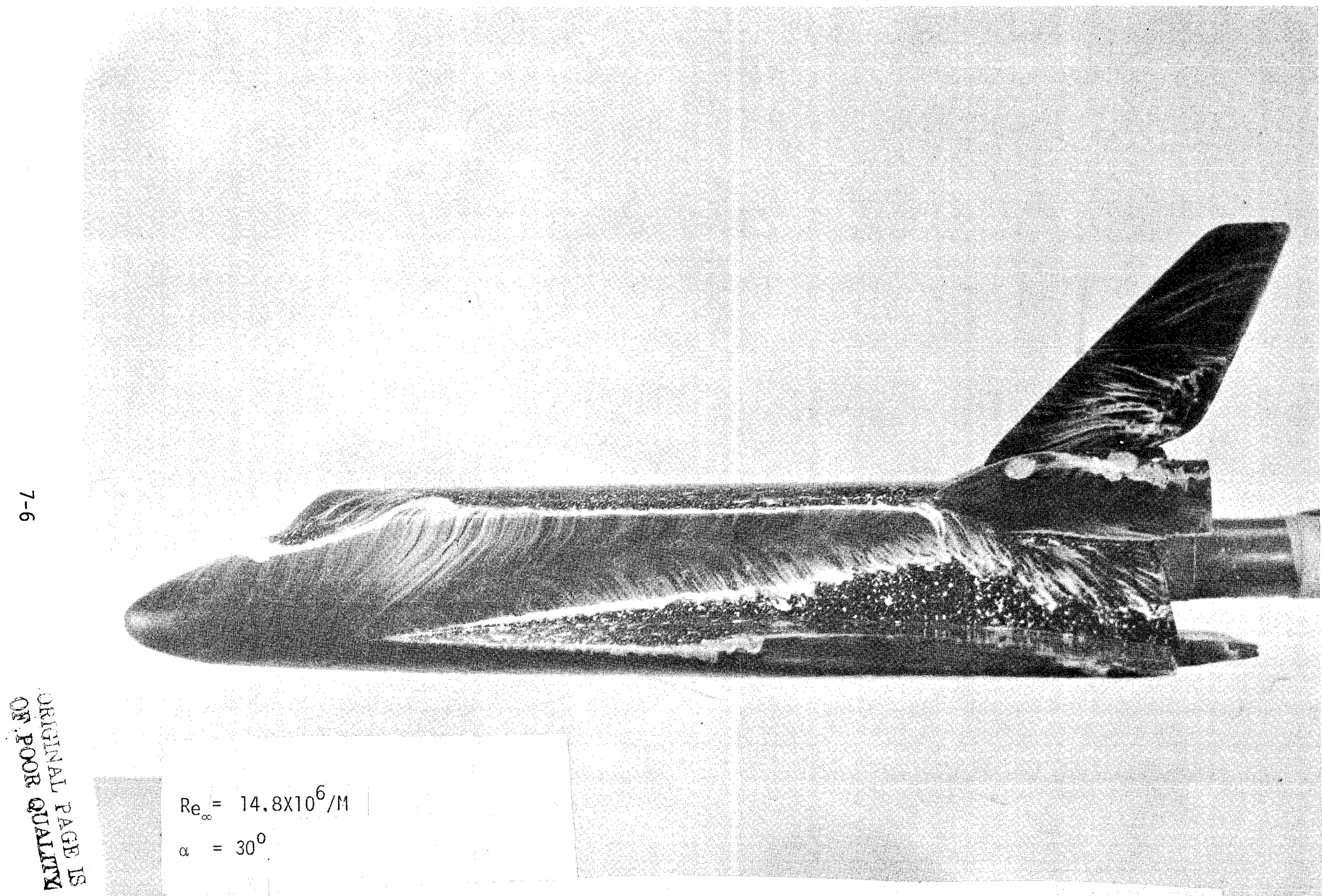

FIGURE 7-4 OIL FLOWS USED TO ESTIMATE LOCAL FLOW ANGLES RELATIVE TO THE VEHICLE ROLL AXIS. SIDE FUSELAGE 


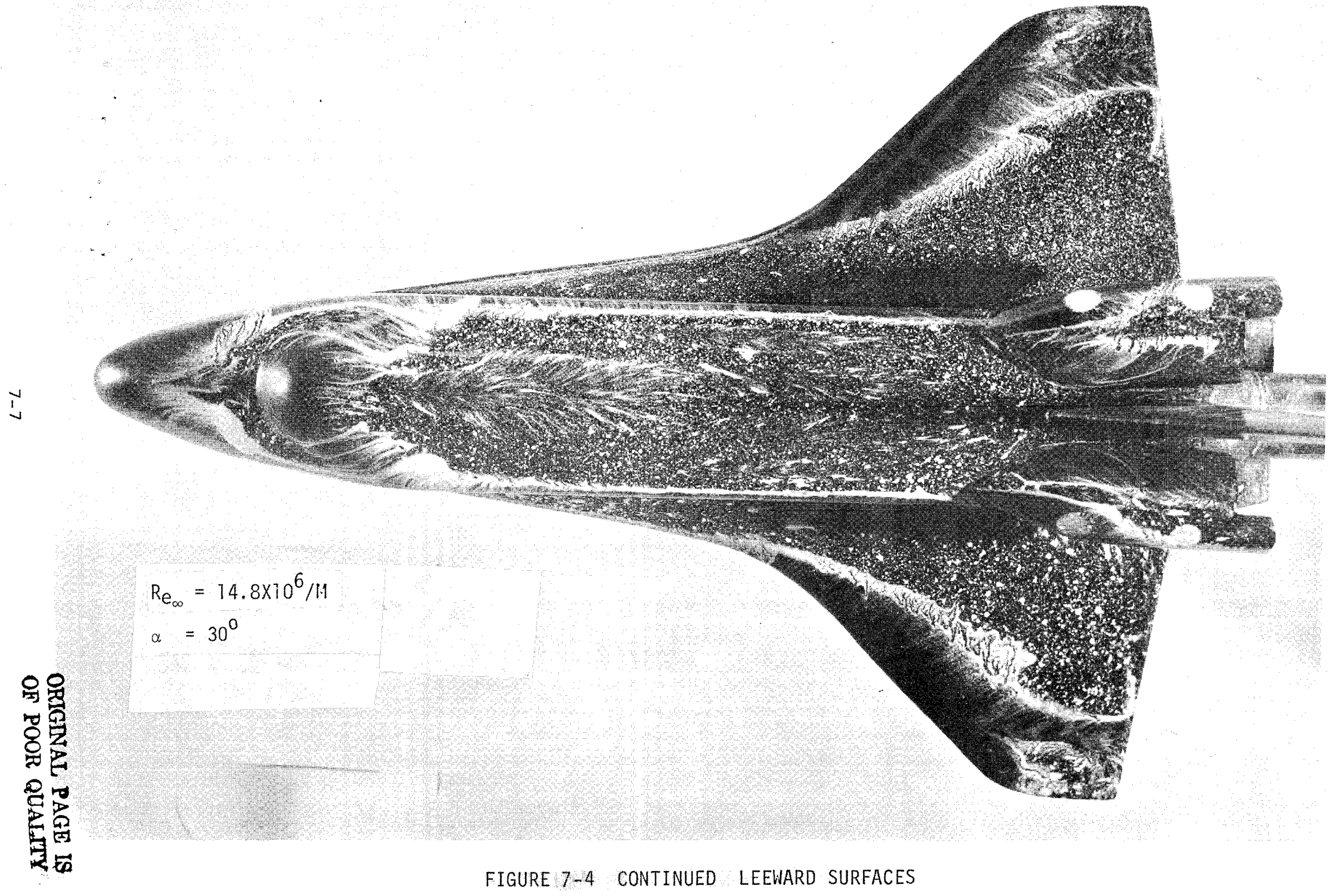





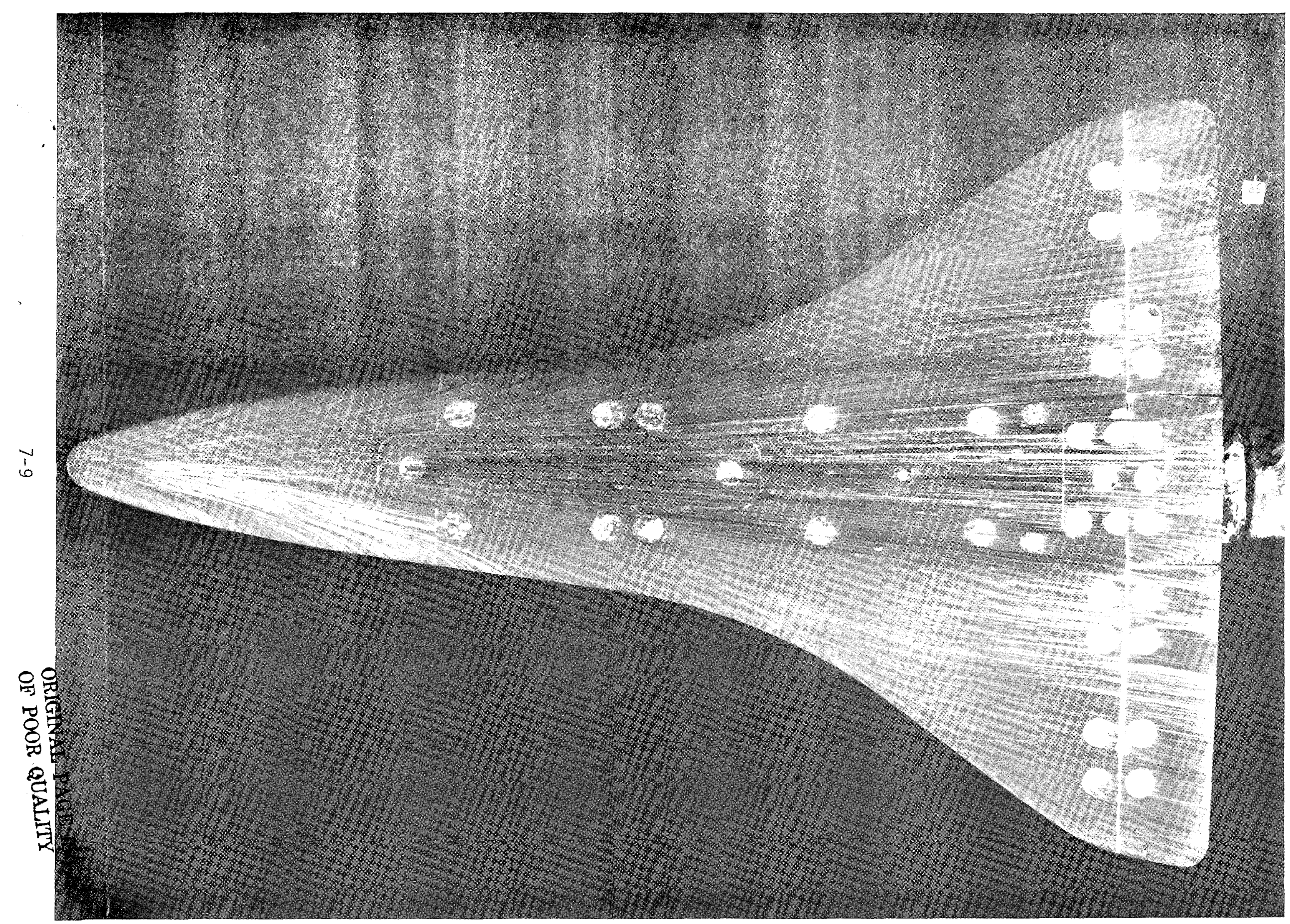

FIGURE 7-4 COOC:1114 
The MRA correlations for peak heating and associated estimates of the spatial distribution of neating and temperature on the corrugation were evaluated for these assumed maximum corrugation angles to determine the peak temperature penalty in regions for which this angle is poorly defined, i.e., for the high local flow angles typical of leeward surfaces. Alternately, the possibility of a significant reduction in peak corrugation temperature was allowed for regions in which close alignment of the corrugation with the local flow may be realistic (typical of windward surfaces).

Evaluation of the MRA average heating correlation and estimates of insulation thickness were also confined to the estimated maximum local flow angles that would result from simple alignment of the corrugations with the vehicle roll axis, i.e., $60^{\circ}$ on leeward and side surfaces, $10^{\circ}$ on the lower body centerline and $20^{\circ}$ for the lower body off center point and lower wing.

Inviscid Flow Models

Trajectory time dependent boundary layer edge conditions and smooth body heat transfer coefficients for each point of interest on the vehicle were calculated using the Miniver version of the JA-70 aerodynamic heating code (Ref. 20).

On windward surfaces, it was assumed that the local pressure is approximated by that predicted for cone flow. In regions of separated flow on the leeward side, turbulent attached flow was assumed for the purposes of modeling and a turbulent design factor (heat transfer coefficient multiplier) applied to obtain smooth body temperatures that are in agreement with those determined experimentally (Ref. 21).

The flow models constructed and additional assumptions made are as follows: Lower body

- shock wave angle is obtained from a table of sharp cone shock angles as a function of upstream Mach number and a cone half angle equal to the time dependent angle of attack of the vehicle.

- local pressure is determined from a table of sharp cone real gas pressure coefficients as a function of upstream Mach number and cone half angle.

- local smooth body enthalpy-based heat transfer coefficient is calculated. using a real gas extension of the Spalding Chi flat plate method.

o correction to account for streamline divergence is made to the geometric running length by using the real gas crossflow technique developed by Baranowski (Ref. 22). 
Lower wing

- flow model is the same as that used for the lower body except that the geometric running lengths are shorter and the crossflow correction is omitted.

Upper body and side body

o shock wave angle is obtained in the same manner as that used for the lower surfaces with the cone half-angle again assumed to be equal to the time dependent angle of attack of the vehicle.

- local pressure is determined by specifying the local pressure coefficient $c_{p}=0$.

- local heat transfer is calculated using the Spalding-Chi flat plate method with the turbulent design factor set equal to 2.0 .

upper wing

o shock wave angle is assumed equal to the effective sweep angle of the wing leading edge.

- local pressure coefficient $c_{P}=0$.

- local heat transfer is calculated using the Spalding and Chi method with the turbulent design factor set equal to 3.5 for the upper wing forward point and 2.0 for the aft point.

Boundary Layer Mode1

Local edge conditions calculated by Miniver were input to a simple $1 / 7$ power law flat plate boundary layer model based on the work of Walker and Schumann (Ref. 23) to obtain the bulk and internal boundary layer parameters required to evaluate the correlations for peak and average corrugation heating. The following relations were used:

(ratio of boundary layer thickness to momentum thickness)

$$
\begin{aligned}
\frac{\delta}{\theta} & =(n+1)+\left(\frac{(n+2)}{n} \frac{h_{w}}{h_{a w}}+1\right) \quad(1+\text { ArV }) \\
n & =\text { velocity power law exponent } \\
h_{w} & =\text { enthalpy at the wall } \\
h_{a w} & =h_{\infty}+r \frac{u_{\infty}}{2 g_{C} J} \\
A & =1.69 \text { (a constant) } \\
r & =\text { recovery factor } \\
v & =\frac{u_{\infty}}{2 g_{C} h_{\infty}}
\end{aligned}
$$


(ratio of displacement thickness to momentum thickness)

$$
\frac{\delta^{*}}{\theta}=-1+\left(\frac{(n+2)}{n} \frac{h_{w}}{h_{a w}}+1\right)(1+B r V)
$$

$B=1.16$ (a constant)

(momentum thickness)

$$
\theta=\frac{k x}{\left(\frac{\mu^{*}}{\mu_{\infty}}\right)^{0.2}\left(\frac{\rho^{*}}{\rho_{\infty}}\right)^{0.8}}
$$

$k=0.037$ for flat plates

The resulting velocity profile and the Crocco expression for the enthalpyvelocity relationship through the boundary layer

$$
h=h_{w}+\left(h_{a w}-h_{w}\right)\left(\frac{u}{u_{\infty}}\right)-\left(h_{a w}-h_{\infty}\right)\left(\frac{u}{u_{\infty}}\right)^{2}
$$

were used to determine internal boundary layer parameters $\left(R_{\varepsilon}, M_{\varepsilon}\right.$, etc. $)$ at the corrugation height.

The laminar sublayer thickness was evaluated from Reda's expression (Ref. 24).

$$
\delta_{s}=\frac{11_{\mu_{w}} a_{w}}{\gamma_{w} p_{w} 1_{\infty} \cdot \sqrt{c_{f / 2}}}
$$

where the skin friction coefficient $C_{f}$ is calculated in Miniver using Reynolds analogy.

A summary of the flow conditions calculated using these inviscid and boundary layer models for each of the ten vehicle locations investigated is shown in Table 7-I.

\section{Numerical Boundary Layer Solution}

While the approximate solution used in this study to obtain bulk and internal boundary layer parameters is easily evaluated and thus convenient for repetitive calculations, it represents a great simplification of the actual viscous flow. For this reason, comparison was made with a numerical solution developed by Fivel (Ref. 25). This is an "exact" equilibrium finite difference solution to the compressible turbulent boundary layer equations for a real gas and has previously been applied (Ref. 26) to a $30^{\circ}$ cone for freestream conditions that approximate 


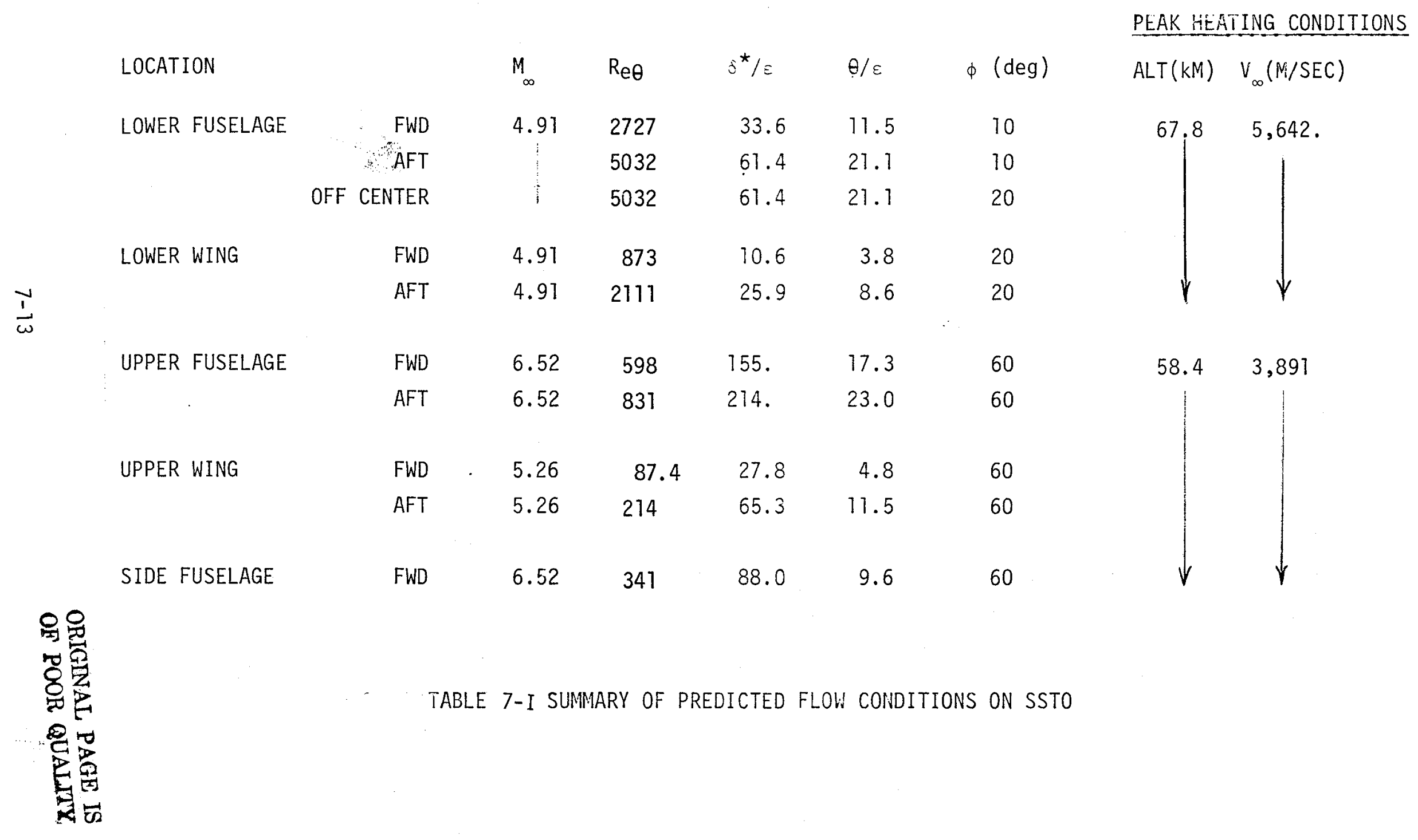


those of the SSTO reentry trajectory near peak heating (Table 7-II). Results of the cone boundary layer solution, at a point chosen to correspond to the SSTO lower body forward location, were used to evaluate the MRA correlations for peak and average corrugation heating, and comparison made with the values obtained using the approximate solution. As seen in Table 7-II agreement is quite good in spite of the sizable difference in displacement thickness predicted by the two methods. Scatter about the mean of the four peak values is only $+13 \%,-3 \%$ and the greatest departure of the peak value based on the approximate boundary layer from that based on the exact solution is $-14 \%$.

The discrepancy in displacement thickness is, at least in part, attributable to the correction made to the turbulent running length via the Baranowski crossflow technique (Ref. 22). This adjustment was included in the approximate calculations to account for the spanwise flow on the SSTO forward lower surface and the consequent deviation of the boundary layer development from that expected for a flat plate. It would be expected that an "exact" solution based on a geometry that corresponds to the SSTO configuration would result in an increase in the predicted displacement thickness over the conical prediction and a consequent decrease in the peak corrugation heating to a value nearer that obtained from the approximate calculations. Of course, the mismatch in free stream conditions may also contribute to the observed differences.

The importance of this comparison is two fold. First, it demonstrates that the approximate analysis used throughout the study results in reasonable boundary layer parameters at least on the windward surfaces and, second, that evaluation of the MRA correlations using these parameters yields values of peak corrugation heating that are in agreement with those predicted using the more rigorous numerical analysis.

IPS Skin Lateral Conduction Model

Since the correlations developed during the present study predict only the peak heating on the windwardside of the corrugation and do not address the spatial distribution of heating over its wavelength, it is necessary, if advantage is to be taken of lateral conduction in the skin, to make some assumption about the "shape" of this distribution. This done, the actual peak temperature of the surface may be calculated. Further, it was desirable to perform these calculations for a range of skin thickness to determine the importance of skin lateral conduction in reducing the peak temperature. 
FREE STREAM CONDITIONS

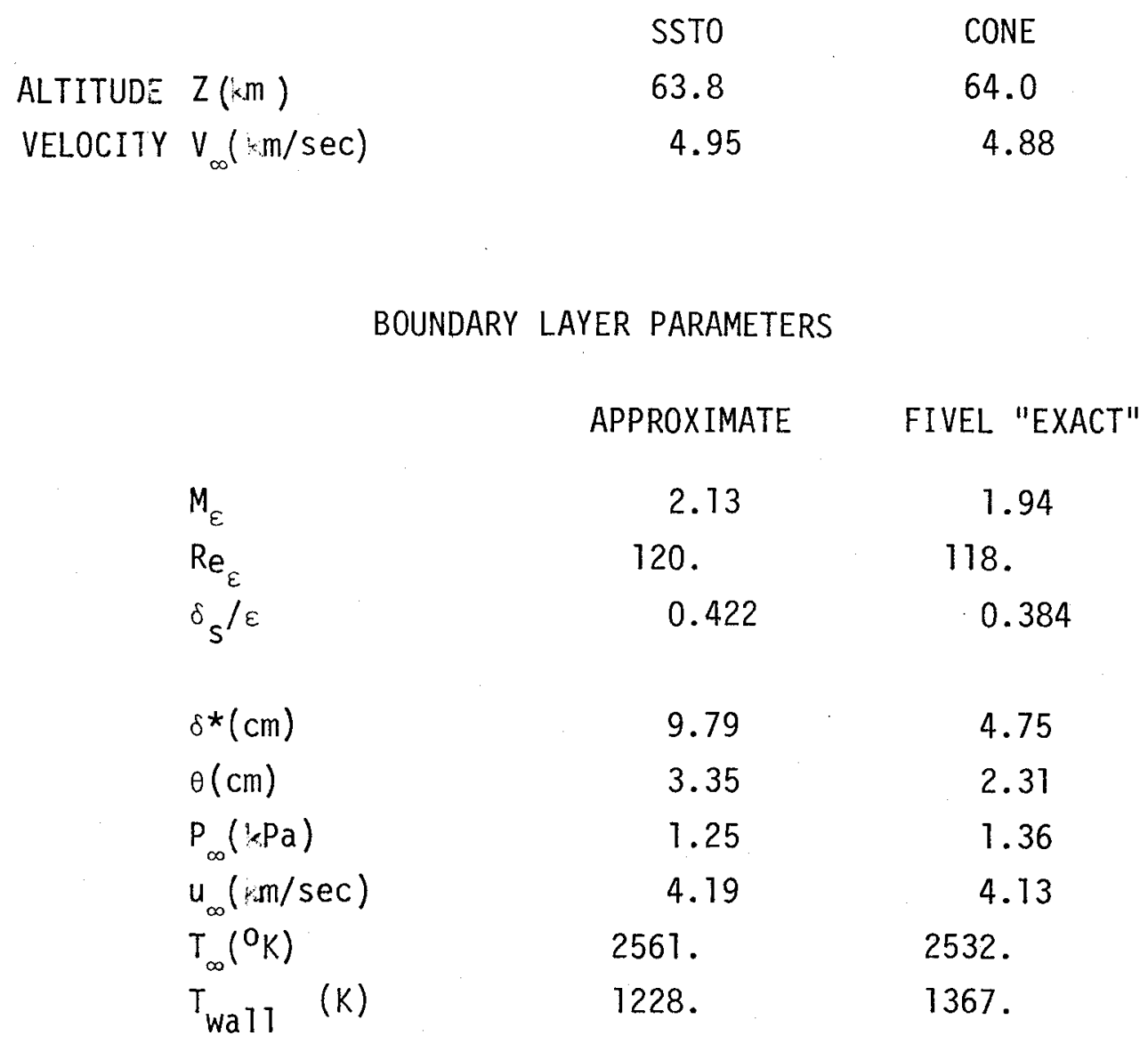

$$
\text { PREDICTED HEATING } h_{\max } / h_{\mathrm{fp}} \text { AND }\left(h_{\mathrm{av}} / h_{\mathrm{fp}}\right)
$$

$\begin{array}{llll}\text { EQUATIONS } 2 \text { and (6) } & 2.15(1.01) & 1.99(0.97) \\ \text { EQUATIONS } 4 \text { and (6) } & 2.21(1.03) & 2.51(1.17)\end{array}$

TABLE 7-II COMPARISON OF APPROXIMATE AND "EXACT" BOUNDARY LAYER RESULTS

ORIGINAL PAGE IS
OF POOR QUAITTY 
A review of the experimental heating profiles disclosed that they appear to be of two genre, one having a broad region of relatively high heating rate near the peak and only narrow regions of heating at or below the flat plate value. This distribution is typical of the -6 type corrugation (Ref. 10) shown in Figure 3-1. Corrugations of a more nearly "sinusoidal" cross-section such as those of the -5 type show a relatively narrow region of high heating rates near the peak and broad areas in which the heating is significantly below the smooth body value.

Since it is not entirely clear that this implied correspondence between the two types of corrugations and their respective heating profiles is real, profiles representative of both types were taken as reference values from which to scale heating distributions corresponding to the predicted peak values. These were then used to calculate two values for the peak temperature expected on the corrugation (lateral conduction effects included), and thus estimate the magnitude of the effect of uncertainties in the heating distribution.

The peak temperatures were calculated using a 20 node, one dimensional thermal model which includes conduction laterally through the metallic TPS skin, aerodynamic heating at each node based upon an evaluation of the MRA peak heating correlation at flow conditions predicted by Miniver for trajectory peak heating, and reradiation from the skin outer surface (emissivity $=0.8$ ) to a $3 \mathrm{~K}$ radiation sink. Figures 7-5 and 7-6 show a schematic of the model, typical applied heating distributions, and the resulting temperature profiles for three different skin thicknesses.

These calculations assume equilibrium conditions and an adiabatic back surface; however, during the course of the transient heating calculations using Miniver, it was noted that the TPS skin does, in fact, very nearly attain the radiation equilibrium temperature even for the relatively large skin thicknesses assumed. For Miniver calculations on the lower body and lower wing a skin thickness of $0.254 \mathrm{~cm}(0.1 \mathrm{in})$ was assumed for the purposes of computing the inviscid flow field since this caused a departure of the wall temperature from the radiation equilibrium temperature of only a few degrees and allowed calculations to be made at less frequent (more economical) time intervals. The lower heating rates characteristic of the vehicle upper surface required a thinner assumed skin $(0.076 \mathrm{~cm})$ to maintain the skin temperature at a value near the radiation equilibrium temperature and a corresponding reduction in the calculation interval to insure a stable solution. In either case, for the present purposes of skin material selection, it may be assumed that the typically much thinner $(0.041 \mathrm{~cm})$ 

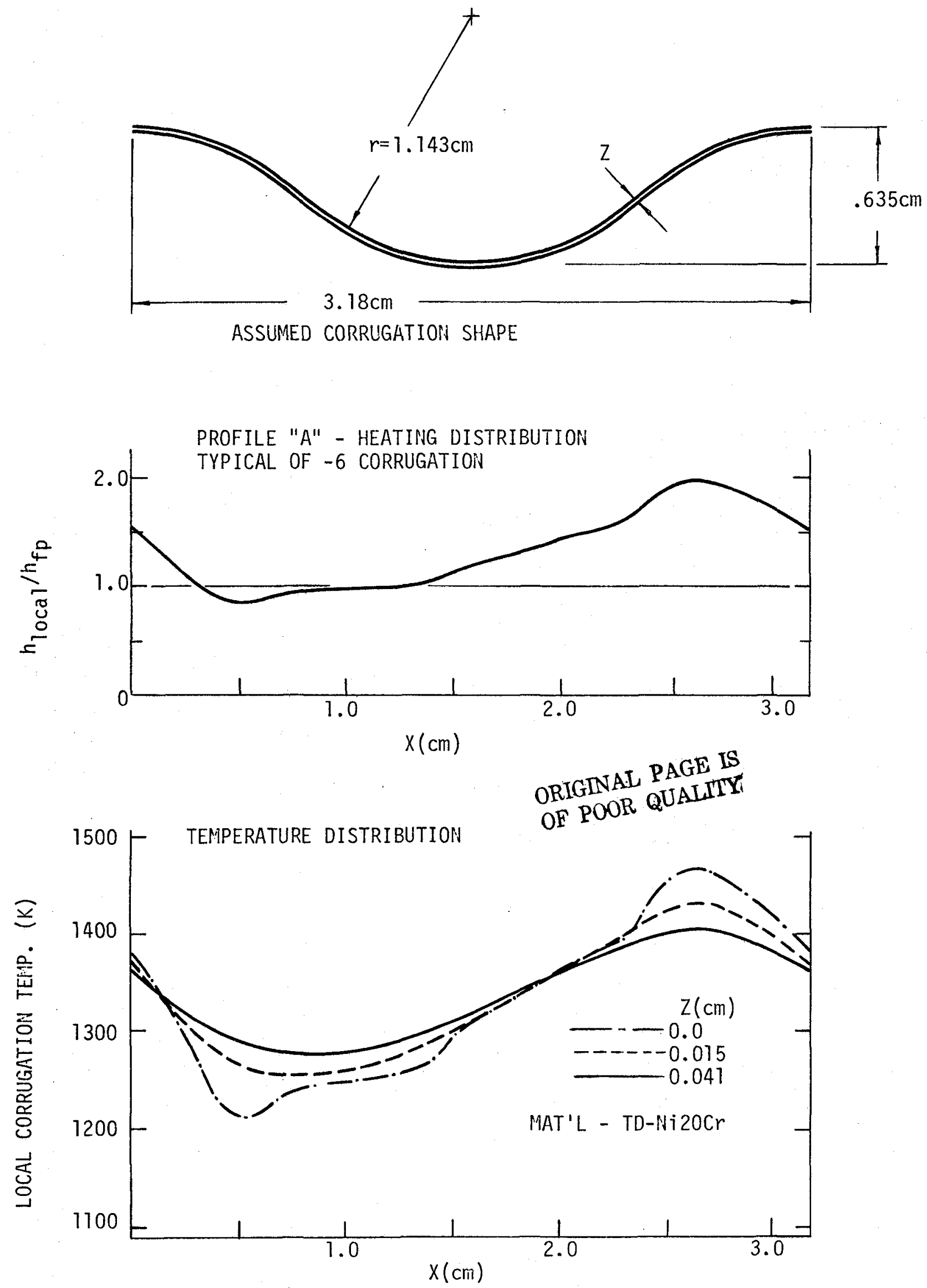

FIGURE 7-5 PREDICTED CORRUGATION TEMPERATURES FOR LOWER FUSELAGE FORWARD LOCATION (HEATING PROFILE "A") 

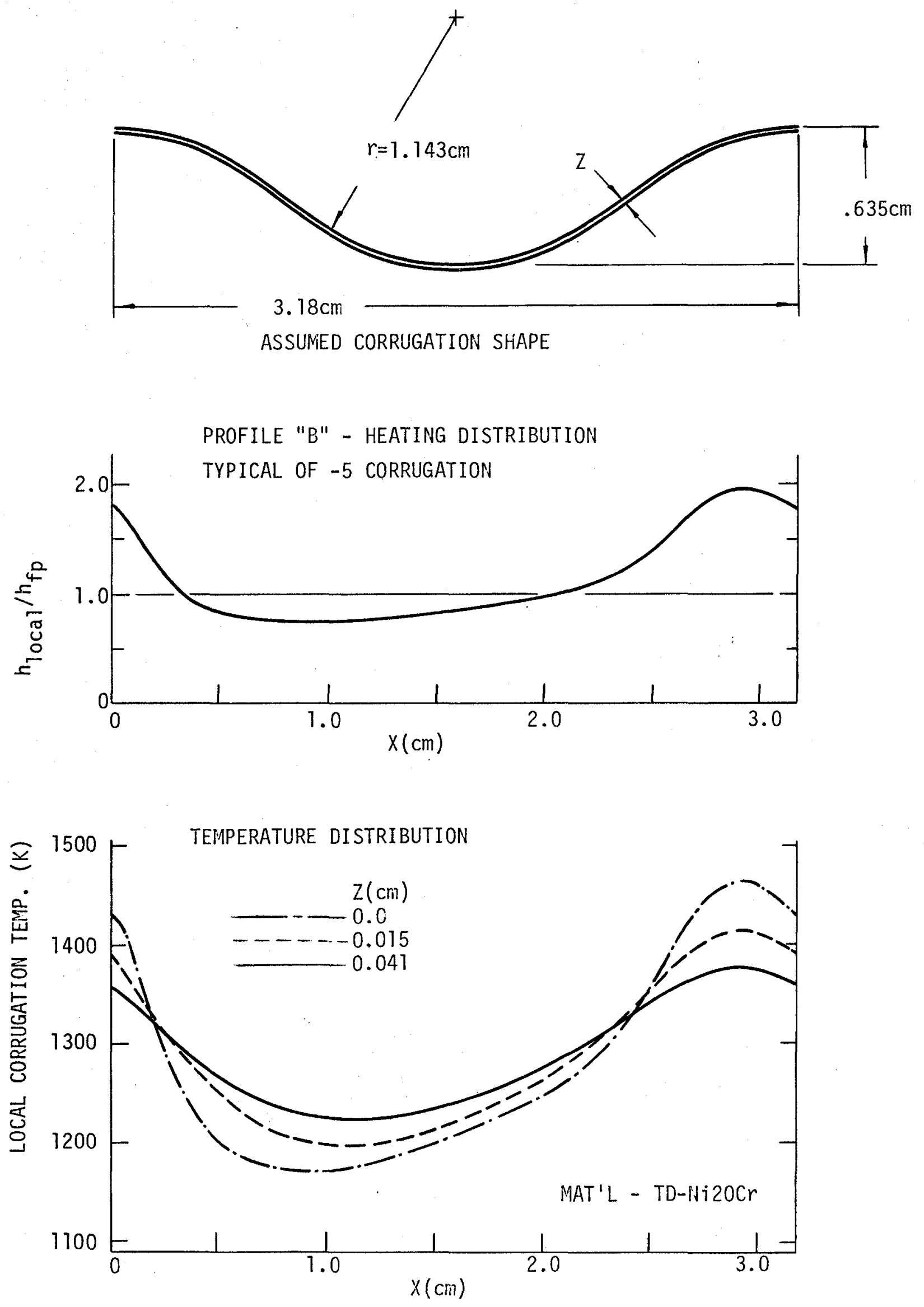

FIGURE 7-6 PREDICTED CORRUGATION TEIIPERATURES FOR LOWER FUSELAGE FORWARD LOCATION (HEATING PROFILE "B") 
TPS skin to be used on a flight vehicle is in thermal equilibrium at the radiation equilibrium temperature. As a result, it may further be assumed that the equilibrium lateral conduction model accurately reflects (within the uncertainty imposed by the assumed heating profile) the actual peak temperatures to be expected during transient heating of the TPS.

Results of these calculations at each point of interest on the SSTO for both heating profiles, skin thicknesses of $0.0,0.015$, and $0.041 \mathrm{~cm}(0.0,0.006$, and $0.016 \mathrm{in}$ ), and several different materials depending upon the temperature range considered are shown in Table 7-III. The correlated ratios of peak and average heating and the corresponding smooth body heat transfer coefficients are listed in Table 7-IV.

The effects of radiation and conduction heat transfer from the backside of the TPS skin to the insulating medium will be discussed in the following section. IPS Insulation Sizing

To assess the impact of the increased average convective heating to the corrugation surface upon. TPS insulation requirements, a one-dimensional transient conduction model was constructed based upon the following assumptions:

0 a fixed TPS outer skin thickness of $0.041 \mathrm{~cm}(0.016 \mathrm{in})$.

$056.1 \mathrm{~kg} / \mathrm{m}^{3}\left(3.5 \mathrm{lbm} / \mathrm{ft}^{3}\right)$ Microquartz insulation (20 nodes) with temperature and pressure dependent conductivity.

$0.254 \mathrm{~cm}(0.1 \mathrm{in}) 2024-\mathrm{T} 4$ aluminum backside to simulate the vehicle primary structure.

- a primary structure transient temperature 1 imit of $450 \mathrm{~K}\left(350^{\circ} \mathrm{F}\right)$.

o an initial temperature of $255 \mathrm{~K}\left(0^{\circ} \mathrm{F}\right)$.

- adiabatic conditions at the primary structure back surface.

Smooth body transient heating rates were read into the model directly from a Miniver output tape consisting of time dependent recovery temperature-heat transfer coefficient pairs that result in the same heating rate as the corresponding recovery enthalpy and real gas heat transfer coefficient. The insulation thickness was then varied in trial and error fashion to determine the smooth body insulation thickness required to limit the primary structure temperature excursion to 450K. Corrugation average heating rate increments determined from the MRA correlations were then input as multipliers on the smooth body values and the trial and error insulation sizing repeated to determine a new thickness required to maintain the $450 \mathrm{~K}$ limit. 


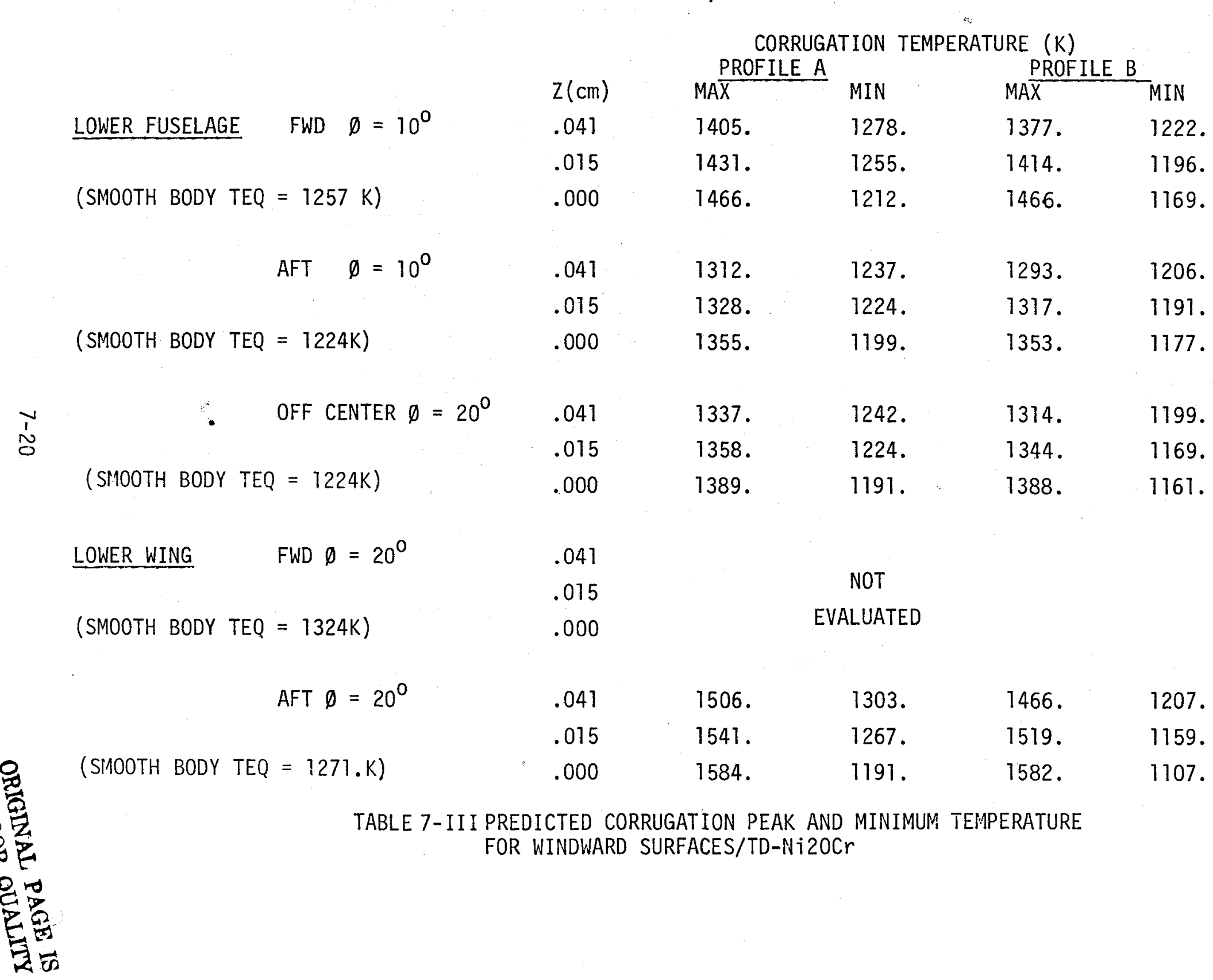


CORRUGATION TEMPERATURE ( $K$ )

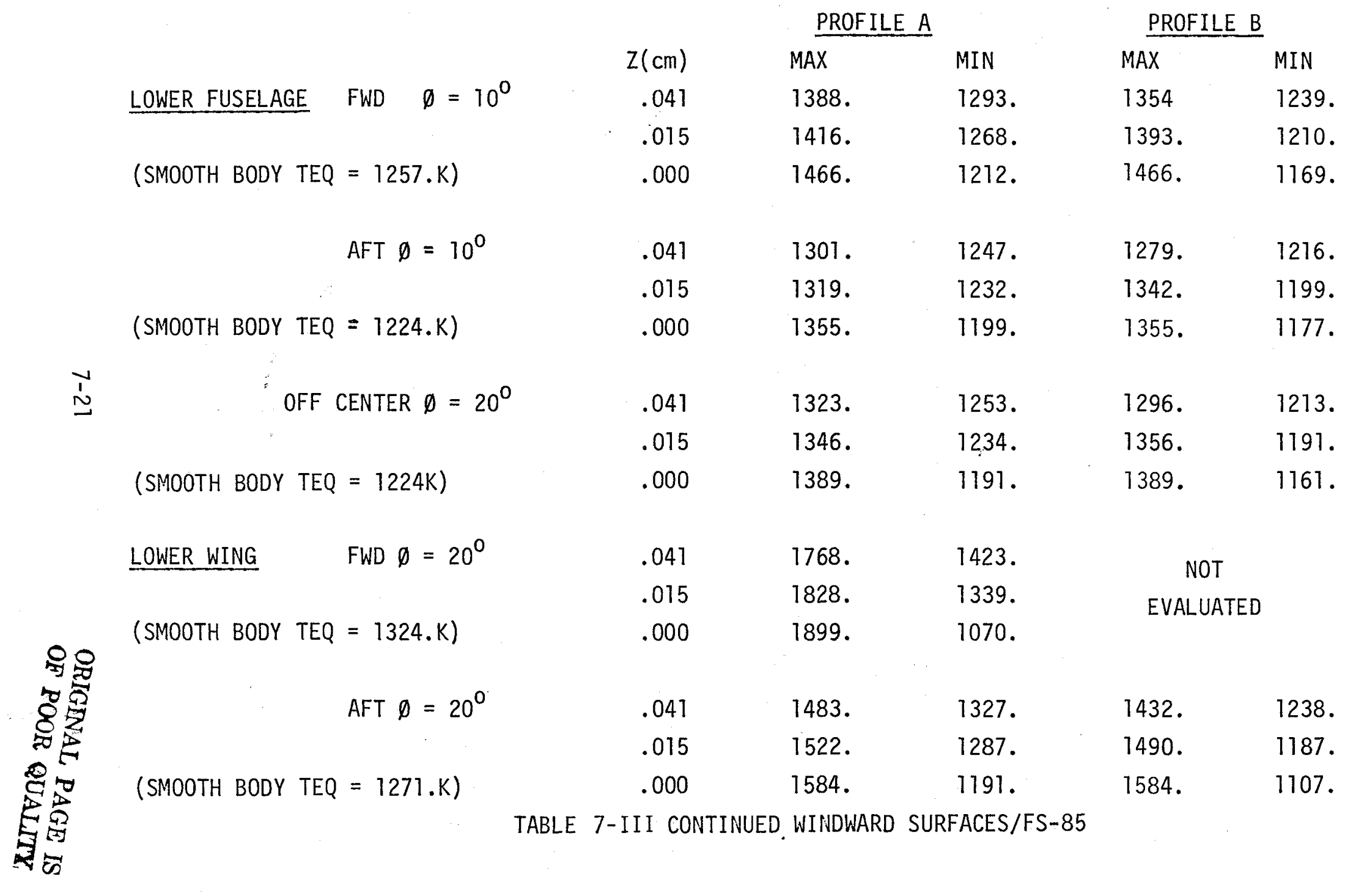




\begin{tabular}{|c|c|c|c|c|c|c|c|}
\hline & & & & \multicolumn{4}{|c|}{ CORRUGATION TEMPERATURE (K) } \\
\hline & & & & \multicolumn{2}{|c|}{ PROFILE A } & \multicolumn{2}{|c|}{ PROFILE B } \\
\hline & & & $Z(\mathrm{~cm})$ & MAX & MIN & MAX & MIN \\
\hline \multirow[t]{2}{*}{ UPPER FUSELAGE } & FWD & $\emptyset=60^{\circ}$ & .041 & 724. & 657. & 682. & 596. \\
\hline & & & .015 & 749. & 628. & 719. & 556. \\
\hline \multirow[t]{3}{*}{ (SMOOTH BODY TEQ } & $609 . K)$ & & .000 & 806. & 521. & 806. & 417. \\
\hline & AFT & & .041 & 692. & 638. & 656. & 588. \\
\hline & & & .015 & 714. & 614. & 686. & 557. \\
\hline \multicolumn{2}{|c|}{$($ SMOOTH BODY TEQ $=600 . \mathrm{K})$} & & .000 & 767. & 528. & 767. & 462. \\
\hline \multirow[t]{2}{*}{ UPPER WING } & FWD & & .041 & 1080. & 851. & 1024. & 746. \\
\hline & & & .015 & 1124. & 774. & 1091. & 643. \\
\hline \multirow[t]{3}{*}{ (SMOOTH BODY TEQ } & $749 . K)$ & & .000 & 1183. & 424. & 1183. & 424. \\
\hline & AFT & & .041 & 795. & 693. & 744. & 615. \\
\hline & & & .015 & 829. & 651. & 793. & 555. \\
\hline \multicolumn{2}{|c|}{ (SMOOTH BODY TEQ $=619 . \mathrm{K}$ ) } & & .000 & 892. & 458. & 892. & 348. \\
\hline \multirow[t]{2}{*}{ SIDE FUSELAGE } & FWD & & .041 & 789. & 693. & 739. & 616. \\
\hline & & & .015 & 827. & 654. & 786. & 558. \\
\hline \multicolumn{2}{|c|}{$($ SMOOTH BODY TEQ $=627 . \mathrm{K})$} & & .000 & 883. & 489. & 883. & 353. \\
\hline
\end{tabular}


CORRUGATION TEMPERATURE (K)

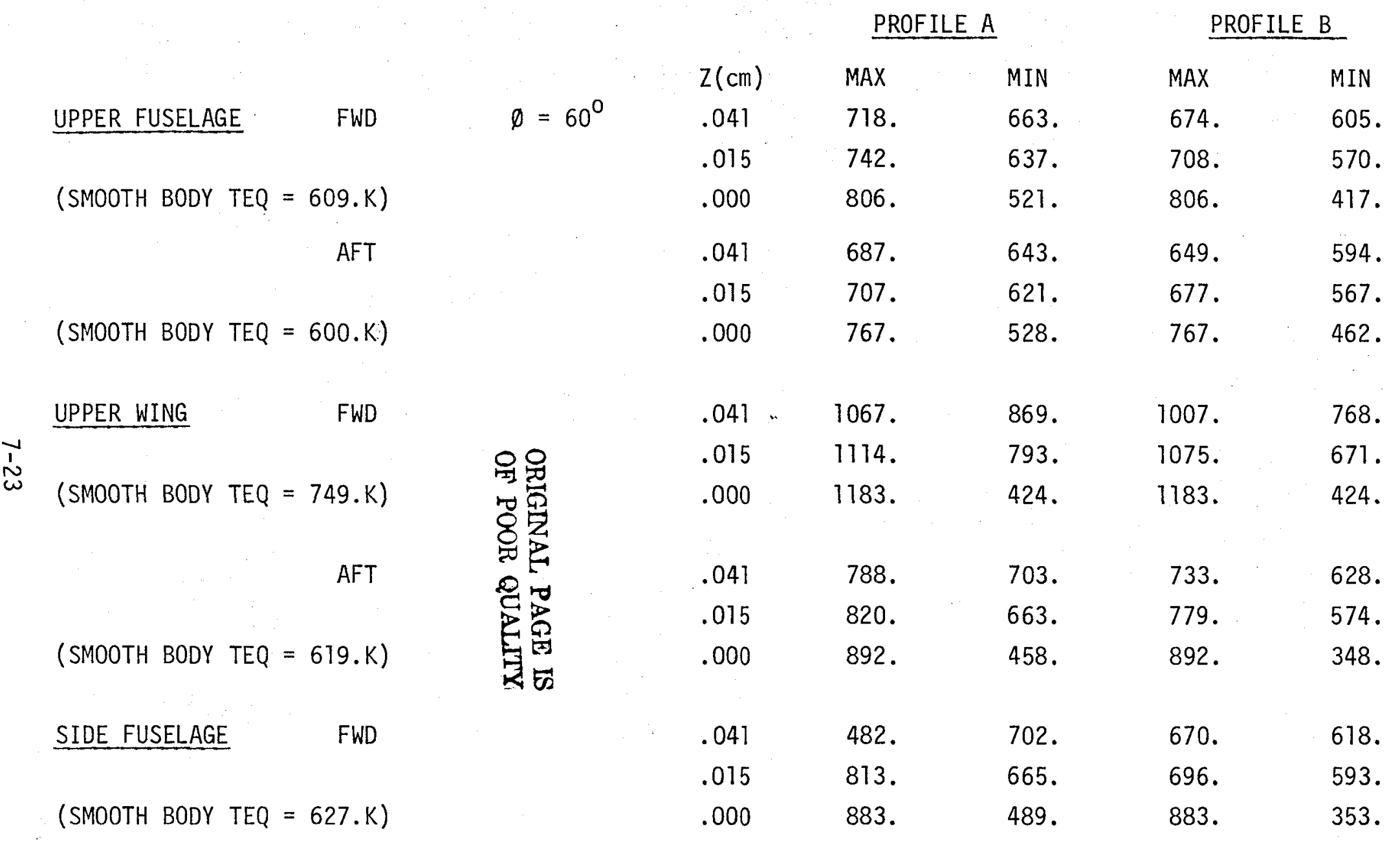

TABLE .7-III CONCLUDED. LEEWARD SURFACES/RENE' - 41 
LOCATION

LOWER FUSELAGE - FWD

LOWER FUSELAGE - AFT

LOWER FUSELAGE - OFF $q$

LOWER WING - FWD

LOWER WING - AFT

SIDE FUSELAGE

UPPER FUSELAGE - FWD

UPPER FUSELAGE - AFT

UPPER WING - FWD

UPPER WING - AFT

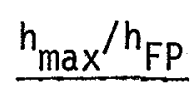

1.97

1.56

1.74

5.04

2.65

5.09

3.84

3.30

9.15

5.62

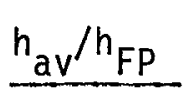

1.05

.95

.96

1.89

1.25

1.25

1.01

.90

1.98

1.36

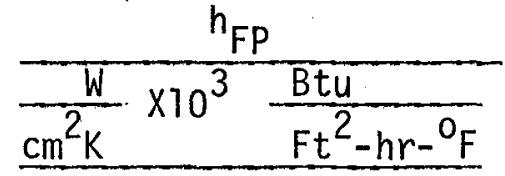

3.05

2.72

2.72

$(5.37)$

$(4.79)$

(4.79)

$(6.75)$

$(5.65)$

3.21

.31

$(.54)$

.27

.25

$(.48)$

.65

.28

TABLE 7-IV SUMMARY OF CORRUGATION PEAK AND AVERAGE HEATING RATES AND SMOOTH BODY REFERENCE HEATING RATE 
The correlated average heating multiplier was in all cases assumed to be a constant equal throughout the trajectory to the value obtained at the time of smooth body peak heating (Table 7-IV). However, to check the accuracy of this approximation, the average heating correlation was evaluated at several points in the trajectory prior to and following peak heating for the lower body forward location and input to the insulation sizing model as a time dependent multiplier. The predicted increase in insulation thickness was approximately $5 \%$ which compares favorably with $3 \%$ found using the constant multiplier.

Results of the insulation sizing analysis are shown in Table 7-V. It is seen that the greatest percentage increases in insulation thickness occur in areas of relatively low smooth body heating and thin boundary layer, e.g., the upper wing at $20 \%$ chord. However, on an absolute scale these represent only smal1 increases in actual insulation weight since the initial smooth body insulation thickness is sma11. As an example, for the upper wing, use of corrugated panels would result in a total insulation penalty on the order of only $70 \mathrm{~kg}$ (150 1bm) per wing.

During the smooth body insulation sizing calculations, it was noted that for the vehicle upper surfaces (regions in which the convective heating rate is relatively low) the skin temperature does not attain the radiation equilibrium temperature. This is obviously a result of heat conduction to the insulating medium, i.e., the skin backside is no longer adiabatic. Moreover, it is reasonable to assume that a similar effect would occur at the point of peak heating on the corrugation if the skin back surface had not been considered adiabatic in the lateral conduction model. A further temperature reduction would be expected to result from the transient nature of the heating. The magnitude of these effects upon the transient smooth body skin temperature was as great as $34 \mathrm{~K}$ in one case. In none of the cases investigated was the reduction in peak corrugation temperature large enough to allow a change to a lower temperature skin material.

Ideally, of course, the insulation sizing and skin temperature estimate should be carried out as part of the same thermal model. This would require knowledge of the variation of the spatial distribution of heating on the corrugation during the trajectory, a problem not addressed during this study. However, an obvious advantage of this approach is that no average heating correlation would be required.

Three phenomena considered to be of secondary importance have been omitted from the insulation sizing analysis: 1) that of "shine through", radiant heat transfer caused by the relative transparency of Microquartz (and other silica 


\begin{tabular}{|c|c|c|c|c|c|}
\hline & & $\begin{array}{l}\text { INSU } \\
56.1\end{array}$ & $\begin{array}{l}\text { LATION } \\
\mathrm{kg} / \mathrm{m}^{3}\end{array}$ & $\begin{array}{l}\text { THICKNESS (cm) } \\
\text { MI CROQUARTZ }\end{array}$ & \\
\hline LOCATION & & SMOOTH BODY & & CORRUGATED SURFACE & PERCENT CHANGE \\
\hline LOWER FUSELAGE & FWD & 6.50 & & 6.68 & 3. \\
\hline & AFT & & NOT & EVALUATED & \\
\hline & OFF CENTER & 5.99 & & 5.94 & -1 \\
\hline LOWER WING & FWD & & NOT & EVALUATED & \\
\hline & AFT & 6.68 & & 7.52 & 13. \\
\hline UPPER FUSELAGE & FWD & .55 & & .56 & 2. \\
\hline & AFT & .51 & & .43 & -16 \\
\hline UPPER WING & FWD & 1.34 & & 2.29 & 71. \\
\hline & AFT & .61 & & .87 & 43. \\
\hline SIDE FUSELAGE & FWD & .64 & & .80 & 25. \\
\hline
\end{tabular}

TABLE 7-V COMPARISON OF SMOOTH BODY AND CORRUGATED PANEL INSULATION REQUIREMENTS 
insulation materials) at infrared wavelengths. Although this mode of heat transfer is presumably accounted for in measurements of thermal conductivity, the work of Hughes (Ref.27) showed that significant errors can occur when consideration of this phenomenon is omitted. 2) Two-dimensional conduction effects in the insulation layer on the upper and side surfaces of the vehicle. This would be caused by the small insulation thickness relative to the corrugation height and the large temperature gradients along the surface of the corrugation. 3) The previously mentioned variation of the correlated average heating with the changing flow conditions of the trajectory.

Although these refinements of the insulation sizing problem should surely be considered in any further study, the present state of development of the heating correlations and definition of the vehicle inviscid and boundary layer flow conditions does not warrant their inclusion at this time. Further, for the present purposes of gauging the approximate insulation penalty associated with corrugated surfaces, omission of these factors in not of great importance. Application of the Wind Tunnel Correlations at Flight Conditions

Two difficulties were encountered with regard to evaluating the full form MRA correlations (Equations $1,3,5,7$ ) at the conditions predicted by the inviscid flow analysis for the upper and side surfaces of the vehicle. The first was a failure of the correlation for the flow reattachment angle to predict values within an acceptable range, i.e., $0.0<\sin \alpha<\sin \alpha_{\max }$. The correlation typically resulted in values of $\sin \alpha$ greater than $\sin \alpha_{\max }$ and often predicted $\sin \alpha$ greater than 1.0. This was initially overcome by arbitrarily limiting the value to sin ${ }_{\max }$; however, even with this limit imposed, the correlation for peak corrugation heating also consistently resulted in unreasonably high values $\left(h_{\max } / h_{f p}\right.$ on the order of 10-20). It is felt that both of these difficulties result from the attempt to apply the correlations to flow conditions far removed from those included in the experimental data, and the ensuing possibility that some of the parameters included in the full form correlations which are of small statistical importance (i.e., poorly correlated at experimental conditions) result in large errors in the predictions made at flight conditions.

Use of the simplified forms of the MRA correlations (Equations 2 and 4) appear to avoid these problems and were for this reason finaliy used to obtain the corrugation heating for the leeward and side points of the vehicle. Since the full form correlations were used to obtain the corrugation heating at windward points, checks were made at the lower body forward and lower wing forward locations 
using both forms of the correlations. Peak heating values calculated using the full form correlations were found to deviate only +5 to $-17 \%$ from those predicted by the simplified form.

While the MRA correlations based on all available data (Equations 3 and 4) were used to determine the corrugation peak heating and thereby the peak temperatures for skin material selection, the correlation based only upon thick boundary layer data (Equation 2) and the associated value of average heating was also evaluated for each leeward case investigated. The peak heating values based on the correlation of thick boundary layer data showed an average absolute deviation of $12 \%$ from those predicted by the correlation of al1 data. An exception was the value predicted for the upper wing forward location which was $47 \%$ lower than the value predicted by the correlation of all data.

Corrugated Panel TPS Applicability

It is apparent from the present analysis that there exist large areas on the SSTO for which use of the corrugated panel TPS is not appropriate. These include, as seen in Table 7-III, the lower wing at $20 \%$ chord for which the predicted peak corrugation temperature exceeds the $1644 \mathrm{~K}\left(2500^{\circ} \mathrm{F}\right)$ upper use limit of $\mathrm{FS}-85$ Columbium and may be presumed to include any other windward surface with relatively thin local boundary layer, i.e., leading edges or near the vehicle nose. Even the somewhat less severe case of the lower wing at $60 \%$ chord results in an increase in predicted peak temperature that spans the usable range of TD-Ni20 $r$. It is further apparent that even in windward areas for which the boundary layer is thick such as the lower fuselage at either the forward or aft points, peak corrugation temperatures dictate a change of material from that required for the smooth body case (typically from $\mathrm{L}-605$ to $\mathrm{TD}-\mathrm{Ni20C_{r }}$ ) for all cases investigated. It may be generally concluded that although the use of corrugated panels on windward surfaces is not precluded by temperatures that exceed the use limits of currently available materials, the resulting peak temperature increments are typically of sufficient magnitude to require material changes.

The leeward and side fuselage points, although subjected to corrugation peak heating multipliers far greater than those of windward side locations (primarily a consequence of the high local flow angles present) experience significantly lower peak temperatures as a result of the much lower leeside smooth body heat transfer and recovery temperature. Material requirements are similarly reduced. With the exception of the upper wing at $20 \%$ chord, the predicted peak corrugation temperatures at all leeward and side locations investigated fall within the use 1 imits of $6 \mathrm{AL}-4 \mathrm{~V}$ 
Titanium. The higher peak temperatures present at the forward wing location are, again, a result of the relatively thin boundary layer and consequent high smooth body and corrugation peak heating rates. It is concluded that the corrugated panel TPS should find wide application for leeward and side fuselage locations and is especially attractive since peak temperatures allow the use of the low density Titanium skin.

As was previously pointed out in Table $7-V$, departures of insulation thickness required for corrugated panels at the lower fuselage locations from those for the smooth body case are quite smal1 (3\% and -1\%) and are, in fact, less than the 1imits of resolution of the present analysis. Application of the corrugated panels at upper fuselage locations results in similar small changes in absolute insulation thickness. Only two of the locations investigated, the lower wing at $60 \%$ chord and upper wing at $20 \%$ chord showed a significant insulation penalty for corrugated panels. The increases for these two points, $13 \%$ and $71 \%$ respectively, both correspond to roughly $0.9 \mathrm{~cm}$ of added insulation thickness $\left(56.1 \mathrm{~kg} / \mathrm{m}^{3}\right.$ Microquartz) or only about $45 \mathrm{~kg}$ per wing for either location. An even more moderate increase $(0.16 \mathrm{~cm})$ is predicted for the side fuselage location. The overall insulation penalties are by these estimates insignificant at fuselage locations aft of $50 \%$ of the vehicle length and of only small weight impact even in areas such as the lower wing for which peak corrugation temperatures exceed the $1478 \mathrm{~K}$ use limit of TD-Ni20Cr. 


\subsection{AERODYNAMIC FLIGHT ASSESSMENT}

The change in entry range of the SSTO due to the drag associated with wavy wall panels was determined and the substantiating analysis is described in the following paragraphs.

The nominal altitude, velocity, angle of attack and bank angle history for entry from $185 \mathrm{~km}$ (100 nmi) orbit is shown in Figure 7-2. For the first 3000 seconds of the entry, the angle of attack exceeds 30 degrees and the drag-due-to-lift will dominate the drag. Changes in zero-angle-of-attack drag, $C_{D_{0}}$, will have a small effect on total $C_{D}$. This can be seen from Figure 8-1 which shows drag coefficients measured on a $1 \%$ scale model of the SSTO in the Langley Research wind tunnels (Ref. 28). At 30 degrees angle of attack the $C_{D}$ is approximately $0.38 ; C_{D o}$ is 0.04 at low angle of attack. A 10 percent change in $C_{\text {Do }}$ results in only a 1 percent change in $C_{D}$. After 5000 seconds into the entry, the angle of attack is reduced to $10 \mathrm{deg}$. and the bank angle to 0 degrees. At these flight conditions, the $C_{D o}$ is important. The wind tunnel data indicate $C_{D o}$ is 70 percent of the total $C_{D}$ at Mach 4.63 .

The SSTO lift and drag coefficients were computed as a function of time from the trajectory data of Figure 7-2 (from Ref. (28)) by assuming the two-dimensional flat earth point mass equations of motion applied. The resulting total $C_{D}$ and $C_{L}$ are shown in Figure 8-2 as a function of altitude. The Mach regime of the wavy wall experiments corresponds to the altitude range from 27 to $39 \mathrm{Km}$ (90 to $127 \mathrm{kft}$ ). Below this altitude range, the panel drag characteristics must be extrapolated.

To estimate the effect of panel $C_{D}$ on range, the worst conditions for panel $C_{D}$ were selected. These conditions are:

Reynolds number $=10 \times 10^{6} /$ Meter

Corrugation angle $=90 \mathrm{deg}$ (perpendicular to freestream)

Boundary Layer thickness, $\delta=2.5 \mathrm{~cm}$

The experimental panel drag coefficient data shown in Figure 8-3 give a $C_{D}$ of 0.0107 at the Mach 2.4 worst case condition. To estimate the worst case Mach $4.5 C_{d}$, the data in Figure 8-4 for the thick boundary layer were used. The ratio $C_{d}$ for a thin and thick boundary layer at Mach 2.4 is $0.0107 / 0.0085=1.26$. The thick boundary layer $C_{d}$ at Mach $4.5,0.0036$, was multiplied by 1.26 to give a $C_{d}$ of 0.0045 for the thin boundary layer at Mach 4.5. An inverse dependency of $C_{d}$ with Mach number was assumed to provide an estimated $C_{d}$ at Mach 10 of 0.0020 . This $1 /$ Mach dependence is slightly weaker than the dependency indicated in Figure 9-4 which is $(1 /$ Mach $) 1.37$. 


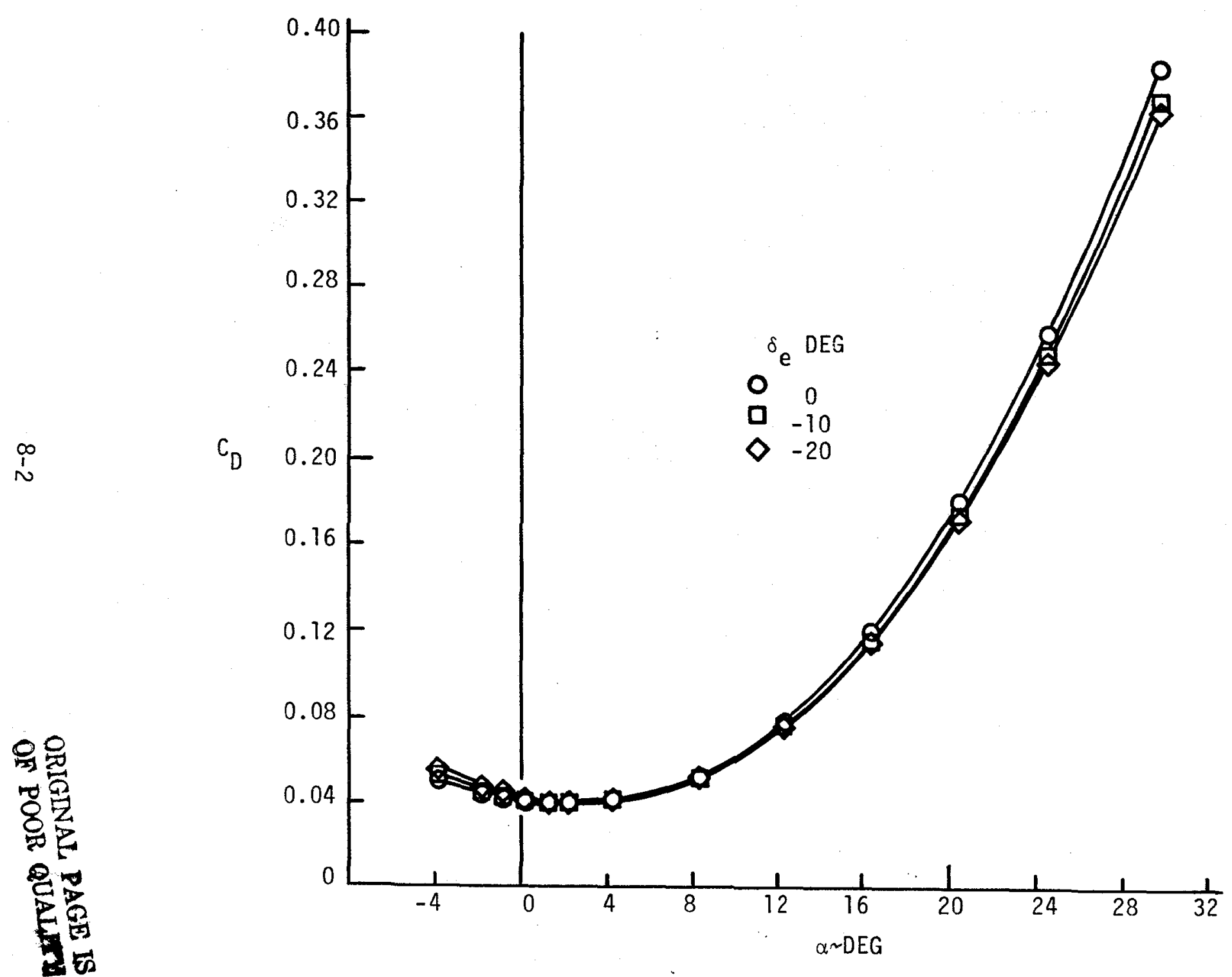

FIGURE 8- 7 SSTO $C_{D}$ VERSUS ANGLE OF ATTACK AT MACH 4.63 


$$
\begin{aligned}
& W / S=29.0 \\
& S_{\text {REF }}=881 \mathrm{~m}^{2}\left(9484 \mathrm{FT}^{2}\right)
\end{aligned}
$$

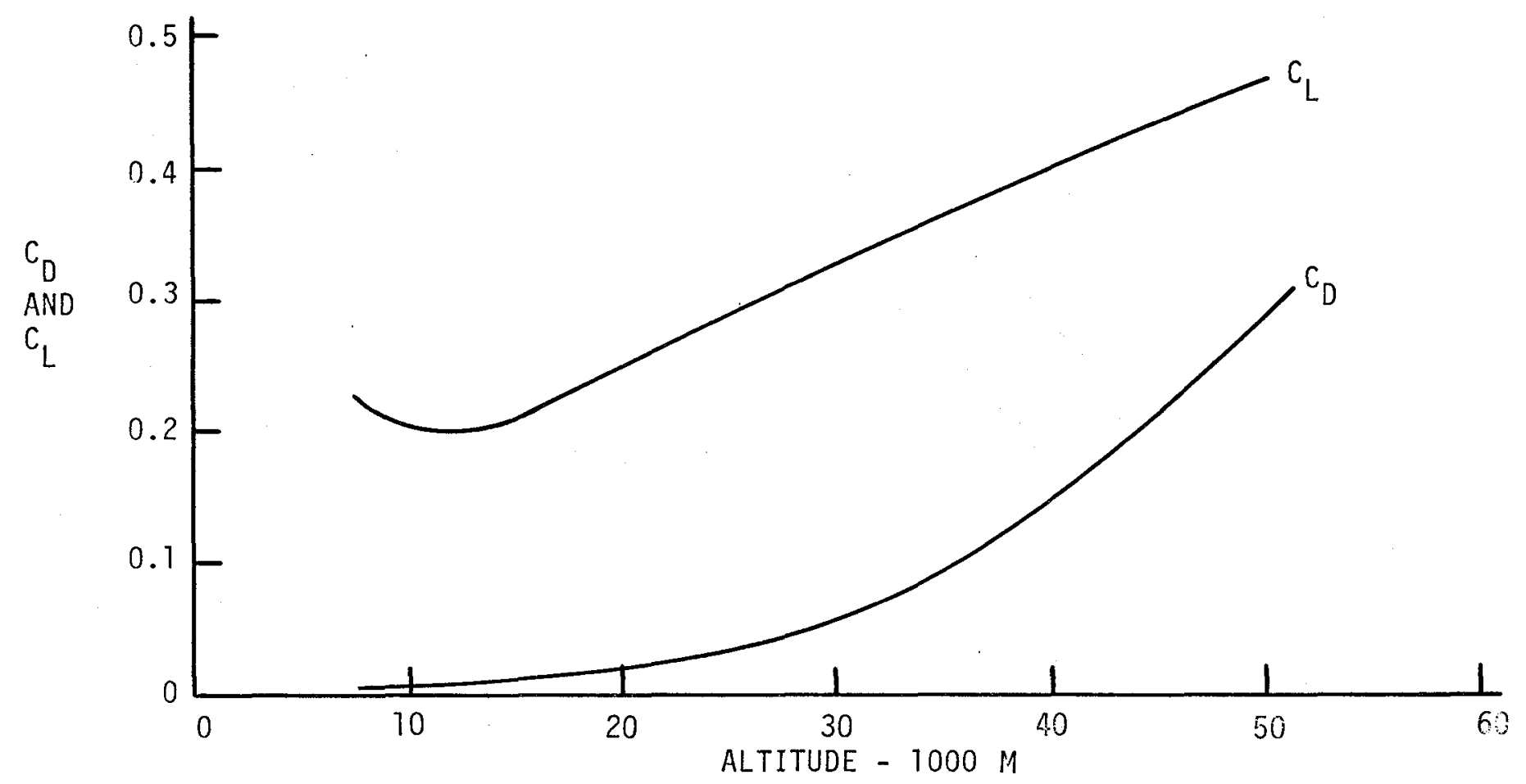

FIGURE 8-2 $C_{D}$ AND $C_{L}$ DETERMINED FROM NUMERICAL TRAJECTORY 


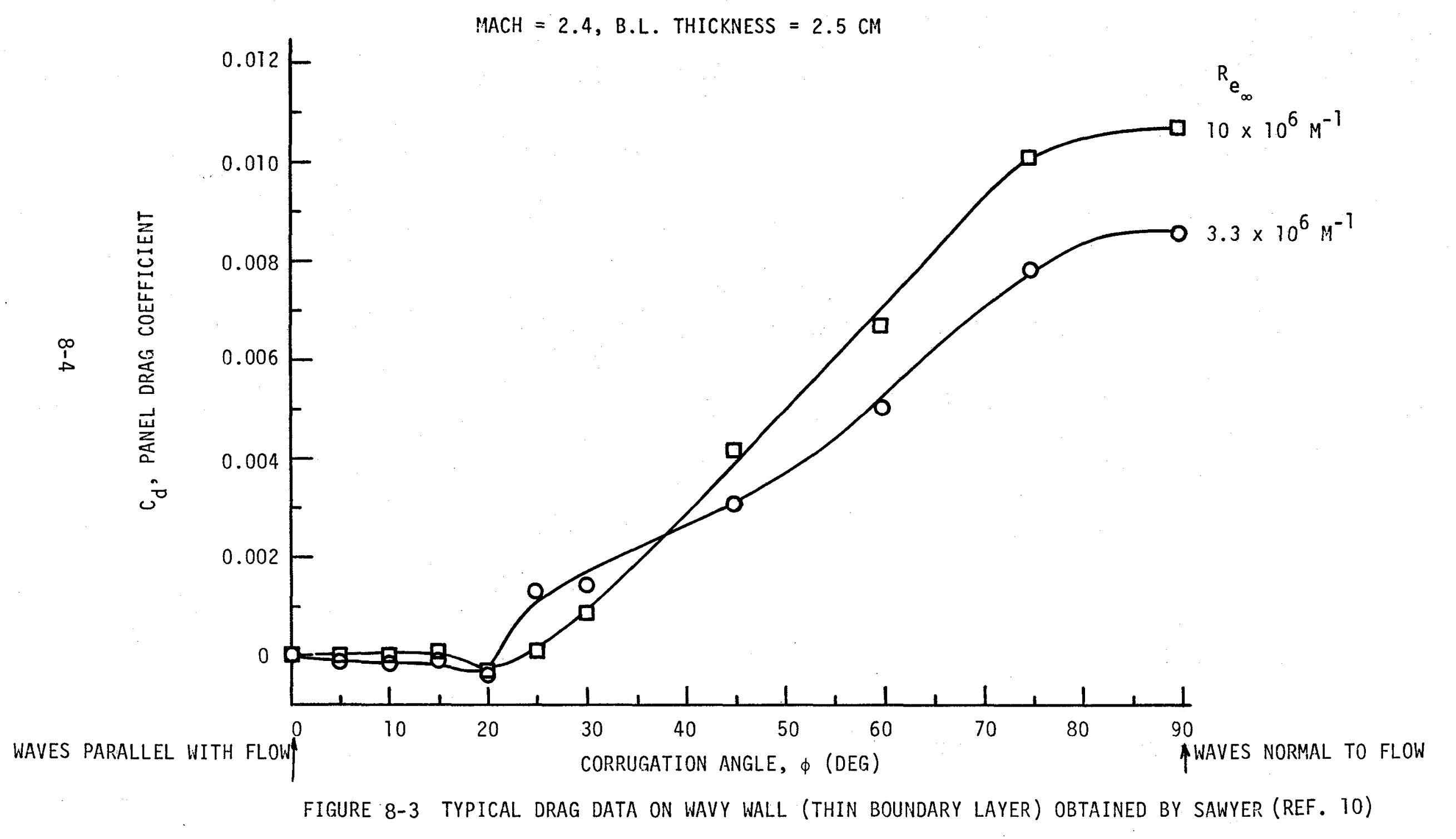


MACH $2.4,4.5$, B.L. THICKNESS $=12.7 \mathrm{CM}$

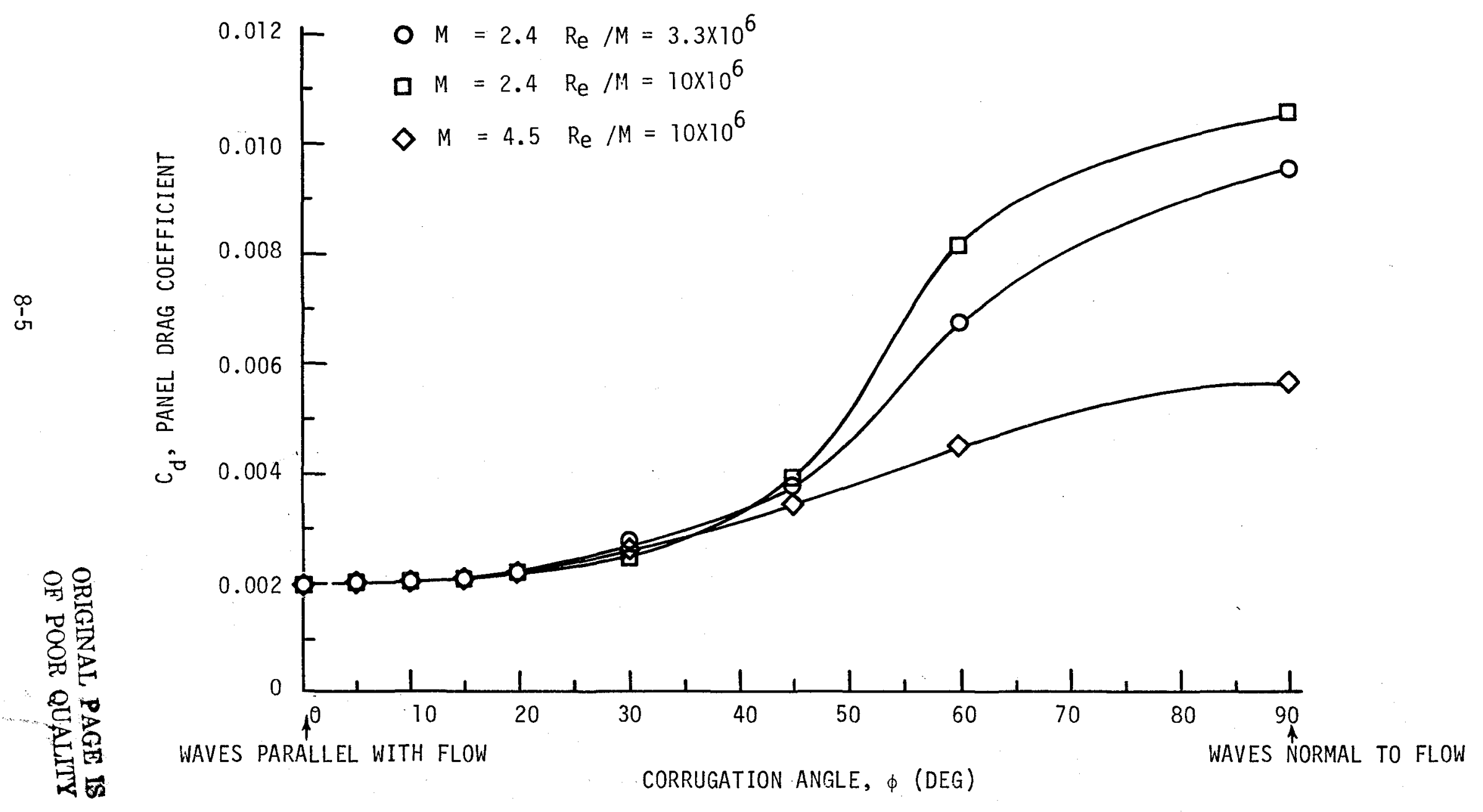

FIGURE 8-4 TYPICAL DRAG DATA ON WAVY WALL (THICK BOUNDARY LAYER) OBTAINED BY SAWYER (REF. 10) 
These individual panel $C_{D}$ 's were related to the total SSTO drag coefficient using the following expression

$$
\Delta C_{D}=C_{d} \times \frac{S_{\text {panel }}}{S_{\text {ref }}} \times \frac{S_{\text {total }}}{S_{\text {panel }}}
$$

where $S_{\text {panel }}=$ experimental panel area for $C_{d}\left(8.01 \mathrm{~cm}^{2}\right)$

$S_{\text {ref }}=$ SSTO reference area $881 \mathrm{~m}^{2}\left(9484 \mathrm{ft}^{2}\right)$

$S_{\text {total }}=$ total panel area on SSTO (parametrically varied)

By varying $S_{\text {total }}$ the maximum change in SSTO drag coefficient, $\Delta C_{D}$, can be determined. Figure 8-5 summarizes these results for Mach 2.4, 4.5 and 10.0. The $\Delta C_{D}$ varies linearly with total panel area. For the entire SST0 paneled, maximum $\Delta C_{D}$ 's of 0.034 , 0.014 , and 0.006 can result at Mach 2.4, 4.5 and 10.0 respectively. A more practical panelling area would correspond to the leeside body area of $703 \mathrm{~m}^{2}$ (7571 $\mathrm{ft}^{2}$ ) which results in a $\Delta C_{D}$ of $0.0085,0.0035$, and 0.0016 for the same Mach numbers.

In Figure 8-6 these data are compared with the $C_{D}$ computed from the trajectory data. For Mach numbers greater than 4.5 the $\Delta C_{D}$ is small compared to the total drag coefficient and probably can be neglected. However, for Mach numbers less than 4.5, the $\Delta C_{D}$ increases substantially. For a fully panelled SSTO the $\Delta C_{D}$ approximates $C_{D}$ at Mach 2.0 if a 1/Mach dependency occurs. For the leeside body panelling only, the relative magnitudes are reduced but become large at Mach 1.0.

These results were related to trajectory range change by perturbing the $C_{D}$ of the basic trajectory by $a \Delta C_{D}$ and computing the resultant change in range from entry to a given altitude. The results are shown in Figure 8-7. From entry to $30 \mathrm{Km}$ (100 kft) altitude the range change is a maximum of $24 \mathrm{Km}$ (13 nmi) for a worst case, fully panelled SSTO. Below this altitude the Mach number is reduced and the $\Delta C_{D}$ is a larger contribution to $C_{D}$. As a result the range change from entry to $9 \mathrm{Km}$ (30 kft) can be appreciable. For the fully panelled SST0, a $83 \mathrm{Km}$ (45 nmi) range loss can occur. For leeside body only, the range loss is $24 \mathrm{Km}$ (13 nmi). Insufficient panel $C_{d}$ data and trajectory information exist below $9 \mathrm{Km}(30 \mathrm{kft})$ to assess the full impact at these conditions. However, increased $C_{D}$ due to wavy wall effects could substantially reduce range below $9 \mathrm{Km}(30 \mathrm{kft}$ ) altitude. (Note: The $\Delta C_{D}$ for Mach numbers below 2.4 was held constant for the Figure 8-7 results and could be appreciable higher if the 1/Mach dependency applies).

These data were cross-plotted as a function of panel area in Figure 8-8. The variation of range with panel area is readily apparent from the cross 


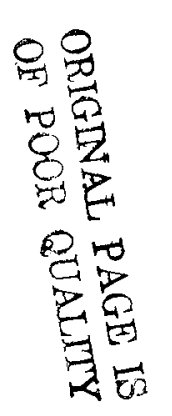

$\stackrel{\infty}{\sim}$

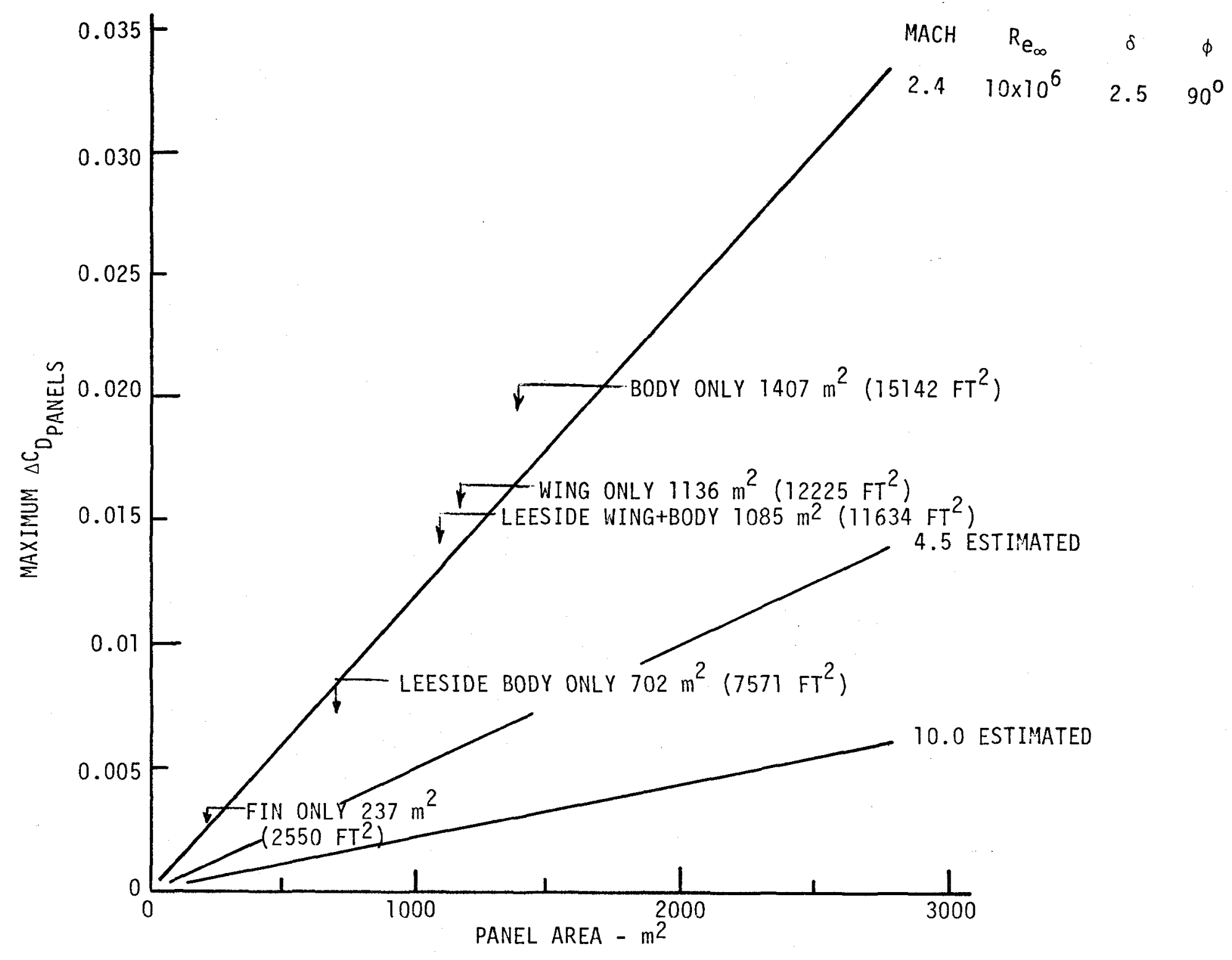

FIGURE 8-5 MAXIMUM $\triangle C_{D}$ DUE TO PANELS 


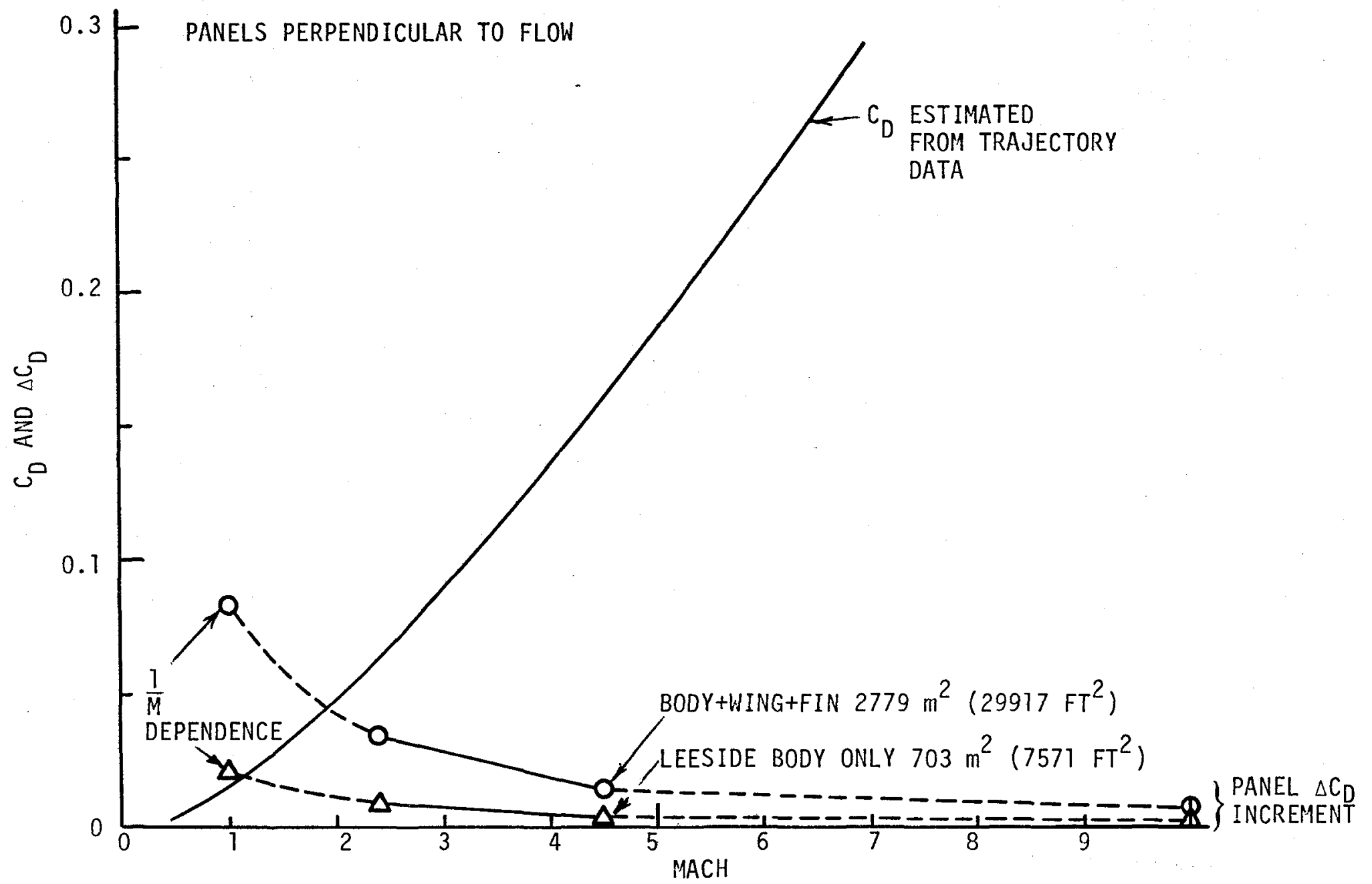

FIGURE 8-6 PANEL $\triangle C_{D}$ INCREIIENT COMPARED WITH $C_{D}$ 


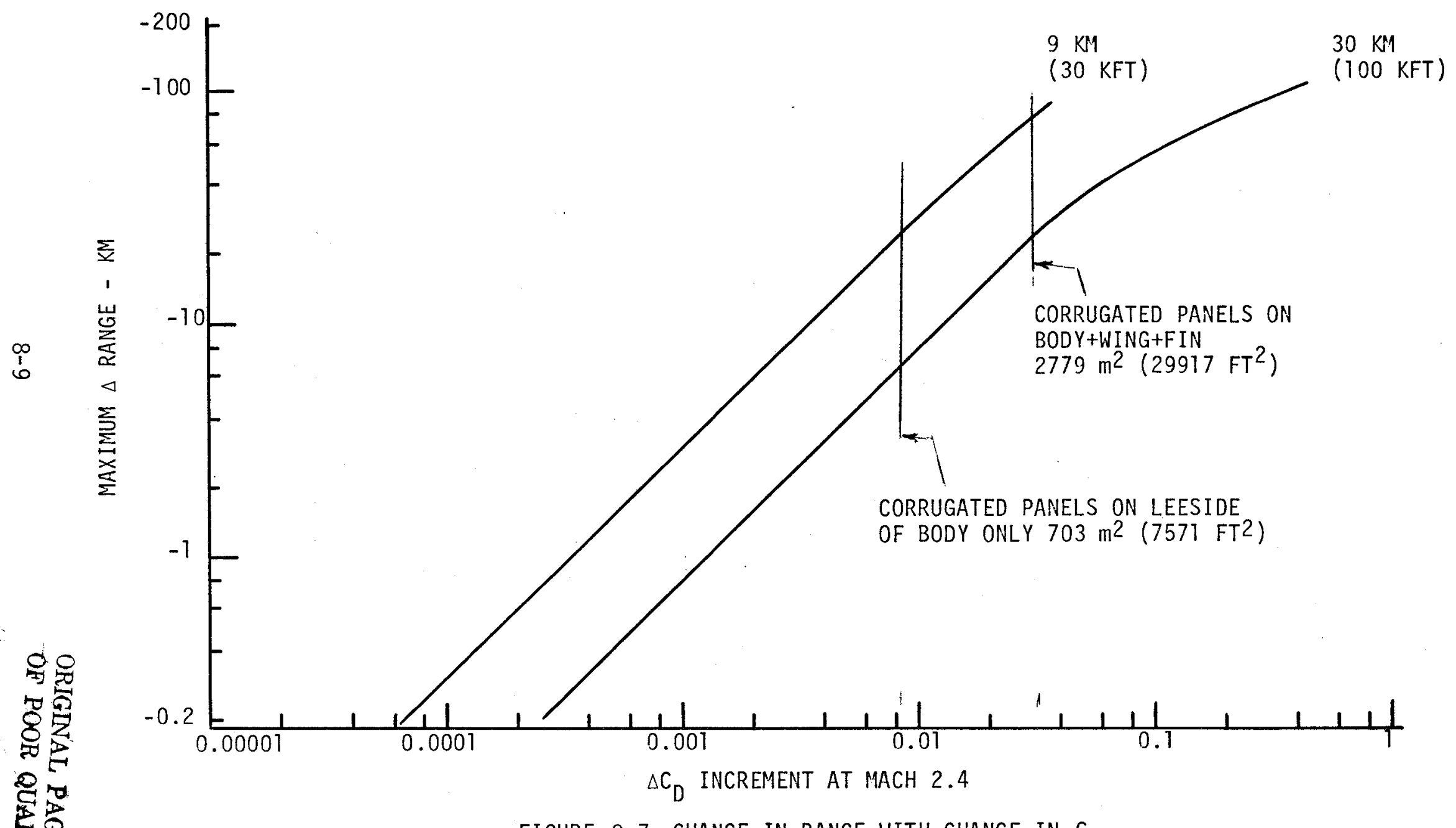

FIGURE 8-7 CHANGE IN RANGE WITH CHANGE IN $C_{D}$ 


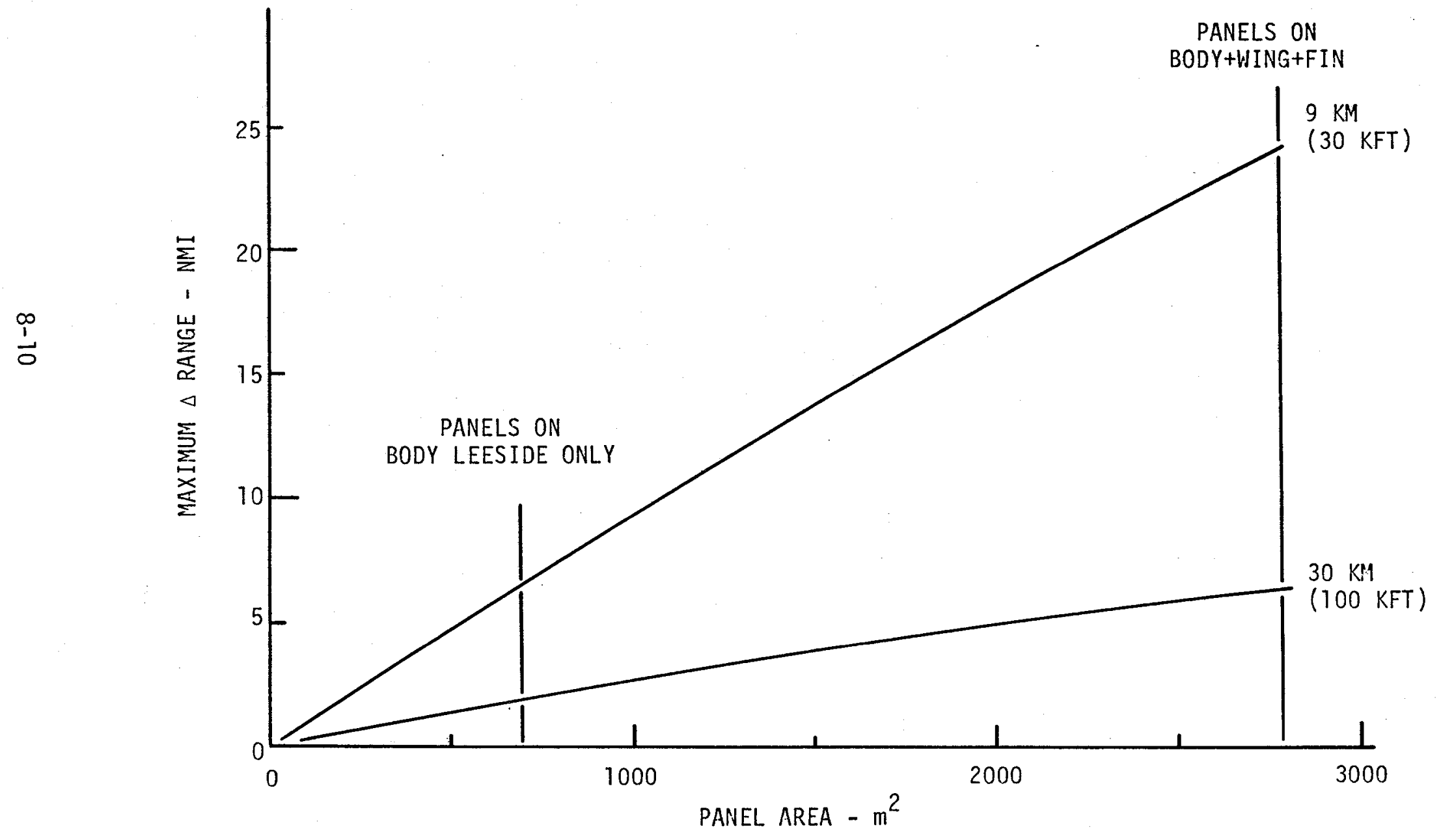

FIGURE 8-8 CHANGE IN RANGE WITH PANEL AREA 
plot. The conclusions from these results are as follows. Wavy wall drag increase has little impact on the SST0 entry trajectory above $30 \mathrm{Km}$ (100 kft) altitude even in the worst case. Below this altitude, panels oriented perpendicular to the freestream can have a significant effect on range. Below $9 \mathrm{Km}(30 \mathrm{kft})$, insufficient data exist to assess the impact on range. However, the trend in the panel $C_{d}$ variation with Mach number appears to be an inverse relationship which could result in large range penalties at the final approach speeds. More data are required to quantify this low speed effect. 


\subsection{STRENGTH AND FLUTTER ASSESSMENT}

For the present corrugated panel flight evaluation, a single corrugation shape (Figure 7-5) based upon longitudinal bending stiffness requirements and previous experience with the Gemini TPS was assumed throughout the analysis. No attempt was made to optimize the panel shape or thickness as a function of the final calculated temperatures. The strength assessment yielded a panel length (distance between supports) ranging from 20.3 to $50.8 \mathrm{~cm}$ and temperature use limits for the corrugation materials considered as follows:

$\begin{array}{ll}\text { Columbium (FS-85) } & 1644 \mathrm{~K}\left(2500^{\circ} \mathrm{F}\right) \\ \text { TD Ni - } 20 \mathrm{C} r & 1478 \mathrm{~K}\left(2200^{\circ} \mathrm{F}\right) \\ \mathrm{L}-605 & 1256 \mathrm{~K}\left(1800^{\circ} \mathrm{F}\right) \\ \text { Rene }^{\prime} 41 & 1144 \mathrm{~K}\left(1600^{\circ} \mathrm{F}\right) \\ \text { Titanium (6AL-4V) } & 811 \mathrm{~K}\left(1000^{\circ} \mathrm{F}\right)\end{array}$

To determine the suitability of such a panel shape and these material selections for application in the SSTO dynamic environment, a flutter analysis was performed for the flow normal to the corrugations using the design approach given by Ref. 29 .

Results of this analysis indicated that flutter does not occur for any of the cases studied for panel lengths up to the $50.8 \mathrm{~cm}$ derived from the strength considerations. Since the flow was assumed to be normal to the waves, flutter should not be a problem for other local flow angles for the high Mach number cases considered in this study. 


\subsection{SUMMARY OF RESULTS}

A wide range of wind tunnel data for aerodynamic heating and pressure distributions on corrugation roughened surfaces in thick supersonic and hypersonic turbulent boundary layers has been analyzed and correlated. The effects of the corrugations in terms of increased aerodynamic heating and drag and the initiation of flutter were also considered for an advanced space transportation (a single-stage-to-orbit) vehicle. The data analysis and flight assessment yielded the following results:

1. For almost all experimental cases studied, the flow separated on the expansion surface and reattached on the compression surface.

2. Peak heat transfer increased as the angle between the corrugations and the free stream flow increased, except for one experiment at the lowest Reynolds number $\left(\mathrm{R}_{\mathrm{e}_{\infty}} / \mathrm{M}=1.3 \times 10^{6}\right)$.

3. The peak heat transfer rates showed a direct proportionality to Reynolds number except for the deepest bead tested at the highest Reynolds numbers in which cases the peak heating was inversely proportional to Reynolds number.

4. Heat transfer and pressure were fairly insensitive to wave amplitude unless the corrugation protruded far out into the boundary layer. Severe heating increases were observed for $\varepsilon / \delta \star 0.1$ in hypersonic flow.

5. Changes in wavelength and surface wave radius by a factor of two produced a small effect on heating.

6. For some flow conditions, the average wave heating was less than the corresponding flat plate value. The functional relation between average heating and corrugation angle was not consistent with maximum heating trends in that the average heating decreased with increasing flow angle for many conditions.

7. The measured pressure drag coefficients on corrugated panels were extremely low for hypersonic flow, ranging from $8.3 \times 10^{-7}$ to $2.16 \times 10^{-3}$.

8. Peak pressure measured on the compression surface could not be explained on the basis of the local internal flow passing through an imbedded shock wave. For the flow normal to the corrugations, the maximum pressure correlated in terms of the total pressure and Mach number of the streamline at the wave height. 
9. Shifts in the peak pressure location were detected. Based on previously obtained data for flow over notches, the changes in the peak pressure location could be explained by a separated flow region dependent on the Mach number at the wave height.

10. Peak heating values for all avajlable data for thin and thick turbuient boundary layers were correlated in terms of bulk boundary layer, internal boundary layer, and geometric parameters.

11. Average heating data for thick turbulent boundary layers were correlated in terms of the corresponding maximum heating values, the local flow conditions, and the geometric parameters.

12. The geometry of the separated flow region was correlated in terms of the local surface angie at the point of maximum heating. This new formulation improved the capability of the neating correlations.

13. For the thermal flight assessment, severe heating penalties were found to exist over large areas of the windward surfaces with thin boundary layers, leading edges, and locations near the nose. Temperature penalties ranged from $100 \mathrm{~K}$ to $500 \mathrm{~K}$, and very large structural advantages of the corrugations would be required to overide these heating penalties.

14. The use of corrugated panels on windward surfaces with thick turbulent boundary layers could dictate a change in material from that required for the smooth body case.

15. Computed peak corrugation temperatures were within allowable limits of the equivalent smooth wall material for leeward and side fuselage locations. Hence, corrugated panel TPS have application for these areas.

16. Insulation weight penalties caused by the use of corrugated panels were insignificant for all vehicle locations where the panels were found to have application.

17. The change in entry range of the SSTO due to increased drag associated with corrugated panels was small for altitudes above $30 \mathrm{~km}$ (100K ft). For a fully panelled SSTO, a maximum reduction in range of almost 10 percent was predicted from entry to $9 \mathrm{Km}$ ( $30 \mathrm{~K} \mathrm{ft}$ ) altitude.

18. Additional corrugation drag data are needed below Mach 2 to assess the impact of corrugations on range at final approach speeds.

19. Panel flutter was not predicted for the SSTO flight trajectory in the supersonic and hypersonic flow regimes. 


\subsection{REFERENCES}

1. Bohon, H. L., Shidler, J. L., and Rummler, D. R., "Radiative Metallic Thermal Protection Systems - A Status Report, "AIAA Paper No. 77-391, March 1977.

2. Shore, C. P., Dixon, S. C., and Griffith, G. E., "Experimental Pressures and Turbulent Heat Transfer Coefficients Associated with Sinusoidal Protuberances on a Flat Plate at a Mach Number of 3," NASA TN D-1626, March 1963.

3. Stallings, R. L., Jr. and Collins, I. K., "Heat Transfer Measurements on a Flat Plate and Attached Protuberances in a Turbulent Boundary Layer at Mach Numbers of $2.65,3.51$, and $4.44, "$ NASA TN D-2428, September 1964.

4. Jaeck, C. L., "Analysis of Pressure and Heat Transfer Tests on Surface Roughness Elements with Laminar and Turbulent Boundary Layers," NASA CR-537, 1966.

5. Cary, A. M., Jr. and Morrisette, E. L., "Effect of Two-Dimensional Multiple Sine-Wave Protrusions on the Pressure and Heat Transfer Distributions for a Flat Plate at Mach 6," NASA TN D-4437, March 1968.

6. Weinstein, L. M., "Effects of Two-Dimensional Sinusoidal Waves on Heat Transfer and Pressure Over a Flat Plate at Mach 8," NASA TN D-5937, Aug 1970.

7. Bertram, M. H., Weinstein, A. M., Cary, A. M., Jr., and Arrington, J. P., "Heat Transfer to a Wavy Wall in Hypersonic Flow," AIAA Journal, Vol. 5, No. 10, October 1967.

8. Brandon, H. J., and Masek, R. V., "Measurement and Correlation of Aerodynamic Heating to Surface Corrugation Stiffened Structures in Thick Turbulent Boundary Layers," NASA CR-132503, September 1974.

9. Brandon, H. J., Masek, R. V., and Dunavant, J. C., "Aerodynamic Heating to Corrugation Stiffened Structures in Thick Turbulent Boundary Layers, "AIAA J., Vol. 13, No. 11, November 1975.

10. Sawyer, J. W., "Pressure and Heating Rate Distributions on a Corrugated Surface in a Supersonic Turbulent Boundary Layer," NASA TP 1024, Nov. 1977.

11. Couch, L. M., "Flow Field Measurements Downstream of Two Protuberances on a Flat Plate Submerged in a Turbulent Boundary Layer at Mach 2.49 and 4.44," NASA TN D-5297, JuTy 1969.

12. Allen, J. M., "Evaluation of Compressible Flow Preston Tube Calibrations," NASA TN D-7190, May 1973.

13. Beckwith, I. E., Harvey, W. D., and Clark, F. L., "Comparison of Turbulent Boundary Layer Measurements at Mach Number 19.5 With Theory and an Assessment of Probe Errors," NASA TN D-6192, June 1971.

14. Howel1, R. H. and Korst, H. H., "Separation Controlled Transonic Drag-Rise Modification for V-Shaped Notches," AIAA J., Vol. 9, No. 10, October 1971.

15. Christensen, H. E. and Kipp, H. W., "Data Correlation and Analysis of Arc Tunnel and Wind Tunnel Tests of RSI Joints and Gaps," MDC Rpt. E1003, January 1974. 
16. Powars, C. A., "Surface Roughness Effects in Reentry Heating," Aerotherm TM-71-10, July 1971.

17. Dirling, R. B., Jr., "A Method for Computing Roughwal1 Heat Transfer Rates on Reentry Nosetips," AIAA Paper No. 73-763, 8th Thermophysics Conference, July 1973.

18. Grabow, R. M. and White, C. 0., "Surface Roughness Effects on Nosetip Ablation Characteristics," AIAA Paper No. 74-513, June 1974.

19. "Technology Requirements for Advanced Earth Orbital Transportation Systems Summary Report," NASA CR 2879, 1978.

20. Hender, D. R., "A Minature Version of the JA70 Aerodynamic Heating Computer Program, H800 (Miniver)," MDC G0462, June, 1970.

21. Strouha1, G., "Shuttle Orbiter Thermal Protection System (TPS)," NASA SP74 14696, 25 September 1974.

22. Baranowski, L. C., "Influence of Cross-Flow on Windward Centerline Heating," MDC E0535, Dec. 1971.

23. Walker, G. K. and Schumann, B. A., "The Growth of Turbulent Boundary Layers," General Electric TIS R615D123, 31 July 1961.

24. Reda, D. C., "Compressible Turbulent Skin Friction on Rough and Rough/Wavy Walls in Adiabatic Flow," NOLTR 74-34, 12 February 1974.

25. Fivel, H. J., and Masek, R. V., "Analytical Comparison of Hypersonic Flight and Wind Tunnel Viscous/Inviscid Flow Fields," NASA CR-132359, July 1973.

26. Fivel, H. J., Masek, R. V., and Mockapetris, L. J., "Analytical Comparison of Hypersonic Flight and Wind Tunnel Viscous/Inviscid Flow Fields, "NASA CR2489, February 1975, and additional calculations made by H. J. Fivel under NASA contract NAS1-17728.

27. Hughes, T. A., "High Temperature Insulation Materials for Reradiative Thermal Protection Systems," MDC E0666, July 1972.

28. Freeman, D. C., Jr. and Fournier, R. H., "Static Aerodynamic Characteristics of a Low Plan Form Loading Single-Stage-to-Orbit Vehicle at Mach Numbers from 0.3 to 4.63 ," Proposed NASA TN.

29. Laurenson, R. M., "Design Procedures for Flutter-Free Surface Panels," NASA CR-2801, March 1977. 
a

$C_{D}$

$\mathrm{C}_{\mathrm{D}_{0}}$

$c_{d}$

$c_{f}$

CFHT

$d_{h}$

h

$k_{e}$

L

M

$\mathrm{P}$

$P_{t}$

q

$\mathrm{Re}_{\infty}$

$\mathrm{R}_{\mathrm{e}_{\mathrm{x}}}$

$\operatorname{Re}_{\varepsilon}$

$R_{e_{\varepsilon},}, R_{\varepsilon}$

r

S

SSTO

T

UPWT

U

$x$

speed of sound

SSTO drag coefficient $=\frac{2 \times \text { DRAG }}{\rho V_{\infty}^{2} S_{\text {REF }}}$

$C_{D}$ at zero angle of attack

Panel drag coefficient

skin friction coefficient

Continuous Flow Hypersonic Tunnel

hydraulic diameter

heat transfer coefficient, $q /\left(T_{a w}-T_{w}\right)$; also enthalpy

equivalent sand-grain roughness height

wavelength

Mach number

pressure

Pitot pressure

heat transfer rate

free-stream Reynolds number, $\frac{\rho_{\infty} U_{\infty}}{\mu_{\infty}}$

Reynolds number based on surface length, $\frac{\rho_{\infty} U_{\infty} X}{\mu_{\infty}}$

Reynolds number based on wave amplitude, $\frac{\rho_{\infty} U_{\infty} \varepsilon}{\mu_{\infty}}$

Reynolds number evaluated at wave amplitude, $\frac{\rho_{\varepsilon} U_{\varepsilon} \varepsilon}{\mu_{\varepsilon}}$

surface wave radius

surface distance measured from top of wave; reference area

Single-Stage-to-Orbit-Vehicle

temperature

Unitary Plan Wind Tunnel

velocity

axial distance measured from top of wave; smooth wall surface distance 


$\begin{array}{ll}X_{\text {sep }} & \text { distance to separation point } \\ Y & \text { spanwise distance along tunnel sidewall; also wave vertical coordinate } \\ Z & \text { skin thickness; also distance through boundary layer } \\ \alpha & \text { local wave surface angle } \\ \gamma & \text { ratio of specific heats } \\ \varepsilon & \text { maximum wave amplitude from wave midline } \\ \delta_{S} & \text { laminar sublayer thickness } \\ \delta * & \text { displacement thickness } \\ \delta & \text { boundary layer thickness } \\ \theta & \text { momentum thickness } \\ \mu & \text { molecular viscosity } \\ \phi & \text { angle of corrugations relative to free-stream flow direction } \\ \rho & \text { (See Figure 4-l) } \\ & \text { density }\end{array}$




\section{SUBSCRIPTS}

$\begin{array}{ll}()_{\text {av }} & \text { average } \\ ()_{\text {aw }} & \text { adiabatic wall } \\ ()_{E Q} & \text { equilibrium } \\ ()_{F P} & \text { flat plate } \\ ()_{L} & \text { local } \\ ()_{M A X} & \text { maximum } \\ ()_{r} & \text { reattachment point taken as point of maximum pressure } \\ ()_{t} & \text { stagnation conditions } \\ ()_{\text {TOTAL }} & \text { total distance } \\ ()_{W} & \text { wall conditions (same as flat plate conditions) } \\ ()_{\varepsilon} & \text { evaluated at maximum wave amplitude } \\ ()_{\infty} & \text { free-stream conditions at edge of boundary layer } \\ ()_{1} & \text { in front of shock }\end{array}$


APPENDIX A

WAVE SHAPE FOLD OUT

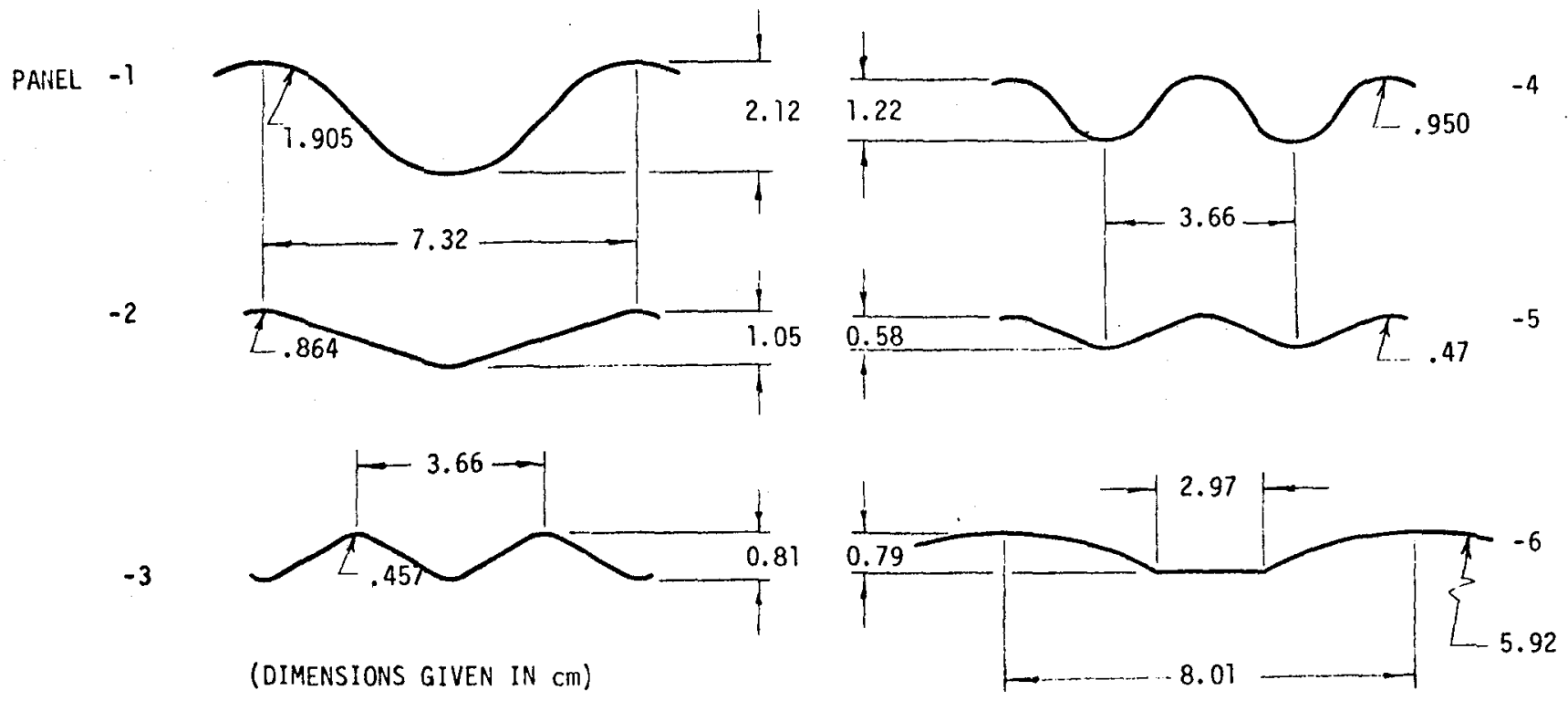

FIGURE A-I CORRUGATION SHAPES INVESTIGATED 